NBER WORKING PAPER SERIES

\title{
THE PRODUCTIVITY CONSEQUENCES OF POLLUTION-INDUCED MIGRATION IN CHINA
}

\author{
Gaurav Khanna \\ Wenquan Liang \\ Ahmed Mushfiq Mobarak \\ Ran Song \\ Working Paper 28401 \\ http://www.nber.org/papers/w28401 \\ NATIONAL BUREAU OF ECONOMIC RESEARCH \\ 1050 Massachusetts Avenue \\ Cambridge, MA 02138 \\ January 2021
}

We thank seminar participants at UCSD, UW (Seattle), NBER Summer Institute (Energy and Enivornmental Economics; and Urban Economics), Stanford SITE Migration Conference, U Richmond, Cities and Development Conference (Johns Hopkins), Ortygia Business School, Georgetown University, Barcelona UAB, the World Bank, Harvard, CUHK, HKUST (China Summer Institute), Nankai-Yale Conference, and Lingnan $U$ for useful comments, and to Ed Glaeser, Matthew Kahn, David Lagakos, Paulina Oliva and David Yang for insightful suggestions. The views expressed herein are those of the authors and do not necessarily reflect the views of the National Bureau of Economic Research.

NBER working papers are circulated for discussion and comment purposes. They have not been peer-reviewed or been subject to the review by the NBER Board of Directors that accompanies official NBER publications.

(C) 2021 by Gaurav Khanna, Wenquan Liang, Ahmed Mushfiq Mobarak, and Ran Song. All rights reserved. Short sections of text, not to exceed two paragraphs, may be quoted without explicit permission provided that full credit, including ()$^{\text {notice, }}$ is given to the source. 
The Productivity Consequences of Pollution-Induced Migration in China

Gaurav Khanna, Wenquan Liang, Ahmed Mushfiq Mobarak, and Ran Song

NBER Working Paper No. 28401

January 2021

JEL No. E24,J61,O18,Q52,R12

\begin{abstract}
$\underline{\text { ABSTRACT }}$
Migration and pollution are two defining features of China's impressive growth performance over the last 30 years. In this paper we study the migration response to pollution in Chinese cities, and its consequences for productivity and welfare. We document a robust pattern in which skilled workers emigrate more in response to pollution than the unskilled. Their greater sensitivity to air quality holds up in cross-sectional variation across cities, panel variation with individual fixedeffects, and when instrumenting for pollution using distant power-plants upwind of cities, or thermal inversions that trap pollution. Pollution therefore changes the spatial distribution of skilled and unskilled workers, which results in higher returns to skill in cities that the educated migrate away from. We quantify the loss in aggregate productivity due to this re-sorting by estimating a model of demand and supply of skilled and unskilled workers across Chinese cities. Counterfactual simulations from the estimated model show that reducing pollution would increase productivity through spatial re-sorting by approximately as much as the direct health benefits of clean air. Physical and institutional restrictions on mobility exacerbate welfare losses. People's dislike of pollution explains a substantial portion of the wage gap between cities.
\end{abstract}

Gaurav Khanna

University of California, San Diego

9500 Gilman Drive

La Jolla, CA 92037

gakhanna@ucsd.edu

Wenquan Liang

Jinan University

No. 601 West Huangpu Road

Tianhe District

Guangzhou

P.R. China

liang.wenquan@jnu.edu.cn

\author{
Ahmed Mushfiq Mobarak \\ Yale School of Management \\ 135 Prospect Street \\ Box 208200 \\ New Haven, CT 06520 \\ and NBER \\ ahmed.mobarak@yale.edu \\ Ran Song \\ Division of Social Science \\ Yale-NUS College \\ 16 \#01-220 \\ College Ave West \\ Singapore, 138527 \\ songr@nber.org
}




\section{Introduction}

The large productivity gaps across regions or sectors within developing countries (Restuccia and Rogerson, 2013, 2017) create an enduring development puzzle: Why do workers remain in low productivity areas when they could experience wage gains elsewhere (Gollin et al., 2014)? It is important to understand the drivers of worker location choices, as spatial reallocation has the potential to produce substantial productivity gains (Bryan et al., 2014; Clemens et al., 2019). The literature proposes a few explanations for the low rates of within-country mobility observed across the world: Migration costs (Bazzi, 2017; Bryan and Morten, 2019), income risk at destinations (Bryan et al., 2014; Lewis, 1954), non-transferable location-specific amenities (Munshi and Rosenzweig, 2016), or urban disamenities (Lagakos et al., 2019) like pollution.

Pollution can have a large effect on where people choose to live and work (Heblich et al., 2020). Particulate matter pollution exceeded WHO air quality guidelines for $96 \%$ of Chinese cities in 2015, and on average was four times higher than the level considered safe. Chinese air pollution reduces citizens' life expectancy and causes elevated rates of heart disease, stroke, and lung cancer (Ebenstein et al., 2015, 2017; He et al., 2020). We document that the sharp increases in pollution in China in recent years were concentrated in a few cities, which increased the cross-city dispersion in pollution, and with it, incentives to migrate between cities.

We analyze whether workers relocate in response to variation in air quality across Chinese cities, and then quantify the aggregate productivity consequences of this movement. While one branch of the literature argues that workers are efficiently sorted (Young, 2014), we show that asymmetric migration responses of skilled and unskilled workers to pollution can create losses in aggregate productivity. This is because skilled workers choose to leave polluted places where they would be more productive, and the production complementarities between skilled and unskilled workers makes the unskilled less productive when the skilled leave. Migration costs, both physical and from Chinese hukou policy, differentially restrict mobility by skill. This exacerbates the productivity and welfare losses from pollution for both types of workers.

Pollution and the skill-composition of the workforce are jointly determined, and both depend on other factors such as industrial growth. The first part of our paper is therefore careful to identify the migration response to exogenous variation in pollution. To build confidence that our estimates indeed represent the causal effect of air quality on mobility, we assemble several datasets, and investigate this relationship under multiple independent sources of variation. We isolate exogenous fluctuations in pollution leveraging variation in wind direction combined with the historical placement of distant thermal power plants (as in Freeman et al., 2019), a regression discontinuity around the Huai river (as in Chen et al., 2013), and a meteorological phenomenon called thermal inversions that traps pollution (as in Arceo et al., 2016; Chen et al., 2017; Hicks et al., 2015). We also model changes in worker location as a function of changes in pollution, following individuals over time, and conditioning on individual fixed effects. Across these research designs, we find robust evidence that college-educated workers leave areas with 
higher levels of pollution, while the less educated are comparatively less responsive.

Yet, quantifying the exact migration responses without a model remains a challenge, since all parts of the country are affected either directly or indirectly by the re-location of workers, making finding true 'control groups' for comparison elusive. Residents of a city experiencing no change in pollution may still see a change in their incentives to migrate, if in-migration from other newly-polluted places changes the equilibrium wage rate in that city. Indeed, the quantities of workers, equilibrium wages, and pollution levels are jointly determined in spatial equilibrium, making it difficult to interpret certain magnitudes in reduced-form relationships.

Quantifying the productivity implications of these mobility responses requires a model. For instance, the differential emigration of skilled workers changes the skilled wage premia across cities, which in turn also affects the location choices of the unskilled in general equilibrium. We empirically document that the relative scarcity of skilled workers in polluted cities raises the marginal product of skill in those locations (Giles et al., 2019). Cleaning up polluted cities therefore induces a relocation of skilled workers from low marginal product areas to high marginal product areas, which raises aggregate output, as in Hsieh and Klenow (2009) and Hsieh and Moretti (2018).

The model allows us to quantify the magnitudes of these productivity shifts. The differential response to (exogenous variation in) pollution by skill shifts the labor supply of workers, and produces a valid estimate of the compensating wage-differential that workers have to be paid to reside in polluted cities. This traces out the labor demand curve, and allows us to estimate the elasticity of substitution between the skilled and unskilled, which show that in China, they are complements in production. To trace out the labor supply curve, we create instruments based on trade-induced growth from the permanent normalization of trading relations (PNTR) between the US and China, and the change in world import demand (WID), which differentially generate variation in the demand for skilled and unskilled workers across Chinese cities. ${ }^{1}$

For a more comprehensive and accurate quantification, our model incorporates alternative mechanisms linking production, pollution and productivity: (a) pollution can directly affect health and productivity (He et al., 2016; Zivin and Neidell, 2012); (b) production, in turn, affects air quality (Andreoni and Levinson, 2001); and (c) worker location decisions may affect agglomeration (Au and Henderson, 2006), (d) house prices (Bayer et al., 2009; Glaeser, 2014a), or (e) the pollution-intensity of production (Glaeser and Kahn, 2010; He et al., 2020). We introduce additional instruments to estimate these elasticities. ${ }^{2}$ In summary, we quan-

\footnotetext{
${ }^{1}$ Pierce and Schott (2016) use the PNTR import shock and Autor et al. (2013) use the WID import shock to document effects on the United States. Our approach takes advantage of the fact that these are simultaneously export shocks that had differential effects on skilled and unskilled labor demand in Chinese cities that were more or less exposed to trade. With unique city-level data on the production of each product for which we have tariff information, we are able to construct an instrument for export-induced growth across Chinese cities.

${ }^{2}$ For instance, to estimate skilled-worker agglomeration effects, we leverage a large-scale expansion of university seats that rapidly expanded college enrollment by $20 \%$ in certain Chinese cities. Our estimated elasticities are similar to credible estimates in the literature on the direct effect of pollution on productivity (Adhvaryu et al., 2016; Chang et al., 2019; Kahn and Li, 2019), and of worker location on agglomeration (Gaubert, 2018; Moretti, 2004). As such, if we were to discipline our model by borrowing elasticities from the literature (instead
} 
tify the productivity effects of pollution via worker re-sorting, accounting for other important mechanisms through which production, pollution, and migration are related.

The model allows us to quantify how much of the wage gap across Chinese cities is attributable to pollution differences. For instance, our estimates imply that equalizing pollution between high-pollution Tianjin and low-pollution Chongqing would bridge the between-city skilled wage gap by $14 \%$. Companies in China reportedly offer up to $20 \%$ wage premiums to induce workers to relocate to polluted productive cities, so our estimates appear to be in line with the real-world behavior of firms and workers (AFP News, 2019).

The fact that pollution explains a meaningful portion of the productivity gaps across cities sheds some light on the behavioral puzzle we raised at the outset: Concerns about pollution keep workers away from cities where they could be more productive. This phenomenon is not limited to China: When 9,000 Delhi residents were asked about their plans to deal with pollution, the single-most common response was "relocate" (Kapur, 2019). Recent reports of emigration following wildfires in California suggest that this may not be solely a developing world phenomenon either. ${ }^{3}$

To quantify the productivity loss from pollution, we perform a set of counterfactuals for Beijing. In one we halve the 'exogenous' component of pollution in our model (say, by relocating upwind coal-fired plants), and in another we halve the amount of total pollution in Beijing (say, by setting pollution caps for the city), which would also be a function of factors that are endogenous to our model. In each scenario, GDP per worker rises by more than $12 \%$, mostly as a consequence of skilled workers moving into Beijing. Unskilled wages in Beijing rise by at least $16 \%$ as more (complementary) skilled workers enter the city. Increased wages are largely driven by the relocation of workers rather than the health benefits of lower pollution.

To understand the consequences of policy choices regarding the spatial allocation of pollution within the country, we conduct counterfactuals where we move pollution away from cities with more skill-biased capital (i.e., industries with greater demand for skilled work like finance, technology or skilled manufacturing) to cities with less skill-biased capital. Again, we perform two versions of this exercise: either setting pollution caps, or relocating 'exogenous' drivers of pollution like coal-fired plants. GDP in the country rises by $6.7 \%$ in the former, and $3.67 \%$ in the latter scenario. Again, spatial resorting of workers plays a driving role in income increases, and relaxing migration costs (e.g. less stringent hukou restrictions) further amplifies the effects.

Next we use our model to predict the consequences of pollution-control programs that the Chinese government recently introduced. The 12th Five-Year Plan on Air Pollution Prevention and Control in Key Regions sets targets for ambient concentrations of particulate matter, with more stringent targets for high-productivity, polluted regions like Beijing. ${ }^{4}$ Despite targeting only a subset of cities, this exercise increases aggregate GDP in China by 3.6\%. Our simulations of estimating them ourselves) we would get similar quantitative results.

${ }^{3}$ See Lustgarten (2020) and "How Climate Migration will Reshape America," New York Times, Sep 15, 2020, https://www.nytimes.com/interactive/2020/09/15/magazine/climate-crisis-migration-america.html.

${ }^{4}$ http://www.mep.gov.cn/gkml/hbb/bwj/201212/t20121205_243271.htm, accessed September 17, 2019. 
suggest the policy largely benefits skilled workers. Reducing migration barriers in conjunction with pollution control would result in a more equitable distribution of benefits across skilled and unskilled workers.

The model simulations show that relocation of workers is a major driver of these effects, larger than the direct effect of air pollution on worker health and labor productivity. The relationship between pollution and health is the subject of a much larger literature in economics and epidemiology, but we learn that ignoring labor mobility grossly underestimates the overall consequences of air pollution on an economy's prosperity. It is important to incorporate this into policy analysis, because increased pollution and migration have been two of the defining features of the impressive Chinese growth experience over the last 30 years (Brandt et al., 2008; Tombe and Zhu, 2019; Zheng and Kahn, 2013).

Whether relocating pollution also affects aggregate welfare (beyond productivity effects) depends on the precise underlying reason as to why the high and low-skilled react differently to pollution. Survey data shows that this is partly due to different preferences and environmental awareness of the rich. Several Chinese cities have adopted a point-based system that exempts workers with skills or higher education from their hukou restrictions (see Appendix Table C2). Without the exemption, the system imposes a burden on poor in-migrants to cities by limiting or prohibiting their access to many government-provided benefits (Combes et al., 2019). With high mobility costs (physical or institutional), unskilled workers may be trapped in polluted cities with low wages even as their skilled counterparts leave.

Once we incorporate migration costs into our analysis, our model shows that the welfare losses from pollution are magnified. When unskilled workers cannot easily leave with their skilled counterparts, migration costs exacerbate the mismatch between where workers are situated. Relocating pollution away from cities with skill-biased capital and lowering migration costs simultaneously has an amplified effect on welfare. ${ }^{5}$ These exercises allow us to answer the question we pose in the first paragraph of this paper: how much of the wage gap across cities can be explained by pollution-induced spatial sorting of workers?

Our research confirms anecdotal evidence from news reports about firm and worker location choices in China. ${ }^{6}$ Other work documents Chinese households' willingness to pay to avoid pollution using variation in housing prices (Freeman et al., 2019) and air filters (Ito and Zhang, 2019). As a result, firms in China pay substantial 'pollution premiums' to attract workers (New York Times, 2015).

\footnotetext{
${ }^{5}$ While China's hukou policy is unique, institutional restrictions on migration are not without precedent in other countries. For example, state-level entitlement schemes in India discriminate against out-of-state migrants and inhibit inter-state mobility (Kone et al., 2018). Furthermore, migration costs are high for the poor in most developing countries (Bryan and Morten, 2019). Public transportation infrastructure is often of poor quality, posing a disproportionate burden on the poor.

${ }^{6}$ See for instance, "Why leave job in Beijing? To breathe." Wall Street Journal, April 142013. https://www.wsj.com/articles/SB10001424127887324010704578418343148947824,

and also "Execs fleeing China because of bad air," CBS news, Jan 29 2013, https://www.cbsnews.com/news/execs-fleeing-china-because-of-bad-air/.
} 
Most closely related to our reduced-form analysis, Chen et al. (2017) also report that workers migrate in response to air quality. They infer this from data on population changes and find large mobility responses to pollution even during a period when information on air quality was not readily available. ${ }^{7}$ In contrast, the first part of our paper uses the restricted-access 2015 One-percent Population Census of China on actual migration decisions (after information about pollution was widely disseminated) and a longitudinal panel data which track individual migration over time from 2008 to 2016 (before and after information about pollution was widely disseminated) to explore the relationship between pollution and internal migration. We additionally document similar changes in net populations, but recognize them to be the consequence of resorting across all cities in general equilibrium. Xue et al. (2020) use firm financial data to show that polluted Chinese cities experience drops in skilled executives, and value once pollution data was made public. Very different data and empirical strategies produce consistent results.

We describe our data sources in Section 2, describe geographic and time-series patterns on pollution and migration in Section 3, identification strategies in Section 4 and discuss the estimates of the causal effect of pollution on migration in Section 5. The quantitative part of the paper consists of the theoretical framework in Section 6, estimating model parameters in Section 7, and conducting counterfactual exercises in Section 8. Section 9 concludes.

\section{Data and Measurement}

\subsection{Demographic and Migration Data}

We measure internal migration using the 2015 Population Census of China. The 2015 Census is the latest census with restricted public access. Importantly, it is the only population census after both the 2008 disclosure of PM2.5 data by the US Embassy in China and the publication of city-level PM2.5 data by the Chinese Government in 2012. The census records demographic and economic characteristics of individuals, including education levels, employment details, hukou location, and current residential city. We use the 2015 One-Percent Census sample, and restrict our attention to the working age population.

We define migration in a few different ways. First, in the Census, migrants are defined as those who are away from their hukou city for more than six months. ${ }^{8}$ Hukou status determines citizens' access to state-provided goods (such as schools for children) and services (like marriage registries or passport renewals). ${ }^{9}$ Given the strong (forced) attachment to one's hukou city, when a person's location of residence differs, it can be reliably characterized as migration.

\footnotetext{
${ }^{7}$ The US embassy started disclosing PM2.5 data in Beijing in 2008. In 2012, the Chinese government started releasing data more widely, and by 2013 most cities had publicly available PM2.5 data.

${ }^{8}$ This definition is consistent with other recent work on internal-migration in China (Combes et al., 2019; Tombe and Zhu, 2019). Only 7\% of individuals have a hukou city that is not their birth city.

${ }^{9}$ In China, hukou plays a critical role as an internal-passport which determines one's entitlements to pursue many activities and eligibility for state-provided goods and services in a specific place. The migrants who do not hold a local hukou have limited or no access to many government-provided benefits, including public education for children and medical care.
} 
Second, we construct an individual-level longitudinal panel using the China Labor-force Dynamics Survey (CLDS), which records individual histories of location changes for a sample of 14,226 households across 29 provinces of China. The CLDS is a national longitudinal social survey, with information on education, work and migration experience. Since the survey asks retrospective migration histories of each individual, we are able to construct a longitudinal panel of location histories between 2008 and 2016. We define migration to be an indicator for whether an individual changed city locations between years, regardless of whether they change their hukou status. The CLDS allows us to account for individual-specific unobservables, track those who have moved multiple times and those who have moved and returned home.

We supplement the migration data with a measure of the stock of workers by skill level computed using the Census. Migration choices ultimately affect the net number of skilled and unskilled workers in each city. We show that the number of workers by skill vary systematically with air quality across cities. These changes in stock are the summary outcome of (net) migration decisions for all reasons and through all modalities (whether or not individuals change hukou status), and the object most sensible to use in our structural analysis for the quantification of productivity. Our structural quantification helps account for the fact that changes in the net-stock of workers cannot simply be interpreted as a migration response to pollution.

Jointly, the three different migration measures we use either follows best practice, or improves on the approaches in the existing literature to measure migration in China.

\subsection{Air Quality Measures}

We use satellite data to measure air quality, which has a few advantages over official sources of pollution data. First, satellite-based PM2.5 measures are available for all cities between 1998 and 2015, whereas official PM2.5 data are only available since 2012. ${ }^{10}$ Second, official air quality data may be subject to manipulation by local governments (Chen et al., 2012; Ghanem and Zhang, 2014; Greenstone et al., 2020). Satellite-based measures seem more reliable: Their correlation with monitor-based PM2.5 data collected by US Consulates in China is approximately 0.8. City-level annual PM2.5 concentrations are measured using the Global Annual PM2.5 Grids derived from satellite data by Van Donkelaar et al. (2016). ${ }^{11}$ This yields a comprehensive air quality measure for a wide range of cities in China, covering all the prefecture, sub-provincial, and provincial cities.

\footnotetext{
${ }^{10}$ Fine particles (diameter $<2.5 \mu \mathrm{m}$ ) are most hazardous and PM2.5 is considered to be the best indicator for health risks from air pollution. For more background information see WHO report: http://www.who.int/mediacentre/news/releases/2014/air-quality/en/. We use the Air Quality Index (AQI) released by Ministry of Environmental Protection (MEP) for robustness checks.

${ }^{11}$ They estimate ground-level PM2.5 by combining Aerosol Optical Depth (AOD) retrievals from the NASA MODIS, MISR, and SeaWiFS, which are subsequently calibrated to daily global ground-based observations of PM2.5 using Geographically Weighted Regressions (GWR) at high grid resolution.
} 


\subsection{Inputs into Instrumental Variables}

We obtain information on large-scale (capacity $>1$ million $\mathrm{KW}$ ) power plants, their coal consumption, and plant-level electricity generation from China's Electric Power Yearbooks and Energy Statistical Yearbooks. We supplement this with information on the establishment year of plants, the angle between their locations and annual prevailing wind direction of each city, and the distance from each city.

We collect data on thermal inversions from the Modern-Era Retrospective Analysis for Research and Applications, Version 2 (MERRA-2), which records the 6-hour air temperature at different atmospheric layers. For each 6-hour period, we calculate the temperature change from the first to the second above ground atmospheric layer. If the temperature change is positive, a thermal inversion occurs and the difference in temperatures measures the strength of thermal inversions. We calculate the annual occurrence and the annual sum of thermal inversion strength from the 6-hour data.

Estimating the structural model requires us to develop a few other instruments. First, we derive information from a large-scale university expansion in China at the turn of the century that suddenly expanded college enrollment by $20 \%$ in certain cities, to identify skilled-worker agglomeration effects. Data on the number of college students and graduates at city level are from the China Regional Statistical Yearbook. Second, we leverage variation in trade shocks to identify migration responses to wages. Data on Chinese trade are from the UC Davis Center of International Studies. The quantity and value of exports and imports by Harmonized System (HS) of product classification are available at the city level. Data are available annually between 1997 and 2013, covering periods before and after China's 2001 accession to the WTO. We construct city-level measures of baseline dependence on products more likely to be affected by tariff changes and trade policy.

\subsection{Wages, Controls and City-level Characteristics}

Since the 2015 Census does not record individual-level wages, we use the CLDS to calculate city-and-education specific average wage. We collect city characteristics, such as population and GDP, from the City Statistical Yearbooks. Weather data come from the Meteorological Data Service Center. We gather monthly data on temperature, humidity, sunshine duration, and other weather amenities. We calculate distances from each city to the three large seaports (Tianjin, Shanghai and Shenzhen) and employ these variables as controls. Appendix Table C1 reports summary statistics and a full description of the key variables used in the analysis.

\section{Descriptive Patterns of Pollution and Migration}

In this section we describe the spatial and temporal patterns of pollution, migration and wages in the raw data. These patterns motivate the hypotheses linking pollution to migration and wages, which we then subject to rigorous inquiry in subsequent sections. 
Figure 1: The Distribution in Pollution and Wages Across Cities

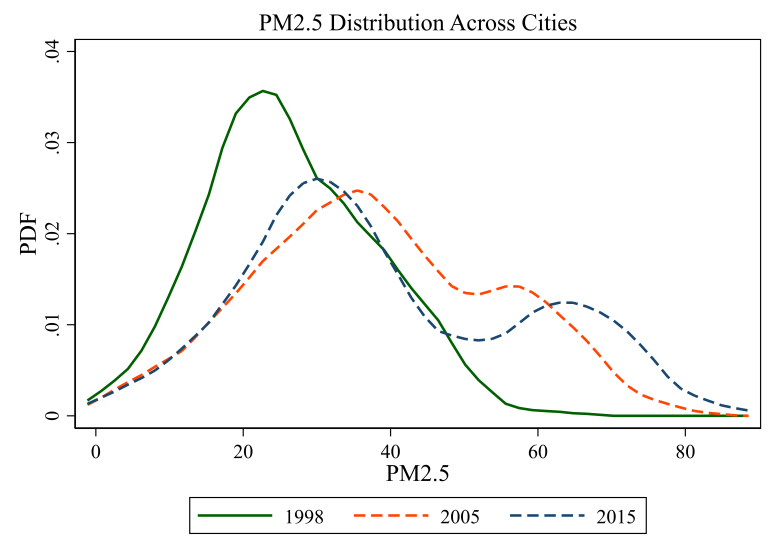

(a) Increasing Spread in Pollution Across Cities

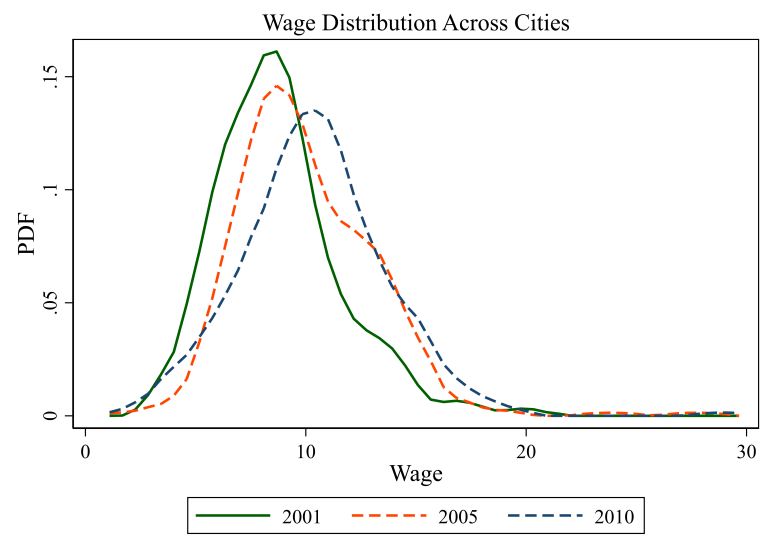

(b) Real Wage Distribution Across Cities

Notes: Distributions across cities for different years. Wage distribution across cities drawn from the City Statistical Yearbooks. Real wages are nominal wages deflated by local housing price. PM2.5 data from the Global Annual PM2.5 grids.

Figure 1 shows the increases in both city-level spatial dispersion of PM2.5 and real wages over time. The left panel documents that pollution not only increased between 1998 and 2015, but also became more variable across regions. The double-peak in the figure further indicates that the overall increase in PM2.5 was driven by the emergence of some high polluting cities.

The right panel shows that both wages and the cross-city variance in real wages rise over time. If this implies an increase in the spatial dispersion of marginal products of labor, then that raises the possibility that moving workers from low marginal product cities to high marginal product cities may increase aggregate output.

Figure 2: The Distribution in Pollution Across Cities and Over Time

(a) Change in mean PM2.5 over time

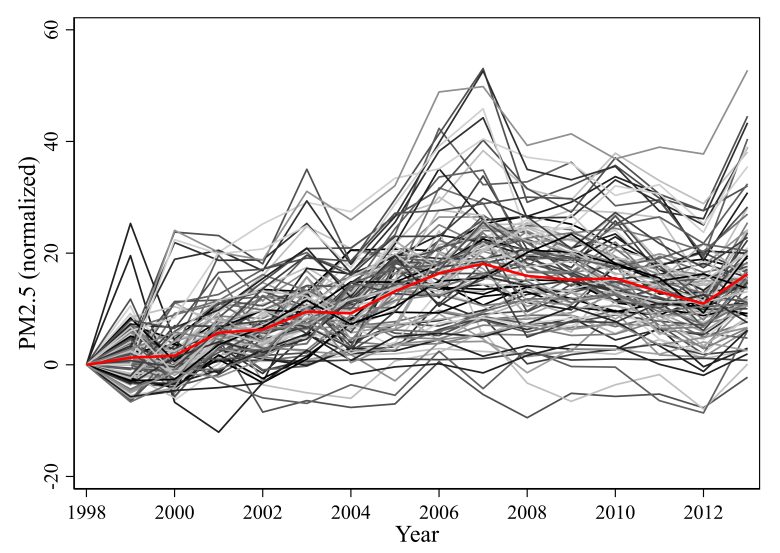

(b) PM2.5 Concentration in China

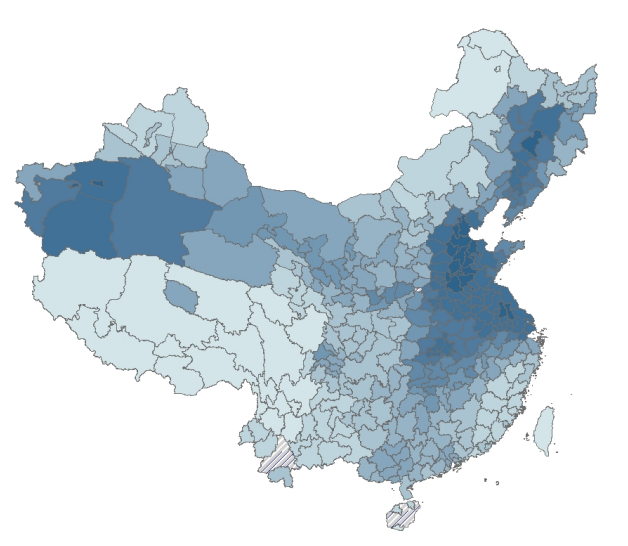

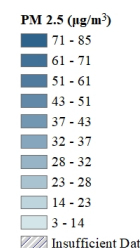

Notes: Spatial and temporal distribution of PM2.5 using the Global Annual PM2.5 Grids. The map shows the geographic spread in 2015. Figure 2a shows the increase in PM2.5 over time for the 100 largest cities in China, relative to the 1998 PM2.5 value (the difference with respect to 1998). The red line is the unweighted average. 
Figure 2a illustrates the time trend of annual PM2.5 concentrations in Chinese cities since 1998. The mean concentration exceeds WHO air quality guidelines every year. ${ }^{12}$ The figure also shows that the increase in the mean coincided with the increase in cross-city dispersion in pollution documented in Figure 1a. The increase in the overall mean was driven by dramatic increases in PM2.5 in a subset of cities.

Figure $2 \mathrm{~b}$ displays the spatial variation in annual average satellite PM2.5 concentration for 2015. Air quality is unevenly distributed. The coastal areas of north-east and eastern China experience the severe air pollution. Manufacturing industries are concentrated in the east. The north-east further suffers from coal-burning for heating needs, exacerbating pollution relative to high economic growth areas of the south. ${ }^{13}$

Figure 3: The Geographic Distribution of the Share of Out-Migrants by Skill

(a) Share of Low-Skill Out-Migrants

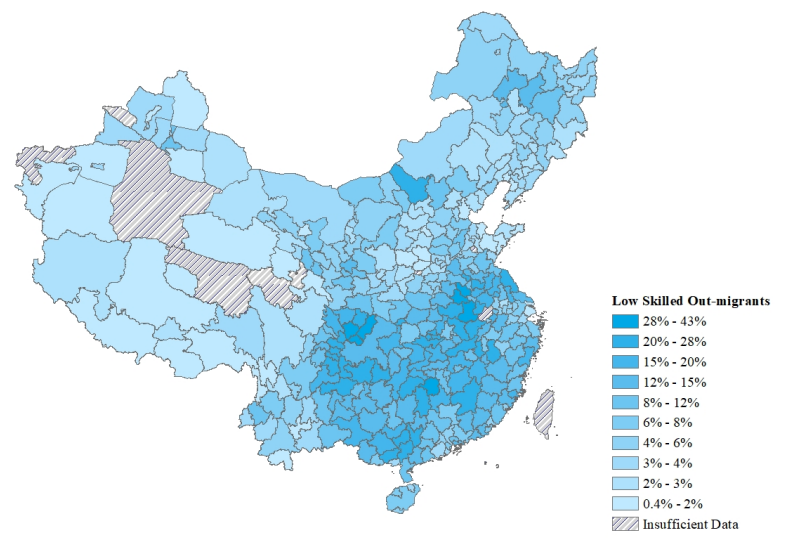

(b) Share of High-Skill Out-Migrants

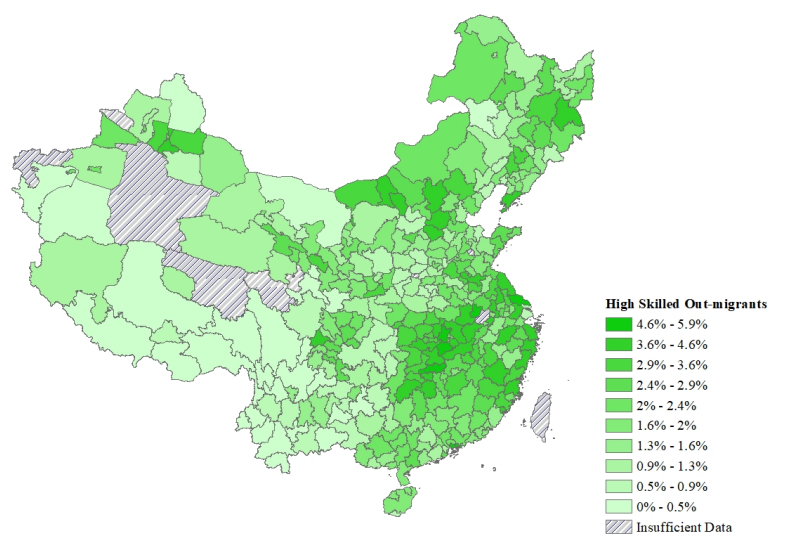

Notes: Low-skilled denotes people whose highest degree is high school or below. High-skilled denotes people whose highest degree is some college or above. Out-migrant shares are ratio of those who leave their hukou city for more than six months, and the number of people whose hukou location is a given city.

Correspondingly, we examine the geographic patterns of emigration of low-skill (Figure 3a) and high-skill (Figure 3b) migrants. Low-skill emigration rates are very high in the south of China, while high-skill out-migrants are comparatively more populous in the north-east and the east. Recall from Figure $2 \mathrm{~b}$ that pollution is also relatively more concentrated in the north-east than in the south. These three figures therefore jointly indicate that pollution is more spatially correlated with high-skilled emigration rather than low-skilled.

Figure 4a explores whether that observed spatial correlation creates a city-level association between pollution and the share of high-skilled that choose to emigrate. There is a clear positive association: the high-skilled are more likely to leave polluted areas. We explore this intriguing correlation more rigorously in subsequent sections, to isolate a causal relationship.

Finally, Figure 4b examines the association between pollution and the wage returns to skills

\footnotetext{
${ }^{12}$ See http://www.who.int/mediacentre/factsheets/fs313/en/ for information on WHO guidelines.

${ }^{13}$ Dust-storms in southern Xinjiang province are responsible for the isolated area of high particulate matter observed in the west. This area is otherwise not highly economically active.
} 


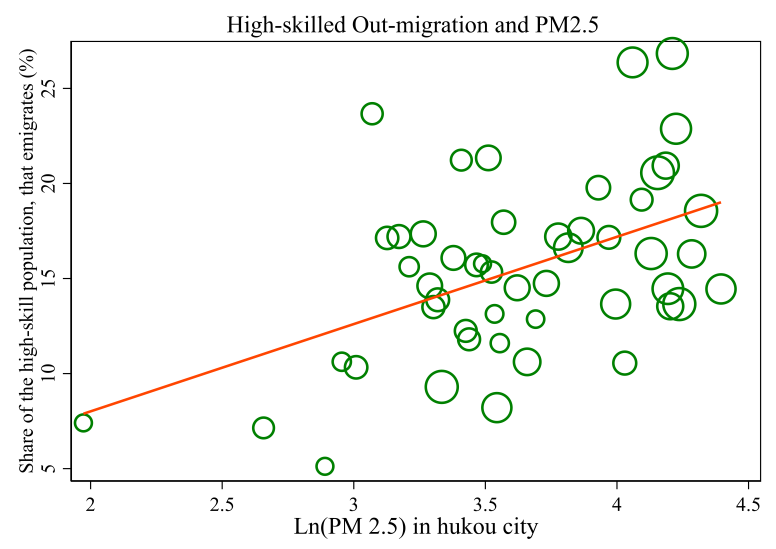

(a) High-Skill Emigration Share and PM2.5

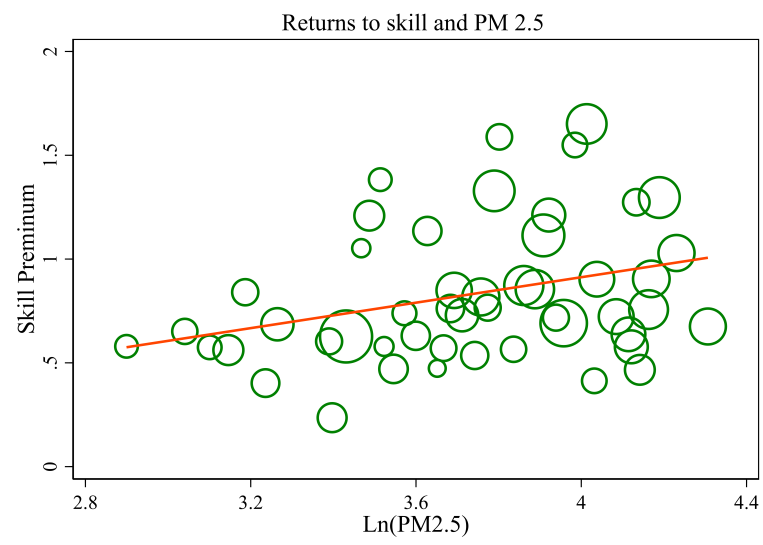

(b) Returns to Skill and PM2.5 at Origin

Notes: The share of high-skilled out-migrants denotes the share of some college (or above)-educated outmigrants from the city-level college-educated hukou population. 'Returns to skill' denotes the return to some college or above education. Each bubble is a city. The bubble size is weighted by the population in 2000 .

that emerges in each city. ${ }^{14}$ Returns to skill are higher in polluted cities. Economic theory provides a simple explanation for the two related correlations depicted in Figure 4: Higher outmigration of college workers in response to pollution makes the high-skilled relatively scarce in those cities, and in equilibrium, creates a compensating differential for poor air quality for skilled workers. This relationship will endogenously emerge in the general equilibrium model of pollution, migration and wages that we develop. Figure 4b also highlights a key insight about the benefits of pollution control policy that will emerge in our model: Reducing PM2.5 in highly polluted cities would induce high-skilled workers to move to the cities where their skills are relatively scarce (and so their marginal product may be relatively higher), and this re-sorting could be a mechanism that raises aggregate productivity.

\section{Identifying the Causal Effect of Pollution on Migration}

Our main specification studies the effects of PM2.5 concentration in origin city $o$ on the amount of out-migration by skill group. Our primary regression of interest is as follows:

$$
M_{i o}=\alpha+\beta_{1} \log (P M 2.5)_{o}+\mathbf{X} \beta+\epsilon_{i o},
$$

where $M_{i o}$ is an indicator for whether or not individual $i$ left origin city $o$, and $\mathbf{X}$ are controls. That is, we begin our reduced-form analysis with the dependent variable defined as the actual migration decision. Later, we show results using the net stock of workers by skill group, recognizing that changes to the net stock are difficult to interpret in reduced form without the aid of the model, as the quantities of workers are determined in spatial general equilibrium. ${ }^{15}$

\footnotetext{
${ }^{14}$ Our estimates of returns are consistent with recent estimates from other work, such as Giles et al. (2019).

${ }^{15}$ As other work has noted, in such settings when using net quantities of workers, there is no 'control group,' as all movement out of a polluted city implies movements into a non-polluted city. As such, population quantities
} 
Before 2012, information about local PM2.5 concentration was not available in most Chinese cities. The Chinese government started releasing PM2.5 data in 2012, and that unexpected data disclosure affected the avoidance behavior of Chinese citizens (Jia et al., 2019). ${ }^{16}$ We therefore use the most recent census data in China - the 2015 One-Percent Population Census, conducted after the 2012 data disclosure - in our preferred specification. In robustness checks, we also estimate this relationship using longitudinal panels with individual fixed effects.

Pollution is likely associated with the underlying structure of the economy, as polluted areas may have bigger manufacturing-bases, which independently affects the skill composition of the workforce. OLS estimates of equation 1 may be biased as a result. To get around these issues, we use a few different identification strategies to isolate the causal effect of pollution on migration: Panel fixed-effects models, as well as two different instrumental variables strategies. To build confidence in our causal effect of pollution on emigration, our strategy is to examine the same relationship using multiple data sources, different types of variation, and conduct large sets of robustness checks (see Appendix A), to examine whether we see consistent patterns.

\subsection{Instrument 1: Wind Direction and Coal-Fired Power Plants}

Our first source of plausibly exogenous variation in pollution is based on an insight from Freeman, Liang, Song, and Timmins (2019). We measure the extent to which each city is down-wind of a coal-fired power plant located outside the city. The instrument is a function of wind direction and coal consumption in large-scale thermal power plants located in a 100$500 \mathrm{~km}$ radius around the city. The instrument value is penalized if the plant is farther away, and if it is not located directly upwind of the city, using the formula of our first-stage equation:

$$
\log (P M 2.5)_{o}=\gamma_{0}+\gamma_{1} \sum_{p}^{P}\left(\frac{1}{\alpha_{p}+1}\right)\left(\frac{1}{\text { dist }_{p o}}\right) C_{p}+\varepsilon_{o}
$$

where $\alpha_{p}$ denotes the angle between the annual prevailing wind direction of city $o$ and the plant $p$, dist $t_{p o}$ is the distance between the plant $p$ and city $o, C_{p}$ is the annual coal consumption in plant $p$. We restrict our analysis to all large-scale thermal power plants that are located more than $100 \mathrm{~km}$ from a city, but within a $500 \mathrm{~km}$ radius from the city center. Figure 5 a explains the intuition behind the instrument. The underlying variation is driven by how wind patterns blow pollutants from distant coal plants to cities. Our first-stage relationship in Figure 5b shows that cities downwind from, and closer to, higher coal-consumption power plants are more likely to be affected by poor air quality.

We expect that our instrumental variable is orthogonal to local economic activity. These large-scale thermal power plants supply electricity to vast areas of China; many do not even

in all cities are affected, violating the Stable Unit Treatment Value Assumption (SUTVA). A GE model, like the one we posit, helps properly interpret the magnitudes in such a setting (Bryan and Morten, 2019).

${ }^{16}$ Appendix B shows that the disclosure of PM2.5 data has meaningful effects on both internal migration and air purifier purchases in China. 
Figure 5: Wind direction, distance, and coal consumption in thermal power plants

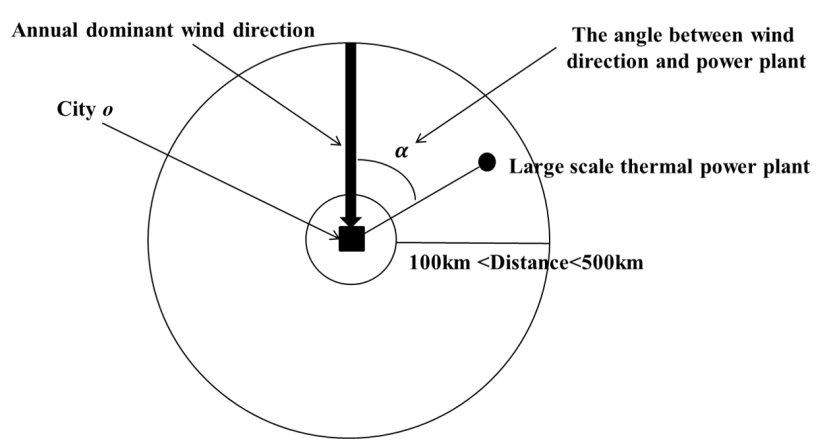

(a) Depiction of instrument

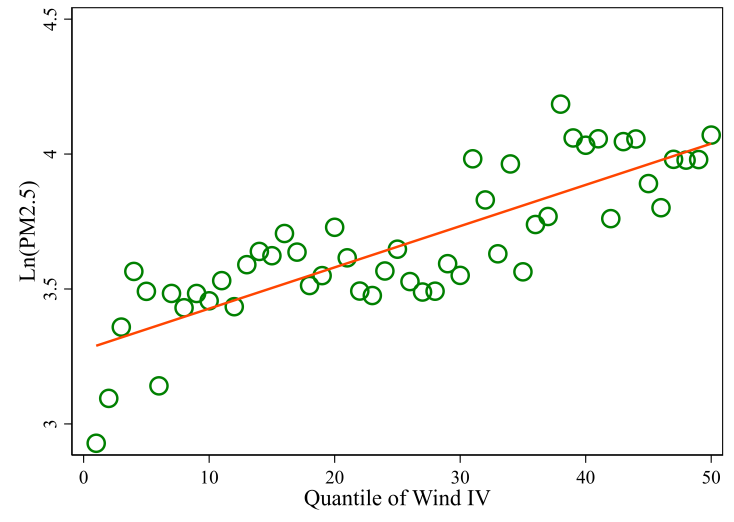

(b) First-stage relationship

Notes: In the left panel, the thick arrow represents the annual dominant wind direction of city 0 . The dark dot represents a large-scale thermal power plant located at least $100 \mathrm{~km}$ outside city $o$ and within $500 \mathrm{~km}$ from the city. The angle $\alpha$ denotes the angle between the annual prevailing wind direction of city $o$ and the large-scale power plant. Large-scale thermal power plants are defined as plants whose installed-capacities are larger than 1 million KW. In the right panel, cities are grouped into one hundred groups according to the quantile of the wind direction IV measure. The y-axis denotes the mean value of PM2.5 in each quantile and $\mathrm{x}$-axis denotes the mean value of wind direction IV in each quantile.

supply electricity to their nearby cities, but rather to many remote provinces. The allocation of electricity supply from large-scale power plants is determined by the central government. Although many reforms have taken place over the past 30 years, there are still strict regulations in the power sector and ownership of the sector largely remains with the state. The central government owns the grid, and controls the setup and operation of power plants if their generating capacity is large. Thus, local governments find it difficult to exert influence on the setup of large-scale power plants, their siting decisions, or the allocation of electricity supply from them. The impact of distant power plants on local economic activity is extremely small, and we also chose to focus on plants at least 100km away to be cautious about this.

We examine possible concerns with this instrument in Appendix A.1.2. We consider whether the location of power plants may depend on the simultaneous combination of wind direction, distance to the city, and the amount of coal consumed. For instance, if we are concerned that newly built plants are placed away from important cities, we show robustness to excluding power plants in a $200 \mathrm{~km}$, and then a $400 \mathrm{~km}$ radius from cities. Among other specification tests, we show robustness to excluding richer or capital cities, coal producing regions, using other outcome measures of air quality, and additional controlling for electrification, demographics and industrialization. The public's recent concerns around pollution are relatively recent, and we show robustness to using only old power plants, such as those built more than twenty years prior to our data. We also conduct numerous falsification tests showing that baseline city characteristics do not predict the future placement of plants, and tests with placebo wind directions indicate that plants that are downwind are less likely to affect air quality and migration. 


\subsection{Instrumental Variable 2: Thermal Inversions}

Our second instrument uses the number and strength of thermal inversions, a meteorological phenomenon where the above-ground temperature is abnormally higher than the ground temperature, trapping pollutants. This has been used as an instrument for air quality in Mexico (Arceo et al., 2016), the US (Hicks et al., 2015) and Sweden (Jans et al., 2014), among other places. Most recently, Chen et al. (2017) show that the number of thermal inversions predicts the movement of people across China as well. We build upon their work by using newer migration data from the 2015 Census at the individual level, rather than quantifying migration indirectly from population changes.

Figure 6: Thermal Inversions and Air Quality
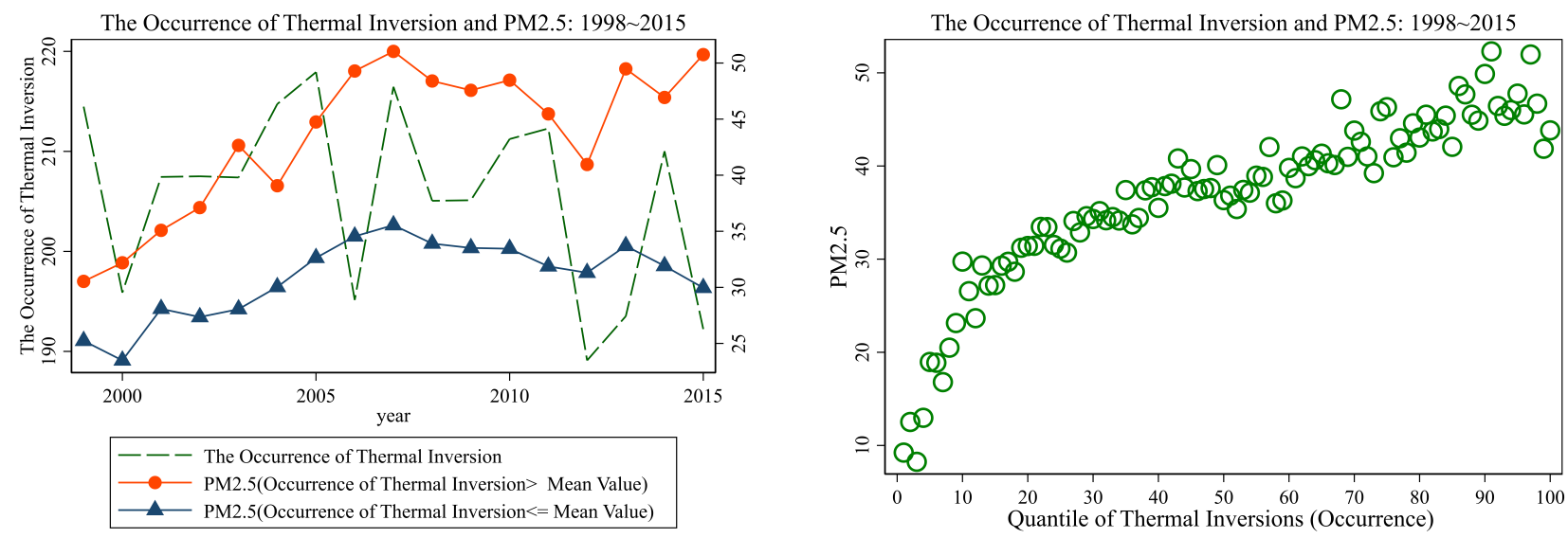

Notes: In the left panel, we divide cities into the two groups based on whether or not they lie above the average annual occurrence of thermal inversions. The red line represents the mean value of PM2.5 in cities where the occurrence of the thermal inversions are above average. The violet line represents the mean value of PM2.5 in cities where the occurrence of the thermal inversions are below average. The green-dash line presents the average annual occurrence of thermal inversions. In the right panel, cities are grouped into one hundred groups according to the quantile of the occurrence of thermal inversions. The $y$-axis denotes the mean value of PM2.5 in each quantile and $\mathrm{x}$-axis denotes the mean occurrence of thermal inversions in each quantile.

We create two measures of inversions in city $o$. First, we count the number of thermal inversions in each year. Next, we measure the annual mean strength of these inversions. We use these measures in both the cross-section and panel form.

As polluting potential rose over time in China, areas with more thermal inversions trapped pollutants in the nearby atmosphere. Figure 6 shows that although there is no trend over time in the frequency of thermal inversions, as cities pollute more over time, areas with more inversions saw a sharper rise in poor air quality over the decade. The right panel shows a strong correlation between inversions and PM2.5 indicating a strong first stage. In our specifications we control for time-varying natural amenities like sunshine and weather, show variants of our measures of inversions, and show how past pollution does not predict future inversions.

We use the two instruments described above independently as they capture very different types of variation in air quality (due to wind direction versus a meteorological phenomenon). The consistency in the estimated direction of the relationship between pollution and migration 
is comforting. In specification checks in Appendix A, we compare the different instruments and their combinations, lagged panel structures, cumulative pollution over time, relevant controls, and excluding some cities. Finally, in Appendix A.2 we introduce yet another source of variation in pollution - a Regression Discontinuity (RD) across the Huai-river (Chen et al., 2013).

\section{$5 \quad$ Empirical Results}

Our theoretical model will help quantify the productivity consequences of pollution-induced migration. First, however, we need to establish that pollution indeed has a causal effect on (a) high and low-skilled differential migration rates, and (b) on the returns to skill in a city, because those are key inputs on which the model rests. We discuss reduced-form estimates of these relationships here, but relegate the more extensive discussion to Appendix A, which includes a long set of specification tests, falsification tests, sample restrictions, different paneldata structures, and different types of controls.

Figure 7: The Ratio of High-to-Low Skilled Out-Migration

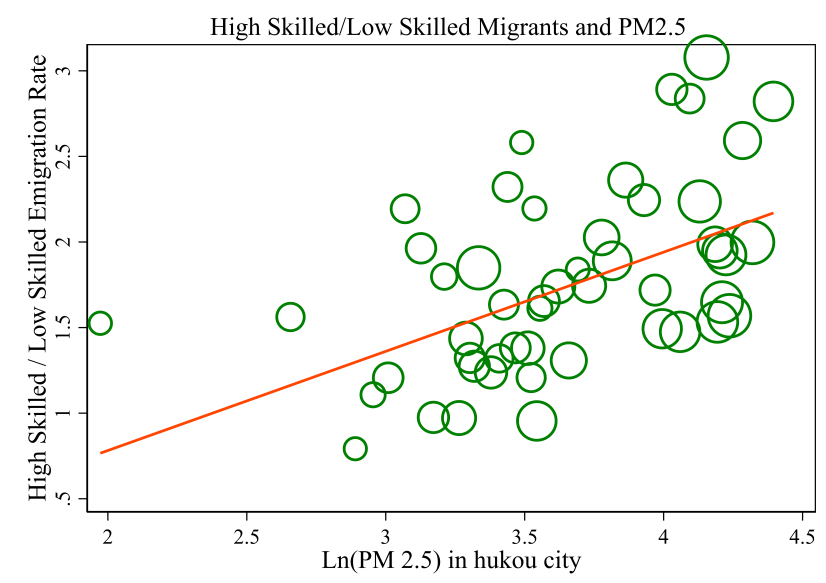

Note: High/low skilled emigration rates is the ratio of out-migration rates for high-skilled (some college or above) to low-skilled emigrants (high school or below). We plot these ratios in 2015 against PM2.5 levels.

\subsection{The Causal Relationship Between Pollution and Migration}

Figure 7 captures the relationship between differential mobility and pollution in the raw data. The ratio of high-skilled to low-skilled emigration rates increases with higher PM2.5 levels in the city of origin, suggesting that the location choices of high-skilled workers are more sensitive to pollution than that of low-skilled workers.

In Table 1 we examine the effect of pollution on an individual-level binary indicator of leaving one's hukou city. We show results separately for those with some college degree or above, and those without. We control for demographics, and for distances to three large seaports to account for the spatial distribution of economic development in China. 
Table 1: Pollution and Out-Migration

\begin{tabular}{|c|c|c|c|c|c|c|}
\hline \multirow{3}{*}{ Panel A } & \multicolumn{6}{|c|}{ Dependent variable: Leave hukou city indicator } \\
\hline & \multicolumn{3}{|c|}{ OLS Regression } & \multicolumn{3}{|c|}{ Wind+coal IV } \\
\hline & Full sample & Low edu & High edu & Full sample & Low edu & High edu \\
\hline $\log (\mathrm{PM} 2.5)$ & $\begin{array}{c}0.0428^{* * *} \\
(0.00974)\end{array}$ & $\begin{array}{c}0.0399 * * * \\
(0.00993)\end{array}$ & $\begin{array}{c}0.0501 * * * \\
(0.0112)\end{array}$ & $\begin{array}{c}0.0772^{* *} \\
(0.0389)\end{array}$ & $\begin{array}{c}0.0609 \\
(0.0423)\end{array}$ & $\begin{array}{c}0.140^{* * *} \\
(0.0382)\end{array}$ \\
\hline Coeff diff pval & \multicolumn{4}{|c|}{0.00} & \multicolumn{2}{|c|}{0.00} \\
\hline Observations & 761,548 & 643,124 & 118,424 & 761,548 & 643,124 & 118,424 \\
\hline R-squared & 0.029 & 0.030 & 0.045 & 0.027 & 0.029 & 0.036 \\
\hline F-test of IVs & & & & 52.53 & 46.52 & 41.54 \\
\hline
\end{tabular}

\begin{tabular}{|c|c|c|c|c|c|c|}
\hline \multirow{3}{*}{ Panel B } & \multicolumn{6}{|c|}{ Dependent variable: Leave hukou city indicator } \\
\hline & \multicolumn{3}{|c|}{ Number of inversions } & \multicolumn{3}{|c|}{ Strength of inversions } \\
\hline & Full sample & Low edu & High edu & Full sample & Low edu & High edu \\
\hline $\log (\mathrm{PM} 2.5)$ & $\begin{array}{c}0.0906^{* * *} \\
(0.0202)\end{array}$ & $\begin{array}{c}0.0871^{* * *} \\
(0.0211)\end{array}$ & $\begin{array}{c}0.112^{\text {**** }} \\
(0.0233)\end{array}$ & $\begin{array}{c}0.0779^{* * *} \\
(0.0228)\end{array}$ & $\begin{array}{c}0.0740^{* * *} \\
(0.0238)\end{array}$ & $\begin{array}{c}0.107^{* * * *} \\
(0.0279)\end{array}$ \\
\hline Coeff diff pval & \multicolumn{4}{|c|}{0.00} & \multicolumn{2}{|c|}{0.00} \\
\hline Observations & 761,548 & 643,124 & 118,424 & 761,548 & 643,124 & 118,424 \\
\hline R-squared & 0.035 & 0.037 & 0.047 & 0.037 & 0.039 & 0.047 \\
\hline F-test of IVs & 102.5 & 97.33 & 84.83 & 51.09 & 49.60 & 40.54 \\
\hline
\end{tabular}

Notes: Individual level regressions in 2015 across 332 cities. Standard errors clustered at the hukou city level are reported in parentheses. 'Coeff diff pval' reports the p-value of a test of equality of coefficients between the low and high educated groups, using the Fisher's permutation test. The instrumental variables specification in the top panel uses the interaction between wind direction, distance to coal plant, and coal consumption at power plant. Instrumental variables specifications in the bottom panel use thermal inversions. All panels have: (a) City controls which include the log distance to Shanghai seaport, to Tianjin seaport and to Shenzhen seaport, and (b) demographics which include age, age-squared, gender, marital status, and an urban hukou indicator. The bottom panel using thermal inversions also have (c) weather controls which include temperature, wind speed, sunshine duration and humidity.

The OLS estimates in Panel A suggest that air pollution leads to the out-migration of all types of workers, and this effect is statistically stronger for those with higher education ( $p$ val<0.001). Given endogeneity concerns, columns 4-6 employ our first instrument based on wind direction and distant coal-fired power plants (Freeman, Liang, Song, and Timmins, 2019). The differential impact by skill level increases in magnitude when using our instruments. A 10\% increase in PM2.5 raises out-migration rates by 0.77 percentage points overall, with the effect being meaningfully larger for those with higher education attainment (1.4 percentage points) than those without (0.61 percentage points). The high and low-skilled emigration responses are statistically different from each other with $>99 \%$ confidence.

In Panel B, we study how variation in PM2.5 from our second instrument of thermal inversions affects out-migration propensities. We follow the literature, and control for weather amenities. In the first three columns, we employ the annual occurrence of thermal inversions as 
the instrumental variable. Again, the emigration response is more pronounced for high-skilled workers. A $10 \%$ increase in PM2.5 leads to a 1.12 percentage point increase in emigration rates for those with high education attainment, but only 0.87 for those without. In the last three columns, we leverage the variation coming from the annual strength of thermal inversions. We obtain similar results.

Appendix A.1.1 provides further details on our instrumental variable strategies. Table A1 shows the (strong) first-stage estimates, Table A2 shows similar result when omitting the weather controls, and Table A3 combines multiple instruments in the same specification, and shows we obtain even greater precision.

Table A4 shows that workers also pay attention to the pollution levels at destinations, in deciding which city to migrate to. In other words, workers leave polluted areas, and also seek out less polluted cities. Again, similar to the emigration response, the immigration location choices are more sensitive to pollution among higher educated workers. As destination choices are not independent across cities, we derive a model that disciplines these results. These facts play an important role in our model: Fewer skilled workers in a polluted city will tend to raise the skill premium. As a result, cleaning up polluted cities will move skilled workers from a city that has a lower marginal product of skilled labor to a city with a higher marginal product, increasing aggregate output via relocation.

\subsection{Alternative Specifications, Robustness and Heterogeneity}

In Appendix A.1.2 we examine various threats to identification. We summarize the results of these exercises in Figure 8, where a simple pattern emerges: the high-skilled respond to poor air quality by emigrating, but the effect on the low-skilled is smaller.

First, we seriously evaluate the claim that power plants may be systematically built near poorer, less influential cities, and so the instrument may be correlated with unobservable characteristics of nearby cities. In Table A5, we exclude nearby plants, placed either in a $200 \mathrm{~km}$ or a $400 \mathrm{~km}$ radius of a given city, and find that, if anything, our results are more precisely estimated. We may also be concerned that newly built plants are subject to more regulation as the Chinese government only recently paid attention to environmental issues. So, in Table A6, we restrict our sample to only old plants, and find similar effects. We drop coal producing regions to address the concern that coal-fired plants may locate near coal production (Table A7), and show that baseline population, GDP and electricity consumption do not predict future upwind plants, or future iterations of our IV (Table A10). The results suggest that it is not that policymakers avoid richer, influential cities when building plants, and that plants are not built in areas that have a higher need for electricity at baseline, perhaps as most electricity is directly supplied to the larger grid.

In Table A11, we extend this by creating various 'placebo' instruments, artificially changing the wind direction and showing that these falsified instruments are less likely to predict pollution levels and migration decisions. Similarly, for our thermal inversion instruments, in Table A12 
we show that lagged pollution levels do not predict future inversions. Indeed, even lagged inversions do not predict future ones - suggesting that their occurrences are hard to predict.

Figure 8: Different Sources of Variation
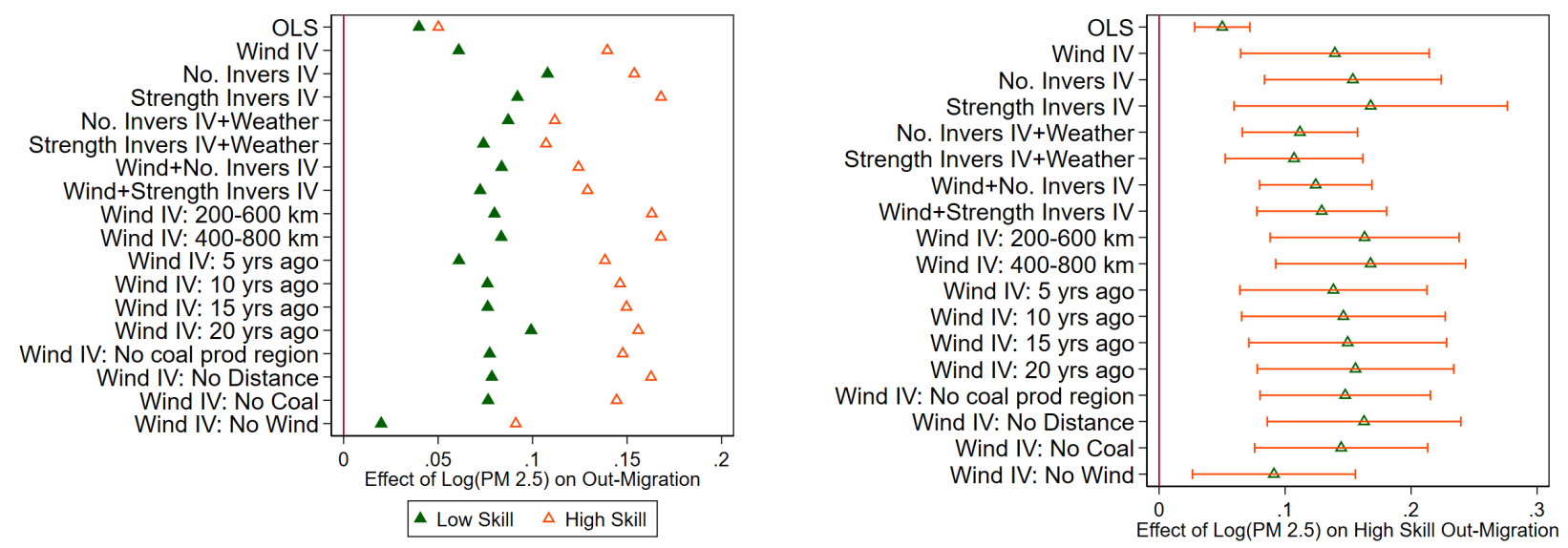

Notes: Summary of results using different sources of variation. We compile coefficients from different specifications. On the left we show both the coefficients on high and low skilled workers. On the right, we concentrate on high-skill workers, and include 95\% confidence intervals. Instruments include number ("No. Invers" for short) and the strength of thermal inversions ("Strength Invers") as well as different versions of the wind direction and coal-fired power plants IV ("Wind IV"). "Wind: 20 yrs ago" relies on plants built before 1995, and excludes newly built power plants. We do this so as to allay any concerns that newly built plants may be placed endogenously simultaneously based on wind direction, distance to cities and access to coal. The "Wind IV 400-900 km" IV excludes any plants built within a 400km radius from a city and instead only captures plants built 400-900 km away. This is done to allay concerns related to the endogenous placement of plants in close proximity to the city.

In Appendix A.2 we exploit an entirely different source of variation in pollution, driven by China's Huai river heating policy. As Chen et al. (2013) show, the heating policy generated an artificial discontinuity in air quality on two sides of the Huai river. North of the Huai river, the government encouraged centralized heating systems for homes, which primarily relied on coalfired boilers. Even in the 2000s, there is a sharp discontinuity in the use of boilers for heating, leading to a discontinuity in air quality across the Huai river. While there is no differential out-migration in areas immediately north versus south of the Huai river, skilled workers are discontinuously (and statistically significantly) less likely to migrate into the more polluted cities just north of the Huai river, relative to cleaner cities just south of the river.

In Appendix A.3, we turn our attention to studying different model specifications, subsamples, and checking the robustness of our estimates to different controls. Figure 9 summarizes the results of this large set of robustness exercises.

First, in Appendix A.3.1 Table A13, we use individual-level longitudinal panel data and a different definition of migration to replicate our results. The longitudinal panel allows us to track individuals' spatial sorting over time, and control for city and individual-level characteristics. Importantly, we define migration to be an indicator for whether or not an individual changed their city between years, regardless of whether they change their hukou location. This panel data with individual fixed effects approach produces the same pattern of results as the 
OLS and instrumental variables approaches: High-skilled workers are more likely to leave polluted cities relative to their low-skilled counterparts.

We then study the effects of cumulative pollution exposure in Appendix A.3.2. The results shown in Table A14 and A15 indicate that pollution exposure spread over a longer time period has a larger impact than shorter time frames. In Appendix A.3.3, we disaggregate education levels into more fine-grained categories and see a sharp education gradient in out-migration responses. Those with more education are more responsive to pollution (Table A16). In Table A17 we exclude large, influential cities, cities that pollute a lot, and major province capitals, to account for any differences in political influence or outliers in the access to skilled jobs. We find that youth are more responsive to pollution when making location choices (Table A18). Table A19 studies heterogeneity across rural and urban locations.

We next replace PM2.5 with an alternative measure of local air quality. Table A20 uses the Air Quality Index (AQI) as the endogenous variable of interest, capturing the combined impact of many pollutants. The AQI is officially reported and widely disseminated, and individuals may be more likely to respond to it. Appendix A.3.4 Table A21 highlights robustness to a long list of controls, including the skill-distribution, baseline economic indicators, and industrial pollutants. These controls do not qualitatively affect the main patterns we observe. Finally, in Appendix B, we show that the disclosure of official pollution data affected migration decisions.

Figure 9: Different Models, Samples and Controls
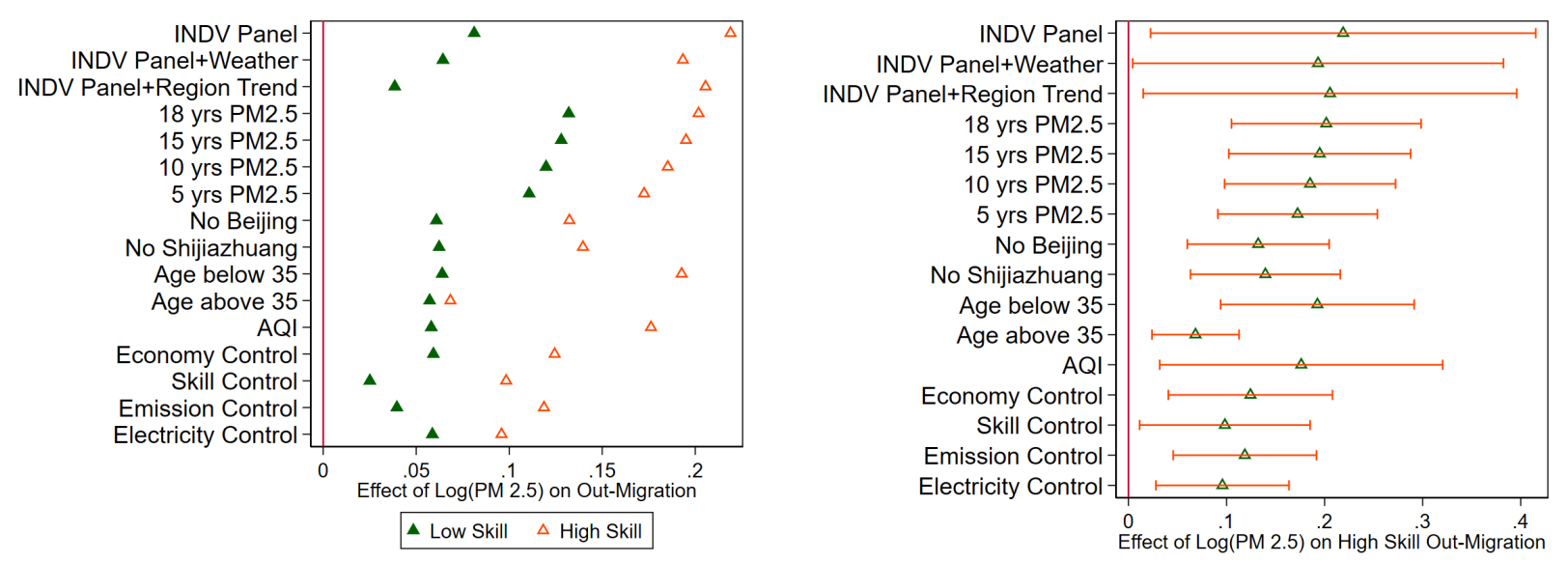

Notes: Summary of results using different models, samples and controls. We compile coefficients from different specifications. On the right we show both the coefficients on high and low skill workers. On the left, we concentrate on high-skilled workers, and include $95 \%$ confidence intervals. Individual longitudinal panel accounts for individual fixed effects ("INDV panel"), and for local weather conditions ("INDV panel+weather") or regionspecific trends ("INDV panel+region trend")

The striking consistency of the migration response to pollution, especially among the highskilled, across a large set of robustness checks, many different, independent sources of variation in the data, different estimation strategies, samples and variable definitions, gives us confidence that we are indeed identifying an effect that is real. 


\subsection{Wage Returns and Pollution}

Table 2: Pollution and Returns to Skill

\begin{tabular}{|c|c|c|c|c|}
\hline \multicolumn{5}{|c|}{ Dependent variable: City-specific returns to college education } \\
\hline & \multicolumn{2}{|c|}{ OLS } & \multicolumn{2}{|c|}{ Wind+Coal IV } \\
\hline $\log (\mathrm{PM} 2.5)$ & $\begin{array}{c}0.248^{* *} \\
(0.125)\end{array}$ & $\begin{array}{c}0.453^{* * *} \\
(0.135)\end{array}$ & $\begin{array}{c}0.789^{* *} \\
(0.309)\end{array}$ & $\begin{array}{c}1.570^{* * *} \\
(0.539)\end{array}$ \\
\hline Observations & 130 & 130 & 130 & 130 \\
\hline R-squared & 0.028 & 0.090 & 0.00 & 0.00 \\
\hline City controls & No & Yes & No & Yes \\
\hline F-test of IVs & & & 44.11 & 23.31 \\
\hline
\end{tabular}

Notes: City-level regressions of 130 cities weighted by the population in 2000, for the sample of CLDS cities with non-missing skill-specific wage data. Standard errors at the city level are reported in parentheses. Instrumental variables specification using the interaction between wind direction, distance to coal plant, and coal consumption at power plant. City controls include the log distance to Shanghai, Tianjin and Shenzhen seaports. Returns to college education is calculated as the coefficient on 'some college or above' indicator in Mincer wage regressions controlling for age and gender. These regressions were done for each of the 130 cities in the CLDS data separately.

This spatial re-allocation of skilled workers could produce a systematic relationship between pollution and the returns to skill across cities. Skilled workers are going to be relatively scarce in cities that they leave, raising their value in the labor market in such cities. Additionally, given the complementarity between skilled and unskilled workers, cities that lose skilled workers will have less productive unskilled workers. As such, cities that lose skilled workers would have higher skilled wages, lower unskilled wages, and therefore higher returns to skill.

Table 2 documents a simple empirical fact: As in the raw-data plot of Figure 4b, returns to skill are higher in polluted cities. We estimate the city-specific Mincerian returns to skill using the CLDS data, and explore the relationship between pollution and skill returns. The first two columns of Table 2 show the OLS results. The impacts of pollution on skill returns are positive and statistically different from zero. The effect of pollution on the skill premium increases in magnitude when we employ the wind direction and coal-fired plants IV to address endogeneity concerns. Our model will formalize this link between pollution, differential out-migration of skilled workers, and the relative marginal products of skilled and unskilled work.

\subsection{Why are the High-skilled More Sensitive to Pollution?}

For the policy analysis we aim to conduct, it is important to understand precisely why skilled workers are more willing and able to leave polluted cities than the unskilled. Other than the typical pecuniary costs of migration, Chinese households must deal with institutional restrictions to mobility. Administrative records indicate that China's hukou policy explicitly makes it easier for skilled workers to be mobile. People with higher education are more easily able to move to certain cities and retain access to jobs and public services. In Table C2 we 
show a few examples of such restrictions, highlighting how educational attainment can help a person gain enough points to be eligible to receive hukou at certain attractive destinations.

When migration costs (both physical and institutional) make it more difficult for certain subsets of workers to move, they may create artificial mismatches in the locations of skilled and unskilled workers who would otherwise complement each other in production. That can exacerbate productivity losses from worker re-allocation. The effect of poor air quality may also differ by skill level, as richer households may be able to afford air filters.

Beyond mobility costs, different preferences may also be important drivers of the differential mobility responses we observe. Pollution concerns may loom larger for skilled workers, as the unskilled are focused more on making ends meet with their lower wages. Table C3 documents, using data from the China General Social Survey (CGSS), that educated workers are more likely to claim environmental issues in China are "terrible." In Table C4, we use the survey to explore not just concerns for environmental issues, but also actions taken on such issues. Once again, across the board, individuals with more education are statistically significantly more likely to discuss environmental issues, make donations for environmental protection, and make appeals or raise concerns on environmental problems. The differences in migration patterns of the high-skilled in response to changes in pollution therefore partly reflect differences in preferences for environmental quality, and partly differences in mobility restrictions.

\section{Theoretical Framework}

We use a simple theoretical framework to aid our quantification of the productivity consequences of pollution-induced migration. Our model captures a few key features necessary for quantification. First, it endogenizes the compensating differential, by allowing pollution to have differential effects on the utility of skilled versus unskilled workers. Second, mobility costs vary by skill level. Together, these contribute to the empirical patterns that show a differential outmigration by skill level. Third, as college educated workers leave polluted cities, the marginal product of skilled labor rises. If skilled and unskilled workers are complements, the marginal product of unskilled work falls. This leads to differences in the skill-wage premium, consistent with the empirical observation that returns to skill are higher in more polluted regions. An additional source of geography-specific returns to skill is driven by the fact that some cities have more skill-biased capital.

Furthermore, the changing structure of skills in a city affect production and pollution levels. A population influx, or presence of more skilled workers may induce either more or less pollution-intensive industries to expand, and as such change the quality of air in the city. This feedback effect of migration patterns on pollution emissions affects subsequent migration, which in turn affects production, and so on. Additionally, agglomeration forces may increase aggregate productivity if skilled workers converge to high amenity cities, but house prices may also

respond to such movements creating congestion in such cities. Importantly, we allow pollution to affect the health (and lower the productivity) of all workers. 
Our framework accounts for these feedback effects, and generates estimable equations that we identify using instrumental variables. We use the model to perform quantitative counterfactuals on the equilibrium effects of pollution control policies.

\subsection{Production and Labor Demand}

Aggregate output $Y_{d}$ in destination city $d$ depends on $L_{d}$ (effective labor), $K_{d}$ (capital), and $A_{d}$ (TFP). TFP may vary across cities, and may depend on air quality $Z_{d}$, and on agglomeration forces. Capital is perfectly elastically supplied across cities at rental rate $R^{*}{ }^{17}$ Effective labor $L_{d}$ depends on labor $L_{s d}$ at each skill level $s=\{h, u\}$, the high-skilled $h$ and the unskilled $u$.

$$
Y_{d}=A_{d} L_{d}^{\varrho} K_{d}^{(1-\varrho)} \quad \text { where } L_{d}=\left(\sum_{s} \theta_{s d} L_{s d}^{\frac{\sigma_{E}-1}{\sigma_{E}}}\right)^{\frac{\sigma_{E}}{\sigma_{E}-1}}
$$

$0<\varrho<1$ is the share of output accruing to labor, $\theta_{s d}>0$ is the productivity of workers with skill level $s$, and $\sigma_{E}>0$ is the elasticity of substitution across skill groups.

The skill-biased productivity parameter $\theta_{s d}$ captures the productivity of each skill level. For instance, $\theta_{h d}$ increases with an increase in high-skill capital $k_{h d}$, such that $\theta_{h d}^{\prime}\left(k_{h d}\right) \geq 0 .{ }^{18}$ $\theta_{h d}$ also captures other labor demand shocks or policies that raise wages for skilled workers in certain cities. The value of $\theta_{s d}$ therefore varies across cities because of the variation in skillbiased capital $k_{s d}$, and other factors that make workers of a skill-group more productive in $d$. The average log earnings for skill $s$ in destination $d$ are: ${ }^{19}$

$$
\log w_{s d}=\log \left(\frac{\partial Y_{d}}{\partial L_{s d}}\right)=\frac{1}{\varrho} \log A_{d}+\log \widetilde{\varrho}+\log \theta_{s d}+\frac{1}{\sigma_{E}} \log L_{d}-\frac{1}{\sigma_{E}} \log L_{s d},
$$

where $\log \widetilde{\varrho} \equiv\left(\frac{1-\varrho}{\varrho}\right) \log \left(\frac{1-\varrho}{R^{*}}\right)$ is common across all cities and workers. ${ }^{20}$ There are a few components that drive the differences in average earnings when comparing two different skillgroups $s$ in two different labor markets $d$.

Let us consider the determinants of the high-skilled wage $w_{h d}$. First, $A_{d}$ is the amount of TFP at the city level, which may raise average earnings of all in the city. Second, $\theta_{h d}$ is the higher skill-biased productivity associated with more education. Not only are skilled workers more productive, but variation in the supply of skill-biased capital across cities affect earnings. Third, earnings differ due to differences in the supply of more educated workers $L_{h d}$. As with any downward sloping demand curve, the more skilled workers there are, the lower the skilled wage. Yet, $L_{d}$ captures production complementarities, whereby an increase in the number of

\footnotetext{
${ }^{17}$ The perfectly elastic capital assumption is not essential and can be relaxed. See Appendix D.2.

${ }^{18}$ Skill-biased capital for high-skilled workers captures the presence of industries that may be more likely to hire college-educated workers, such as finance, technology, skill-intensive manufacturing, and professional services. For completeness, in Appendix D.2 we explicitly model skill-biased capital within the nested CES framework and show how incorporating it does not affect the qualitative predictions.

${ }^{19}$ This is at the optimal value of $K_{d}^{*}$, so that $Y_{d}=A_{d}^{\frac{1}{\varrho}}\left(\frac{1-\varrho}{R^{*}}\right)^{\frac{1-\varrho}{\varrho}} L_{d}$.

${ }^{20}$ For tractability, output is the numeraire. Housing is not traded across cities, and will have price effects across cities. Since output is not skilled biased, an output price would not change the skill-specific returns.
} 
unskilled workers may actually raise the skilled wage. Equation 4 is the (inverse) labor demand curve and highlights the importance of elasticities: how much the skill distribution affects the difference in earnings depends on the elasticities of substitution $\sigma_{E}$. Migration of skilled or unskilled workers will change these quantities and affect skill-premia.

Additionally, we assume that economic production produces pollution as well. In equation 5, each city has some 'exogenous' component of pollution $\bar{Z}_{d}$, that (say) depends on the occurrence of thermal inversions. Yet, the equilibrium pollution levels $Z_{d}$ depend on other endogenous factors as well. As the workforce composition changes, some cities produce more output than others, which in turn raises pollution. The increase in pollution depends on both aggregate population (capturing the size of the economy, industrial production and congestion) as well as the skill mix. The skill mix affects pollution by changing the type of production (industry vs services), amenities, energy consumption, or even local pollution policies:

$$
Z_{d}=\bar{Z}_{d}\left(\frac{L_{h d}}{L_{u d}}\right)^{\psi_{1}}\left(L_{h d}+L_{u d}\right)^{\psi_{2}}
$$

We also allow for agglomeration economies, and for pollution to directly affect productivity. In equation $6, \bar{A}_{d}$ is 'exogenous' city-level productivity (fertile soil, rivers, land etc.). If $\phi_{1}<0$, pollution lowers the productivity of all workers. We expect the number of skilled workers to raise TFP levels in the city via non-excludable innovation (Arrow, 1962), such that $\phi_{2} \geq 0$ :

$$
A_{d}^{\frac{1}{\rho}}=\bar{A}_{d} Z_{d}^{\phi_{1}} L_{h d}^{\phi_{2}}
$$

\subsection{Migration and Labor Supply}

We assume that workers have preferences over locations, either because of tastes (some prefer to be closer to home, others prefer big cities), or because it is more 'costly' for some to migrate and leave home. The indirect utility of worker $j$, with skill group $s$, in destination $d$, from origin city $o$ is:

$$
V_{j s o d}=\epsilon_{j s d} w_{s d} Z_{d}^{-\gamma_{s}} h p_{d}^{-\nu_{s}} a_{s d} \exp ^{-M_{s o d}},
$$

where $\epsilon_{j s d}$ is a random variable measuring preferences for a specific city $d$ by individual $j$. A larger $\epsilon_{j s d}$ means worker $j$ is particularly attached to city $d$. $M_{\text {sod }}$ captures migration costs between $o$ and $d$, including hukou costs, and physical costs that increase with distance. As such, migration costs vary by education level, and $M_{\text {soo }}=0$ for natives. $h p_{d}$ are housing prices, and $\nu_{s}$ are the share of expenditures on housing by skill-level. $a_{s d}$ represents other non-pollution related skill-specific amenities. The compensating differential elasticity will be captured by $\gamma_{s}$, and varies by skill level. ${ }^{21}$ Here, marginal workers are those that are indifferent across cities, and so are likely to be induced into migration by pollution. Inframarginal workers have higher utility in the city they live in currently, than in all the other cities.

\footnotetext{
${ }^{21}$ If $\gamma_{h}>\gamma_{u}$, good air quality is a normal good.
} 
We assume that $\epsilon_{j s d}$ are independently distributed and drawn from a multivariate extreme value distribution (Eaton and Kortum, 2002). The joint distribution of $\epsilon_{j s d}$ is given by:

$$
F\left(\epsilon_{s 1}, \ldots . \epsilon_{s D}\right)=\exp \left(-\sum_{d}^{D} \epsilon_{s d}^{-\eta_{s}}\right)
$$

where $\frac{1}{\eta_{s}}$ determines how strong the idiosyncratic location preferences are, and so how responsive workers are to wage or pollution changes. If location preferences are very strong, then workers may not migrate even when wages differ widely, or pollution levels are high.

Workers move to places where their utility is higher, implying that given costs of moving, there are no further arbitrage opportunities available. Local ties and migration costs (including hukou and distance-based costs) are captured by $\epsilon_{j s d}$ and $M_{\text {sod }}$ respectively. A person chooses city $d$ over $d^{\prime}$ if $V_{j s o d}>V_{j s o d^{\prime}}$. In Appendix D.1 we derive an expression for labor supply and average city-utility, where the share of workers with skill $s$ from city $o$ that move to $d$ is:

$$
\pi_{s o d}=\frac{\left[w_{s d} Z_{d}^{-\gamma_{s}} h p_{d}^{-\nu_{s}} a_{s d} \exp ^{-M_{s o d}}\right]^{\eta_{s}}}{\sum_{d^{\prime}}\left(w_{s d^{\prime}} Z_{d^{\prime}}^{-\gamma_{s}} h p_{d^{\prime}}^{-\nu_{s}} a_{s d^{\prime}} \exp ^{-M_{s o d^{\prime}}}\right)^{\eta_{s}}}
$$

The supply of workers of skill level $s$ in city $d$ additionally depends on the hukou population of origin city $o, P_{o s}$.

$$
L_{s d}=\sum_{o} P_{o s} \pi_{s o d}
$$

Taking logs of equation 9, we derive the labor supply curve:

$$
\log \pi_{s o d}=-\eta_{s} \log \overline{V_{s o}}+\eta_{s}\left(\log w_{s d}-\nu_{s} \log h p_{d}\right)+\eta_{s} \log a_{s d}-\eta_{s} \gamma_{s} \log Z_{d}-\eta_{s} M_{s o d}
$$

where $\overline{V_{s o}}$ captures the average utility of being from city $o .{ }^{22}$ Note that because of migration costs, utilities are not equalized across cities, and as such the term has an o subscript. For instance, if a high-amenity city has a very restrictive hukou policy, it may have a high average utility as not enough people can enter, lowering wages and raising house prices. Yet, higher hukou restrictions will lower the utility for all individuals in other cities, as their option value of moving to a potentially desirable location falls. Therefore, as we show in Appendix D.1, $\overline{V_{s o}}$ depends on city-specific mobility costs.

From equation 11 we see that $\eta_{s}$ is the elasticity of labor supply. If workers are attached to their location, or migration costs are high, then workers will not move even if pollution is high or wages are low.

While we do not explicitly model housing supply, like in Moretti (2011), we assume a simple housing market of the form $h p_{d}=\left(L_{h d}+L_{u d}\right)^{\psi_{3} \frac{L_{h d}}{L_{u d}}} \psi_{4}$, where more people in the city raise house prices, and wealthier residents raise them further.

\footnotetext{
${ }^{22}$ As we show in Appendix D.1, we can derive: $\overline{V_{s o}}=\left(\sum_{d^{\prime}}\left(w_{s d^{\prime}} Z_{d^{\prime}}^{-\gamma_{s}} h p_{d^{\prime}}^{-\nu_{s}} a_{s d^{\prime}} \exp ^{-M_{s o d^{\prime}}}\right)^{\eta_{s}}\right)^{\frac{1}{\eta_{s}}}$.
} 


\subsection{Equilibrium and Elasticities}

Equations 3-11 characterize the model's equilibrium, which can be described as a set of wages, amenities, house prices, migration costs and labor allocations, such that workers are paid their marginal product, and workers choose cities to reside in. To be specific, the model is characterized by a set of exogenous factors: city level producitivities $\bar{A}_{d}$, total populations of the skilled and unskilled $\overline{L_{h}}$ and $\overline{L_{u}}$, migration costs $M_{\text {sod }}$, amenities $\alpha_{s d}$, skill-biased capital $\theta_{s d}$, and exogenous components of pollution $\bar{Z}_{d}$; and a set of parameters $\left(\sigma_{E}, \gamma_{s}, \eta_{s}, \phi_{1}, \phi_{2}, \psi_{1}, \psi_{2}, \psi_{3}, \psi_{4}\right)$, that together determine the quantities $A_{d}, Y_{d}, L_{h d}, L_{u d}, Z_{d}$ and prices $w_{h d}, w_{u d}, h p_{d}$.

In equilibrium, the labor market clears for each skill level $\{h, u\}$. The supply of $L_{s d}$ equals the demand for $L_{s d}$ for all $d$, and all skills $\{h, u\}$, as in equations 4,9 and 10. Total population of the skilled and unskilled in the country is the sum of the city level populations (or, $\overline{L_{h}}=\sum_{d} L_{h d}$ and $\left.\bar{L}_{u}=\sum_{d} L_{u d}\right)$. The sum of shares of migrant and non-migrants adds up to one, or

$\sum_{d} \pi_{h o d}=\sum_{d} \pi_{u o d}=1 \forall o$. Output produced in a city is consumed in the city $d$, and there are no savings. Aggregate output is simply the sum of output in each city $Y=\Sigma_{d}^{D} Y_{d}$. In Appendix D.3 we describe conditions that determine the existence and uniqueness of the equilibrium.

\section{Estimation of Model Parameters}

Section 5 already confirmed two important model results. As (exogenous) air pollution increases, either skilled labor emigrates out or fewer skilled immigrate in, raising the returns to skill such that the difference in wages is the compensating differential. Yet, our model makes clear that the observed empirical relationship between exogenous air quality $\bar{Z}_{d}$ and the supply of workers by skill is not simply the partial migration response to pollution due to $\gamma_{s}$ (which determines the compensating differential). Instead, in general equilibrium it is the result of corresponding migration changes as wages change, given $\eta_{s}$ (the labor supply elasticity based on local ties and preferences). The wage changes in turn depend on $\sigma_{E}$, the elasticity of substitution across skill-levels in production (or the relative labor demand elasticity). And worker relocation further changes pollution (given $\psi_{1}$ and $\psi_{2}$ ), and other factors (house prices, agglomeration, etc.). As such, any empirical relationship between population changes and pollution, identify a coefficient that is a joint function of many model parameters. These crucial elasticities determine the productivity consequences of pollution, which we need to estimate.

We estimate the following city-level parameters: $\left\{\theta_{s d}, \alpha_{s d}, M_{s o d}\right\}$ and aggregate elasticities: $\left\{\sigma_{E}, \eta_{s}, \gamma_{s}, \psi_{1}, \psi_{2}, \psi_{3}, \psi_{4}, \phi_{1}, \phi_{2}\right\}$ based on city-level relationships for a set of large and mediumsized cities where we have consistent data on all the variables across years. In our preferred estimates we control for city characteristics as in our earlier results, and show robustness to alternative sources of variation. We find estimates of these parameters to be similar to what has already been estimated in the literature. While we could calibrate our model from parameters estimated by other researchers, we feel more confident in using parameters estimated within our own model and data. To generate causal estimates for these parameters, we exploit additional sources of variation stemming from other policy changes. 


\subsection{Labor Demand Curve: Estimating $\sigma_{E}$}

Since $\sigma_{E}$ determines the change in relative skill-unskill wages in response to changes in relative skill-unskill workers, we derive a relative demand curve from equation 4 , where within city $d$, output (and other city-level characteristics) are differenced out, as in equation 12:

$$
\log \frac{w_{h d}}{w_{u d}}=\log \frac{\theta_{h d}}{\theta_{u d}}-\frac{1}{\sigma_{E}} \log \frac{L_{h d}}{L_{u d}}
$$

The parameter $\sigma_{E}$, can be estimated from this relative labor demand curve, as exogenous shifts in relative labor supply $\log \frac{L_{h d}}{L_{u d}}$ trace out the relative labor demand curve and identify the slope, $1 / \sigma_{E}$. As the relationship between the number of workers and wages is determined in equilibrium, we leverage exogenous variation in pollution to identify this relationship. For example, excess pollution from thermal inversions shifts labor supply, and traces out the labor demand curve. That is, to estimate equation 12, we derive variation in $\log \frac{L_{h d}}{L_{u d}}$ from equation 13, once again instrumenting for pollution levels:

$$
\log \frac{L_{h d}}{L_{u d}}=\alpha_{0}+\alpha_{1} \log P M 2.5_{d}+\varepsilon_{1 d}
$$

Table 3: Estimating Labor Demand Elasticities

\begin{tabular}{lcccccc}
\hline \hline IV: & \multicolumn{2}{c}{ Coal+Wind IV } & \multicolumn{2}{c}{ No. of inversions } & \multicolumn{2}{c}{ Inversion strength } \\
& $\operatorname{Ln} \frac{w_{h}}{w_{u}}$ & $\operatorname{Ln} \frac{L_{h}}{L_{u}}$ & $\operatorname{Ln} \frac{w_{h}}{w_{u}}$ & $\operatorname{Ln} \frac{L_{h}}{L_{u}}$ & $\operatorname{Ln} \frac{w_{h}}{w_{u}}$ & $\operatorname{Ln} \frac{L_{h}}{L_{u}}$ \\
\hline \multirow{2}{*}{$\log (\mathrm{PM} 2.5)$} & $1.000^{* *}$ & $-1.238^{* *}$ & $0.703^{* * *}$ & $-1.458^{* * *}$ & $0.850^{* * *}$ & $-1.681^{* * *}$ \\
& $(0.438)$ & $(0.617)$ & $(0.244)$ & $(0.366)$ & $(0.316)$ & $(0.554)$ \\
& & & & & & \\
Observations & 130 & 130 & 130 & 130 & 130 & 130 \\
City Controls & $\mathrm{Y}$ & $\mathrm{Y}$ & $\mathrm{Y}$ & $\mathrm{Y}$ & $\mathrm{Y}$ & $\mathrm{Y}$ \\
Weather & $\mathrm{N}$ & $\mathrm{N}$ & $\mathrm{Y}$ & $\mathrm{Y}$ & $\mathrm{Y}$ & $\mathrm{Y}$ \\
F-stat & 20.54 & 20.54 & 68.84 & 68.84 & 45.41 & 45.41 \\
$\sigma_{E}$ & \multicolumn{7}{c}{1.24} & \multicolumn{7}{c}{2.07} & \multicolumn{3}{c}{1.98} \\
\hline \hline
\end{tabular}

Note: We combine population census data and CLDS data. City level regressions in 2015 using 130 cities that have non-missing skill-based wage information from CLDS. Skilled workers denote those whose highest degree is some college or above, unskilled workers denote those whose highest degree is high school or bellow. City controls include distance to Shanghai, Tianjin and Shenzhen seaports. Robust standard errors reported in parentheses. All regressions weighted by the population in 2000. $* p<0.10, * * p<0.05, * * * p<0.01$.

We perform such an exercise in Table 3, using each of our instruments for pollution in the different columns. We estimate equation 13 in the columns where our outcome of interest is the relative stock of workers $\frac{L_{h d}}{L_{u d}}$, capturing the net migration for all types of workers (whether or not they changed hukou location).

In Table 1 of Section 5, we had used individual-level data to show how the emigration response to pollution was larger for the high-skilled than the low-skilled, while Table A4 showed that in-migration was similarly skill-biased. These differential migration rates affect the relative 
quantities of skilled and unskilled workers at the city level, as we see in Table 3. In equilibrium, cities that have (exogenously) higher level of pollution, have a lower skill ratio $\frac{L_{h d}}{L_{u d}}$.

Along with the columns of Table 3 where the outcome is $\log \frac{w_{h}}{w_{u}}$, we estimate the relationship in equation 12. We take the ratio of the IV relationship for quantities of workers, and the wages of workers. For instance, in the first two columns, we find that $\sigma_{E}=1.238 / 1.000=1.238$. This suggests that the elasticity of substitution across skill levels is 1.238 , an estimate close to the estimates found in the US (Card and Lemieux, 2001). If we were to calibrate elasticities-ofsubstitution from the literature it would produce similar model counterfactuals below.

\subsection{The Labor Supply Curve: Estimating $\left(\eta_{s}, \gamma_{s}\right)$ and $\left\{M_{\text {sod }}\right\}$}

The labor supply curve in equation 11 captures bilateral migration flows between pairs of cities as a function of real wages and pollution at possible destinations, and migration costs between origin-destination pairs. First, we parameterize migration costs $M_{\text {sod }}$ as follows:

$$
M_{\text {sod }}=\lambda_{1 s} \log \text { Dist }_{\text {od }}+\lambda_{2 s}\left(\mathbb{1}_{\text {Migrant }_{\text {od }}} \times \text { hukou }_{\text {sd }}\right)
$$

where $\log$ Dist $_{\text {od }}$ is the $\log$ of the distance between cities $o$ and $d, \mathbb{1}_{\text {Migrant }_{\text {od }}}$ is an indicator for whether $o \neq d$, which is when hukou restrictions can bind. The skill-specific hukou index hukou $_{s d}$, derived from Zhang et al. (2018), measures the ease with which either skilled or unskilled workers can move into city $d .^{23}$ The distance term captures physical and psychic costs associated with moving far away from one's origin city. The interaction of hukou index and migration status captures institutional migration costs. Substituting equation 14 in 11 generates an estimable equation for labor supply:

$$
\begin{aligned}
\log \pi_{\text {sod }}= & -\eta_{s} \log \overline{V_{s o}}+\eta_{s}\left(\log w_{s d}-\nu_{s} \log h p_{d}\right)-\eta_{s} \gamma_{s} \log Z_{d}+\mathbf{X} \beta_{x} \\
& -\eta_{s} \lambda_{1 s} \log \text { Dist }_{o d}-\eta_{s} \lambda_{2 s}\left(\mathbb{1}_{\text {Migrant }_{\text {od }}} \times \text { hukou }_{s d}\right)+\epsilon_{3 s o d}
\end{aligned}
$$

where the residual $\varepsilon_{3 s o d}=\left(\eta_{s} \log a_{s d}+\varepsilon_{2 s o d}\right)$ includes differences in destination city amenities and other idiosyncratic features determining bilateral flows. Below, we describe how we derive amenities from the residual by inverting the model. In our estimation, we include origin-cityby-skill fixed effects to control for $\eta_{s} \log \overline{V_{s o}}$. We include controls, $\mathbf{X}$, including a city's hukou ${ }_{s d}$ index. As such, the interaction with migration status allows us to isolate the part of hukou index that affects migration costs, while controlling for the index accounts for any differences in city level characteristics (correlated with the hukou index), that affect migrants and non-migrants in a similar fashion. Like before, we instrument for pollution using thermal inversions.

One of the key parameters of interest are labor supply elasticities $\eta_{s}$ for skilled and unskilled workers. To estimate these elasticities, we need two instruments that shift labor demand curves

\footnotetext{
${ }^{23}$ Specifically, the index measures the difficulty of obtaining a local hukou based on one's job, family reunion motives, local investments, and contribution to the city's workforce. A higher index indicates a more restrictive policy. The index is highest for Beijing, followed by the other major cities.
} 
and trace out the supply curves. We construct shift-share instruments inspired by China's export-driven economic development and entry into the world trading system. Pierce and Schott (2016) and Autor et al. (2013) have studied the effects of these shifts on US manufacturing employment, but here we focus on their effects on skilled and unskilled wages in China.

The first instrument, the NTR gap (Pierce and Schott, 2016), relies on the changes to the Normal Trade Relations (NTR) tariffs. Prior to joining the WTO, the US Congress needed to continually renew the preferential NTR tariffs bestowed upon China. Joining the WTO reduced the renewal uncertainty (captured by the NTR Gap) defined to be the difference between the non-NTR tariff and the NTR tariff. Unlike Pierce and Schott (2016) who focus on effects in the US, we use this instrument to study what happens to internal migration in China as real wages change across cities following trade liberalization.

We create city-level uncertainty, measured by looking at the weighted sum of industry $i$ 's export shares $E X_{d i}$ in 1997, interacted with the industry-level NTR gaps:

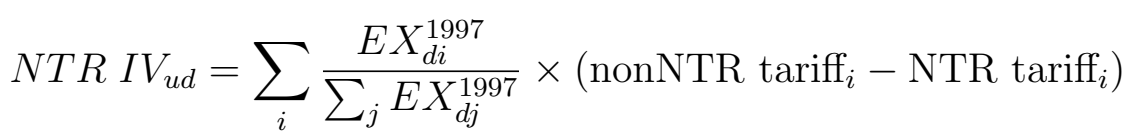

Comprehensive details about this trade shock can be found in Khanna et al. (2020), where they show that the NTR gap instrument better predicts changes to real unskilled wages, rather than skilled wages, possibly because the industries that benefited most from such tariff changes were more likely to hire unskilled labor. We use this as an instrument for unskilled real wage $\log w_{u d}-\nu_{u} \log h p_{d}$. We 'deflate' all our wages by local house prices. ${ }^{24}$

For skilled wages we derive variation from the World Import Demand (WID) for skilled industries. ${ }^{25}$ Following Autor et al. (2013), we use world-import demand shocks by industry, and weight them by initial export shares to derive city-level exposures. As we aim to create an instrument for skilled-wage, in equation 17 we use the share of skill-intensive industries: ${ }^{26}$

$$
W I D_{s d}=\sum_{i} \frac{E X_{s d i}^{1997}}{\sum_{j} E X_{s d j}^{1997}} \times\left(\frac{\text { World } \mathrm{IM}_{i, 2015}-\text { World } \mathrm{IM}_{i, 2004}}{\text { World } \mathrm{IM}_{i, 2004}}\right)
$$

\footnotetext{
${ }^{24}$ We use yearly average data on housing rents from the Xitai Real Estate Big Data depository. Further details and data sources at http://www.cityre.cn/credata.html. The data has been collected since 2005, and covered 337 cities in China, in collaboration with the China National Bureau of Statistics, and the China National Development and Reform Commission. We compare these data to the purchase price of residential properties from the China statistical yearbook, and find a correlation of 0.93 .

${ }^{25}$ We label industries as skill intensive if they are above the median in the ISIC industry data. The skill share is the share of skilled workers in the industry, based on the Annual Survey of Industrial Production (ASIP) available in 2004. We aggregate the firm data into 4-digit ISIC industries. For instance, in ISIC 1810, 5\% of the labor force is "skilled". We construct our measure using the Indonesian manufacturing census (Amiti and Freund, 2010), so as to ensure no confounding effects of using the same sample to construct our skill-intensity measure and regression estimation.

${ }^{26}$ Khanna et al. (2020) perform many robustness checks surrounding these instruments. Recent developments in the shift-share literature discuss additional tests, such as tests for pre-trends, baseline share correlations, and standard error corrections. Khanna et al. (2020) perform these tests, noting that we rely on the assumption that in our case, the 'shifters' are exogenous (as in Borusyak et al. (2018) and Adao et al. (2019)), rather than the 'shares' being exogenous (Goldsmith-Pinkham et al., 2020).
} 
Table 4: Estimating Labor Supply Elasticities

\begin{tabular}{|c|c|c|c|c|}
\hline \multirow{2}{*}{$\begin{array}{l}\text { IV-2SLS Labor Supply } \\
\log (P M 2.5)_{d}\end{array}$} & \multicolumn{2}{|c|}{$\begin{array}{l}\text { Low Skill Workers } \\
\log \pi_{\text {uod }}\end{array}$} & \multicolumn{2}{|c|}{$\begin{array}{l}\text { High Skill Workers } \\
\log \pi_{\text {hod }}\end{array}$} \\
\hline & $\begin{array}{c}-0.0427^{* * *} \\
(0.0090)\end{array}$ & $\begin{array}{c}-0.0488 * * * \\
(0.0114)\end{array}$ & $\begin{array}{c}-0.506^{* * *} \\
(0.0958)\end{array}$ & $\begin{array}{c}-0.513^{* * *} \\
(0.0829)\end{array}$ \\
\hline $\log (\text { Real Wage })_{d}$ & $\begin{array}{c}1.012^{* * *} \\
(0.269)\end{array}$ & $\begin{array}{c}1.126^{* * *} \\
(0.318)\end{array}$ & $\begin{array}{l}1.301^{* * *} \\
(0.251)\end{array}$ & $\begin{array}{c}1.024^{* * *} \\
(0.170)\end{array}$ \\
\hline $\log (\text { Distance })_{\text {od }}$ & $\begin{array}{c}-0.0754^{* * *} \\
(0.0112)\end{array}$ & $\begin{array}{c}-0.0783^{* * *} \\
(0.0129)\end{array}$ & $\begin{array}{c}-0.0308^{* * *} \\
(0.0052)\end{array}$ & $\begin{array}{c}-0.0404^{* * *} \\
(0.0046)\end{array}$ \\
\hline Hukou Index sd $\times$ Migrant $_{\text {od }}$ & $\begin{array}{l}-0.923^{*} \\
(0.487)\end{array}$ & $\begin{array}{l}-0.852^{*} \\
(0.501)\end{array}$ & $\begin{array}{c}-3.489^{* * *} \\
(0.876)\end{array}$ & $\begin{array}{c}-3.061^{* * *} \\
(0.758)\end{array}$ \\
\hline Observations & 13,570 & 13,570 & 13,570 & 13,570 \\
\hline Pollution IV & No. thermal & Strength thermal & No. thermal & Strength thermal \\
\hline Wage IV & NTR IV & NTR IV & WID IV & WID IV \\
\hline Controls & Yes & Yes & Yes & Yes \\
\hline Hukou City FE & Yes & Yes & Yes & Yes \\
\hline First stage F-stat & 19.45 & 15.16 & 30.97 & 70.07 \\
\hline
\end{tabular}

Note: Origin-destination pair level regressions across 118 origin cities and 115 destination cities for which we have data from all sources including population Census, CLDS, hukou index data and trade data. The NTR IV is the weighted average of the NTR gap, where the weights are the baseline industry level export shares (Pierce and Schott, 2016). The NTR gap is measured as the gap in Normal Trade Relation (NTR) tariffs and the non-NTR tariffs. The WID IV is the weighted average of the world import demand, where the weights are the baseline skill-intensive share of industries Autor et al. (2013). The measure of Hukou Index sd varies across cities and skill level (Zhang et al., 2018). We also control for this (non-interacted) measure of the hukou index. We model distance as inverse hyperbolic sine, to be able to include zero values. All regressions also control for temperature, humidity, sunshine duration, and wind speed, as before when using thermal inversions as an IV. High skill workers are those whose highest degree is some college or above, and low skill workers are those whose highest degree is high school or below. Standard errors clustered at the city level are reported in parentheses. The first stage relationships are described in Table C5. $* p<0.10, * * p<0.05, * * * p<0.01$.

Table 4 allows us to estimate $\eta_{s}$ and $\gamma_{s}$ for each skill group. Across the columns we vary the skill groups and the instruments used. The skill-biased trade shocks will raise the demand for some occupations more than others. This changes the wages by city and skill group in response to the trade shocks, and helps us identify $\eta_{s}$, the labor supply response to changes in wages. Our estimates in columns 1 and 3 suggest that $\eta_{u}=1.012$ and $\eta_{h}=1.301$. These are similar to estimates of labor supply elasticities estimated by Tombe and Zhu (2019).

Equation 15 shows that the coefficients on $\log (P M 2.5)_{d}$ equal $\eta_{s} \gamma_{s}$. The $\gamma_{s}$ parameters capture the marginal utility of clean air, and vary by skill level. Given our estimates of $\eta_{s}$, we can infer $\gamma_{h}=0.38$, and $\gamma_{u}=0.042 . \gamma_{h}>\gamma_{u}$ implies that the skilled are more sensitive to air quality than the unskilled. Comparing estimated labor supply elasticities with respect to wages and to pollution levels suggests that both types of workers are far more responsive to changes in wages than they are to pollution levels.

Workers also respond to migration costs. Table 4 shows that migration is less likely to occur over longer distances, and if there are more hukou restrictions. Skilled workers are less sensitive to distance. They are more sensitive to hukou restrictions, even though they face fewer restrictions. The responsiveness perhaps reflects stronger preferences for access to amenities 
(like housing purchases and children's schooling) only obtainable via accessing local hukou.

Note that as workers move in response to higher wages, this affects where production takes place, and as a result, where pollution is located (based on $\psi_{1}$ and $\psi_{2}$ ). As such, our model and estimation allow for the fact that trade shocks will also affect the amount of pollution via production and migration responses.

\subsection{Measuring Amenities and Productivities $\left\{\theta_{s d}, \alpha_{s d}, \bar{A}_{d}\right\}$}

We measure $\theta_{s d}$ from data on labor shares in the wage bill and the properties of a CES function. $\theta_{s d}$ varies at the city level by the amount of skill-biased capital in each city. We use the following relationship, and information on wages and number of workers to measure $\theta_{s d}$ :

$$
\frac{w_{h d} L_{h d}}{w_{h d} L_{h d}+w_{u d} L_{u d}}=\frac{\theta_{h d} L_{h d}^{\frac{\sigma_{E}-1}{\sigma_{E}}}}{\theta_{h d} L_{h d}^{\frac{\sigma_{E}-1}{\sigma_{E}}}+\left(1-\theta_{h d}\right) L_{u d}^{\frac{\sigma_{E}-1}{\sigma_{E}}}}
$$

We plot the city-level distribution of $\theta_{h d}$ in Figure C2. Beijing, Shanghai and other urban centers have high amounts of high-skill capital than the less urbanized, less developed areas.

Table 5: Pollution, Population and TFP

\begin{tabular}{|c|c|c|c|c|}
\hline & \multicolumn{2}{|c|}{ Agglomeration Forces } & \multicolumn{2}{|c|}{ Congestion Forces } \\
\hline & $\log (\mathrm{TFP})$ & $\log (\mathrm{TFP})$ & $\log (\mathrm{PM} 2.5)$ & Log(House Prices) \\
\hline $\log (\mathrm{PM} 2.5)_{d}$ & $\begin{array}{c}-0.0816 \\
(0.256)\end{array}$ & $\begin{array}{c}-0.0595 \\
(0.285)\end{array}$ & & \\
\hline $\log \left(\mathrm{L}_{h d}\right)$ & $\begin{array}{l}0.0970^{*} \\
(0.0528)\end{array}$ & $\begin{array}{l}0.0964^{*} \\
(0.0519)\end{array}$ & & \\
\hline $\log (\text { Population })_{d}$ & & & $\begin{array}{c}0.266^{*} \\
(0.150)\end{array}$ & $\begin{array}{c}0.259^{* *} \\
(0.121)\end{array}$ \\
\hline $\log \left(\mathrm{L}_{h d} / \mathrm{L}_{u d}\right)$ & & & $\begin{array}{r}-0.00781 \\
(0.0786)\end{array}$ & $\begin{array}{c}0.423^{* * *} \\
(0.0583)\end{array}$ \\
\hline Observations & 121 & 121 & 121 & 121 \\
\hline Pollution IV & No. Thermal & Thermal Strength & & \\
\hline First stage F-stat & 25.61 & 15.67 & 12.66 & 12.66 \\
\hline
\end{tabular}

Notes: We combine population census data, CLDS data, and data on the college expansion, consistently available for 121 cities. The first column estimates the relationship between PM2.5, number of skilled workers and TFP. We use thermal inversions as an instrument for PM2.5, and leverage the higher education expansion instrument to identify the effect of the number of skilled workers. For our congestion forces we use instruments for population and the skill ratio that we describe in the text. We control for region fixed effects and distance to seaports. When using thermal inversions as an instrument, we control for weather amenities (temperature, humidity, sunshine duration and wind speed). The first-stage relationships are in Table C5. $* p<0.10, * * p<0.05, * * * p<0.01$.

We follow the literature (Ahlfeldt et al., 2015; Bryan and Morten, 2019) and derive nonpollution amenities as a residual from the labor supply curve, equation 15. Intuitively, bilateral migration flows between cities must be driven by wages, house prices, pollution, migration costs, and other residential amenities. As we measure and account for the effect of all other components, the remaining portion of the flows are due to amenities. We take the residual 
for each skill-specific regression estimated from equation 15, and derive amenities from the destination fixed effects (i.e., $\varepsilon_{3 s o d}=\alpha_{s d}+\varepsilon_{2 s o d}$, where $\eta_{s} \widehat{\log a_{s d}}=\widehat{\alpha_{s d}}$ ).

To quantify changes to output, we create a measure of TFP $\bar{A}_{d}$, which captures features of the local area (e.g, land quality). We follow the literature (Ahlfeldt et al., 2015) and measure TFP as the city-level aggregate residual from output. After accounting for the optimal (unbiased) capital flows, output is simply: $Y_{d}=A_{d}^{\frac{1}{\varrho}}\left(\frac{1-\varrho}{R^{*}}\right)^{\frac{1-\varrho}{\varrho}} L_{d}$. Using our estimates for $\sigma_{E}$ and $\theta_{s d}$, we are able to create a measure of $L_{d}$. We then invert the model to derive $A_{d}^{\frac{1}{\rho}} \cdot{ }^{27}$

\subsection{Estimating Agglomeration and Congestion Forces ( $\phi$ and $\psi$ )}

We use equation 19 to study how our measure of TFP correlates with pollution as instrumented with the thermal inversions instrument for pollution.

$$
\widehat{\frac{1}{\varrho}} \widehat{\log A_{d}}=\log \bar{A}_{d}+\phi_{1} \log Z_{d}+\phi_{2} \log L_{h d}+\varepsilon_{4 d},
$$

where $\phi_{1}$ is the elasticity of pollution with aggregate TFP. ${ }^{28}$ Notice, $A_{d}$ may capture other drivers of city-level TFP, like land, housing supply, innovation. Equation 19 also allows the number of skilled workers to directly affect the amount of TFP in a city. If there are Arrow (1962) style innovation spillovers, it would be captured by the agglomeration elasticity $\phi_{2} \cdot{ }^{29}$

In Table 5 we estimate $\phi_{1}$ using equation 19, and leveraging our instrumental variables strategy for PM2.5 emissions. While not precisely estimated, we conclude that $\phi_{1}=-0.0816$. Chang et al. (2019) document an elasticity of -0.023 in the context of call-center workers in China, while Kahn and Li (2019) estimate an elasticity of -0.18 for public sector workers in China. Our estimate lies in between the two.

We use a sudden expansion of access to universities in China to estimate the effects of skilled workers on TFP, as a way to capture the parameters associated with agglomeration or innovation spillovers. The Chinese government instituted a policy to expand college enrollment in 1999, primarily by lowering the bar for admission. ${ }^{30}$ Che and Zhang (2018) use this policy as an instrument for firm productivity, and discuss identification concerns at length. They establish that the university expansion policy was not targeted at any specific industrial sector. We use this same instrument to predict variation in the number of skilled workers across cities.

\footnotetext{
${ }^{27} \log \varrho \equiv\left[\left(\frac{1-\varrho}{\varrho}\right) \log \left(\frac{1-\varrho}{R^{*}}\right)\right]$ is common across all cities and workers. $\varrho$ is the labor share of income.

${ }^{28} \mathrm{TFP}$ may also be positively associated with pollution. This may generally be true if more production leads to more pollution, but we are using an IV for pollution here.

${ }^{29}$ Agglomeration in this model is represented by the production of non-excludable ideas. Innovators are not directly compensated for ideas in wages. Instead overall output increases, benefiting all in the local economy.

${ }^{30}$ In January 1999 the Ministry of Education (MOE) announced an admission plan of 1.3 million for three and four-year college programs, a $20 \%$ increase over 1998. The following June it revised the admission plan to 1.56 million, an unprecedented increase of $44 \%$ over the previous year. College admissions grew annually by more than $40 \%$ in both 1999 and 2000, and by about $20 \%$ over the next five years. The gross college enrollment rate among $18-22$ year-olds increased from $9.8 \%$ in 1998 to $24.2 \%$ in 2009 . The year 2003 saw the first flow of four-year graduates into the job market as a result of the expansion. The number of students graduating from regular higher education institutions was 2.12 million, a $46.2 \%$ increase from the previous year.
} 
Figure C1 describes this event graphically. Importantly, it shows no differential pre-trends in college students and professors (who subsequently make up the skilled workforce) in cities that subsequently benefited from college expansion.

We create measures of the number of college graduates by city and year, and use the change in the number of graduates from 2001 to 2005 (cohorts just before and after the university expansion policy) as our instrument. ${ }^{31}$ We find $\phi_{2}=0.097$ when we estimate equation 19 , which suggesst a meaningful agglomeration effect in line with other estimates in the literature (Gaubert, 2018; Moretti, 2004; Peri et al., 2015).

Our model allows for the spatial distribution of population to affect pollution (equation 5). We need estimates for the effects of changes in the number of workers and skill share in each city on pollution and house prices. Estimating $\psi_{1}$ requires variation in the skill-ratio that is not driven by air quality. We leverage the college expansion policy (dividing it by the baseline unskilled population in 2000 to get a ratio) to estimate the effect of changes in skill ratios.

Simultaneously, we estimate how changes in total population affect air quality, captured by parameter $\psi_{2}$. Our trick is to leverage any exogenous push factors at the cities of origin that each destination is linked to through migrant-networks at baseline. We instrument for population in each destination $d$ using the growth in out-migration between 2005 and 2015 from all provinces in China, weighted by the share of migrants from each province that came to $d$ in $2000:^{32}$

$$
\text { Population } I V_{d, 2015}=\sum_{p}\left(\frac{\text { Migrants }_{d p, 2000}}{\sum_{d} \text { Migrant }_{d p, 2000}} \times\left(\sum_{d^{\prime} \neq d} \text { Migrants }_{d^{\prime} p, 2005-2015}\right)\right)
$$

Note that this is different from the instruments introduced by Card (2001) and described by Jaeger et al. (2018). As we have rich data on outflows of migrants from provinces, we can leverage 'push factors' from sending regions, and completely omit information on inflows into destinations. The advantage is that identification relies on forces driving the outflows from provinces to all other cities, and not associated with city $d$ specifically, similar to the shiftshare framework described by Borusyak et al. (2018). We combine this idea with the strength of the Card (2001) framework, in which sources of migration at baseline determine the migrant networks that attract more migrants into city $d$ after 2005, whenever there are larger outflows from the set of origin provinces that $d$ was connected to. ${ }^{33}$

Table 5 describes the effect of population and skill ratio on pollution. The first stage of the 2SLS appears to be strong. Our two-staged least squares estimates tell us that $\psi_{1}$ is indistinguishable from zero, and $\psi_{2}=0.266$. Larger population increases the amount of

\footnotetext{
${ }^{31}$ The instrument is number of college graduates in city $d$ in 2005 minus the number of college graduates in city $d$ in 2001. Figure C1 describes the dynamics of the expansion policy, and pre-trends.

${ }^{32}$ When calculating the amount of out-migration between 2005 and 2015, we exclude flows to $d$, so as to not capture labor demand changes at the destination.

${ }^{33}$ Indeed, before 2000 internal migration was highly regulated (Kinnan et al., 2018). After 2000, migration costs have fallen substantially (Tombe and Zhu, 2019), allowing us to estimate the impacts of subsequent growth.
} 
Table 6: Summary of Estimated Model Parameters

\begin{tabular}{lrll}
\hline Parameter & Value & Definition & Identifying Variation \\
\hline$\sigma_{E}$ & 1.24 & $\begin{array}{l}\text { Skill-elasticity of substitution } \\
\text { Relative labor demand elasticity }\end{array}$ & $\begin{array}{l}\text { Pollution-driven geographic sorting } \\
\text { Changes in skill ratio affect wages }\end{array}$ \\
$\eta_{h}$ & 1.301 & High-skill labor supply elasticity & World Import Demand trade shocks \\
$\eta_{u}$ & 1.012 & Low-skill labor supply elasticity & NTR Gap trade shocks post WTO \\
$\gamma_{h}$ & 0.506 & High-skill migration response to pollution & Pollution-driven response by skill \\
$\gamma_{u}$ & 0.0427 & Low-skill migration response to pollution & Pollution-driven response by skill \\
$\theta_{h d}$ & $0.10,0.73]$ & Skill-specific productivity & Skill-labor share in wage bill \\
\hline$\psi_{1}$ & -0.008 & Pollution response to changing skill ratio & University expansion \\
$\psi_{2}$ & 0.266 & Pollution response to population & Out-migration from origin provinces \\
$\psi_{3}$ & 0.423 & House price response to skill ratio & University expansion \\
$\psi_{4}$ & 0.259 & House price response to population & Out-migration from origin provinces \\
$\phi_{1}$ & -0.0816 & TFP response to pollution & Pollution IV affect TFP residual \\
$\phi_{2}$ & 0.0970 & TFP response to skilled workers & University expansion \\
$\lambda_{h}$ & 3.489 & High skill response to hukou index & Skill-biased hukou index \\
$\lambda_{u}$ & 0.923 & Low skill response to hukou index & Skill-biased hukou index \\
\hline \hline
\end{tabular}

Notes: We summarize the parameter estimation using different instruments in this table. The values are from Tables 3-5 and Figure C2. The top half of our table lists the primary parameters for our main model. The lower half of the table includes the additional parameters that complete the estimation process.

pollution in a city, but the skill composition of workers has no detectable effect.

Finally, we consider how house prices may affect our predictions. To do so, we estimate the elasticity of house prices with respect to population $\left(\psi_{3}=0.423\right)$, and with respect to the skill ratio $\left(\psi_{4}=0.259\right)$, leveraging the same instruments. A larger population raises house prices, and these prices rise substantially more when there is an influx of skilled workers in the city.

\subsection{Model Solution and Validation Exercises}

Table 6 summarizes all parameter values and sources of variation. Output in city $d$ depends on the set of parameters: $\left\{\theta_{s d}, \sigma_{E}, \eta, \phi_{1}, \phi_{2}, \psi_{1}, \psi_{2}, \psi_{3}, \psi_{4}\right\}$, a set of 'endogenous' quantities: $\left\{Y_{d}, A_{d}, L_{h d}, L_{u d}, Z_{d}\right\}$, and 'exogenous' quantities: $\left\{\bar{A}_{d}, \bar{Z}_{d}, M_{s o d}, \overline{L_{u}}, \overline{L_{h}}\right\}$. Prices, $\left\{w_{h d}, w_{u d}, h p_{d}\right\}$ are determined in equilibrium, with the output being the numeraire. Changes in exogenous pollution $\bar{Z}_{d}$ will affect the location of workers and TFP, thereby changing output $Y_{d}$ in this city, and in other cities. Given our estimated set of parameters, and exogenous quantities, we create model-predicted measures of our endogenous quantities, like GDP and wages.

We solve the model starting with the list of parameters and exogenous quantities, and a set of initial conditions for the endogenous variables. After estimating the parameters, we no longer use information from the endogenous variables to solve the model. The primary market clearing condition is the labor market equilibrium, since for tractability, we do not model the floor space market, or demand for output. We pick different starting points, beginning in the vicinity of the observed equilibrium, but vary it by as much as changing the starting value by $20 \%$ for each endogenous variable. The model converges to the same unique equilibrium. ${ }^{34}$ We

\footnotetext{
${ }^{34}$ This does not necessarily imply the equilibrium is globally unique. The existence of multiple equilibria
} 
solve the model iteratively, ensuring that we clear the labor market. That is, if there is an excess supply of labor in a city, wages are reduced, and along with the population constraints (the total number of skilled and unskilled in the country) our model converges to an equilibrium which determines the distribution of skilled and unskilled workers across cities.

We conduct tests of model fit in Figure C3, and show that our model's predictions match the main endogenous quantities in the data. We use the parameters we estimated to calculate predicted values for all cities. We test model-fit by first plotting the predicted $\log (G D P)$ and $\log \left(L_{h} / L_{u}\right)$. In the lower panels we plot actual and predicted skill-premia $\log \left(w_{h} / w_{u}\right)$. Notice, these are not necessarily an out-of-sample test as we use these data when estimating different parameters of the model, but not when solving for model equilibrium. Last, we plot city-level GDP per capita $Y /\left(L_{h}+L_{u}\right)$ against actual GDP per capita. Across all these measures, our model replicates the major spatial patterns in the data.

\section{Counterfactuals: The Gains from Relocating Pollution}

There are three mechanisms through which pollution can result in productivity losses. First, and the one this paper seeks to highlight, skilled workers leave cities where they would be more productive, to avoid pollution. Further, since migration costs are larger for the unskilled and they are less responsive to pollution, the unskilled do not leave with the skilled. As we estimate the skilled and unskilled to be complements in production, this creates a mismatch in the location choices of the two types of workers, further reducing aggregate productivity. Second, pollution reduces the agglomeration of skilled workers in the most productive cities, lowering aggregate output. Third, pollution directly affects workers' health and lowers productivity.

In this section, we use our estimated model to conduct counterfactual exercises to quantify how large an effect pollution control policies would have on productivity via each of these three mechanisms. To isolate the health channel, we prohibit workers from changing location when pollution levels change. To shut down agglomeration, we set $\phi_{2}=0$ in the TFP relationship.

There are two types of pollution control policies we consider in our counterfactuals. First, we change only the steady-state level of pollution $Z_{d}$ in a city. This is similar to policies where cities are assigned explicit pollution targets that they must meet. In the second type of policy, we relocate the exogenous component of pollution only, $\bar{Z}_{d}$. This policy is similar to relocating coal-fired plants from upwind to downwind regions. Note that relocating plants would induce new residents to move into the city, change production patterns, and a revised pollution level will emerge in a new equilibrium that will not necessarily equal the modeled change in $\bar{Z}_{d}$.

often depends on the relative strength of agglomeration and congestion forces (Allen et al., 2020). More skilled workers raise TFP (via $\phi_{2}$ ), yet may lead to more congestion, via higher house prices (via $\psi_{3}$ and $\psi_{4}$ ) and more pollution (via $\psi_{1}$ and $\psi_{2}$ ), which in turn may lower TFP (via $\phi_{1}$ ). Given the meaningful congestion forces we may expect a unique equilibrium. Yet, like other work (Ahlfeldt et al., 2015) we envision that if there were to be multiple equilibria for a different set of parameter values, we would select the counterfactual equilibrium closest to the observed real-world outcome. 


\subsection{Changing Pollution in One City: Beijing}

Table 7 describes the effects of changes to pollution and migration policy in a highly productive and polluted city, Beijing. We first reduce the steady state PM2.5 concentration by $50 \%$, a policy akin to setting a pollution cap for Beijing. This raises GDP per worker in Beijing by $14.4 \%$. The health channel raises productivity by $5.8 \%$. The pure relocation channel (without accounting for agglomeration) raises GDP per worker by $4.5 \%$. If we allow for the fact that more skilled workers imply more agglomeration spillovers, GDP per worker due to relocation would rise by $8.1 \%$. Productivity gains through the indirect spatial sorting channel are actually larger than the direct health benefits of air quality improvement. The overall improvements to GDP are not merely the sum of the channels, as they meaningfully interact with each other. For instance, the newly relocated immigrants also benefit from better health.

Second, we examine the effects of reducing the exogenous component of PM2.5, allowing steady state values of pollution to adjust when the population and skill composition of the city changes. This is a policy similar to relocating a powerplant up-wind of Beijing to elsewhere. In this case, we obtain somewhat similar, albeit slightly smaller, outcomes for GDP per worker and wages. The mildly muted effects reflect the fact that when exogenous pollution is reduced, an influx of workers may increase pollution and mitigate some positive effects. Again, relocation effects are larger in magnitude than the direct health benefits.

In the third and fourth rows of Table 7, we examine the effects of relaxing hukou restrictions in Beijing by $50 \%$, allowing workers to move in, but holding pollution fixed. The effects of relaxing mobility restrictions depend on whether we change hukou policy for skilled or unskilled workers. When we relax the skilled hukou, GDP per worker rises by $8.2 \%$, more than half of which is driven by the simple relocation channel, and the rest by the agglomeration forces. Lowering unskilled hukou restrictions lowers GDP per capita, through a compositional change in the population - there are now more low-wage workers in Beijing.

The last two rows combine the changes in steady-state pollution and hukou restrictions. Relaxing skilled hukou restrictions in Beijing increases city GDP per capita by $22.96 \%$. GDP increases by $9.2 \%$ due to reallocation of workers, and $16.2 \%$ when including the agglomeration of skilled work. These are much larger than the direct health benefits of clean air, $5.8 \% .{ }^{35}$

Relocation due to pollution or hukou policy changes affects productivity and wages in the model through multiple channels. First, immigration changes the skill composition of the city population. Average incomes rise if skilled workers move in. Second, the effect of skilled workers on city productivity is larger when the city (like Beijing) has a lot of skill-biased capital. Third, inflow of skilled workers lowers the skilled wage due to a labor supply effect. However, that raises unskilled wages because the unskilled are estimated to be complements in the production function. Finally, agglomeration forces will raise average incomes for all skill groups. When hukou relaxation is combined with pollution reduction, the consequent skilled immigration

\footnotetext{
${ }^{35}$ Appendix Table E1 examines changes to GDP per worker, focusing solely on the main relocation effects and shutting down agglomeration or congestion effects (endogeonous changes to pollution, house prices and TFP).
} 


\begin{tabular}{lcccc}
\hline \hline & & \multicolumn{2}{c}{ Change in GDP per Worker (\%) } \\
& Overall Change & Health Channel & Relocation & Relocation+Agglom \\
\cline { 2 - 5 } Reduce steady state PM2.5 & 14.370 & 5.819 & 4.480 & 8.080 \\
Reduce exogenous part of PM2.5 & 12.773 & 5.344 & 3.777 & 7.052 \\
Relax skilled hukou & 8.174 & 0.000 & 5.109 & 8.174 \\
Relax unskilled hukou & -3.775 & 0.000 & -4.686 & -3.775 \\
Reduce PM2.5 \& relax skilled hukou & 22.959 & 5.819 & 9.147 & 16.197 \\
Reduce PM2.5 \& relax unskilled hukou & 10.533 & 5.819 & 0.036 & 4.454 \\
\hline
\end{tabular}

Notes: In this counterfactual exercise we reduce the steady state amount of pollution in Beijing by $50 \%$ (row 1). We then reduce only the exogenous component of pollution by $50 \%$ (row 2). Next, we lower hukou restrictions for each skill level (rows 3 and 4) by 50\%, keeping pollution fixed. Rows 5 and 6 lower the hukou regulations by $50 \%$ while reducing steady state pollution. Column 1 shows the gain to overall GDP per worker. Column 2 shows the component purely explained by the health-productivity channel. Column 3 shows the pure relocation channel, and Column 4 also incorporates agglomeration as a consequence of relocation.

raises average incomes substantially.

We move beyond overall GDP per capita to examine distributional consequences on the wages of each skill group in Table 8 . When we reduce the steady state amount of pollution in row 1, skilled wages rise slightly. The improved productivity of skilled workers from reduced pollution is counteracted by the reduction in wages as a consequence of an influx of skilled workers. Unskilled wages, on the other hand, rise sharply by $18.3 \%$. Most of this is driven by the relocation channel: When skilled workers enter Beijing, complementary unskilled workers become more productive. As a consequence, average wages in the city rise by $14.4 \%$ (i.e., the increase we saw in GDP per worker in Table 7). Reducing the exogenous part of pollution (row 2) produces similar distributional effects.

Table 8: Distributional Consequences of Reducing Pollution in One City

\begin{tabular}{lcccccc}
\hline \hline & \multicolumn{3}{c}{ Skilled Wage } & \multicolumn{3}{c}{ Unskilled Wage } \\
& Overall & Health & Relocate+Agglom & Overall & Health & Relocate+Agglom \\
\cline { 2 - 7 } Reduce steady state PM2.5 & 2.702 & 5.819 & -2.945 & 18.260 & 5.819 & 11.757 \\
Reduce exogenous part of PM2.5 & 2.589 & 5.344 & -2.616 & 16.699 & 5.344 & 10.779 \\
Relax skilled hukou & -4.332 & 0.000 & -4.332 & 12.462 & 0.000 & 12.462 \\
Relax unskilled hukou & 7.661 & 0.000 & 7.661 & -6.371 & 0.000 & -6.371 \\
Reduce PM2.5 \& relax skilled hukou & -1.580 & 5.819 & -6.992 & 33.108 & 5.819 & 25.789 \\
Reduce PM2.5 \& relax unskilled hukou & 10.438 & 5.819 & 4.365 & 10.559 & 5.819 & 4.479 \\
\hline
\end{tabular}

Notes: In this counterfactual we reduce the steady state amount of pollution in Beijing by $50 \%$ (row 1). We then reduce only the exogenous component of pollution by $50 \%$ (row 2). Next, we lower the hukou restrictions for each skill level (rows 3 and 4) by 50\%, keeping pollution fixed. Finally (rows 5 and 6 ) we relax hukou regulations by $50 \%$ while reducing steady state pollution. The first 3 columns show the effect on the wage of college educated workers, whereas the last 3 columns show the effects on the wage of the non college educated.

When we relax the hukou restrictions in rows 3 and 4 in each skill group, we see that allowing in more workers of a particular skill group lower the wages of that group, while raising the productivity of the other (complementary) worker type. For instance, relaxing skilled hukou lowers skilled wages by $4.3 \%$, but as skilled workers enter the city, unskilled workers become 
more productive and their wages rise by $12.5 \%$. When we combine relaxing hukou regulations with changes to PM2.5, there are more positive effects on wages, especially for the unskilled.

\subsection{Relocating Pollution Away from Skill-biased Capital}

Table 9 considers a different type of counterfactual where we keep the overall levels of pollution in the country to be the same, but simply relocate pollution from regions that have more skill-biased capital (high $\theta_{h d}$ ) to regions with less skill-biased capital. This could, for instance, entail relocating coal-fired plants away from technology hubs, financial centers, and nodes of professional service activities. Spatial reorientation of coal processing is perhaps more feasible than reducing production and pollution in the aggregate. In the first row, we relocate steady state pollution by setting pollution caps based on the amount of skill-biased capital in the city. Overall GDP in the country increases by $6.7 \%$, and much of this increase is driven by the relocation of workers. The contribution of the health channel is a $2.6 \%$ increase in GDP, while the relocation channel alone raises GDP by $2.2 \%$. Agglomeration plays a minor role.

Table 9: The Productivity Effect of Relocating Pollution Across Cities

\begin{tabular}{lcccc}
\hline \hline & \multicolumn{4}{c}{ Change in GDP per Worker (\%) } \\
& Overall changes & Health & Relocation & Relocate+Agglom \\
\cline { 2 - 5 } Relocate steady state PM2.5 & 6.702 & 2.604 & 2.205 & 2.277 \\
Relocate exogenous part of PM2.5 & 3.670 & 1.484 & 1.563 & 1.615 \\
Relax hukou & 2.585 & 0.000 & 2.340 & 2.585 \\
Relax overall mobility constraints & 6.968 & 0.000 & 6.421 & 6.968 \\
Relocate PM2.5 \& relax hukou & 8.329 & 2.604 & 3.615 & 3.844 \\
Relocate PM2.5 \& lower migration costs & 13.832 & 2.604 & 8.156 & 8.814 \\
\hline
\end{tabular}

Notes: In this counterfactual exercise we relocate PM2.5 in all cities based on the amount of skill-biased capital in the city (row 1 ). In row 2 , we relocate only the exogenous component of pollution. In row 3 , we relax the hukou restriction in the 24 top tier cities by $50 \%$, keeping pollution fixed. In row 4 we relax overall migration costs to the 24 high tier cities by $50 \%$, keeping pollution fixed. Column 1 shows the overall gain to GDP. Column 2 shows the increase in GDP as a consequence of the health effects only. Column 3 shows the gain due to the re-allocation of labor channel only. Column 4 shows the gain to GDP accounting for changes in TFP due to changes in re-allocation and the agglomeration of skilled workers.

When we relocate the exogenous part of pollution (say, shift an upwind power plant away from a productive city, to a less productive one), the increase in GDP is smaller. As people relocate to the more productive cities, pollution levels again rise through the feedback loop in the model (where pollution is itself a function of population), and dampens the benefits. The contribution of the relocation channel is slightly larger than the health channel. ${ }^{36}$

As a benchmark, in row 3, we relax hukou restrictions in the top-tier cities by $50 \%$. This raises GDP by less than the pollution changes, but, by construction, is solely driven by worker relocation. When we lower overall migration costs in these top-tier cities (row 4) by $50 \%$, the increase in GDP is similar to relocating steady state pollution (about 6.97\%). Lowering overall

\footnotetext{
${ }^{36}$ The health channel playing a positive role suggests that sources of pollution are concentrated in more populous cities. Moving pollution away from large cities can improve population-weighted average health.
} 
migration costs can be thought of as a policy mix of relaxing hukou restrictions and building more transportation infrastructure to connect cities. Combining reductions to mobility costs to top-tier cities with relocating pollution produces much larger effects on GDP per worker.

The major lessons from this exercise are: (a) A spatial reallocation of pollution away from cities that have the greatest potential for skilled productivity (those with most skill-biased capital) can raise national income as skilled workers relocate to where they are most productive, (b) Pollution caps produce larger productivity effects than relocating sources of pollution, as worker re-sorting undermines benefits, and (c) Combining relaxations to mobility restrictions with pollution reductions can produce large income gains.

Table 10: Distributional Effects of Relocating Pollution Across Cities

\begin{tabular}{|c|c|c|c|c|c|c|}
\hline & \multicolumn{3}{|c|}{ Skilled Wage } & \multicolumn{3}{|c|}{ Unskilled Wage } \\
\hline & Overall & Health & Relocate+Agglom & Overall & Health & Relocate+Agglom \\
\hline Relocate steady state PM2.5 & 17.723 & 4.493 & 10.484 & 1.070 & 1.638 & -1.917 \\
\hline Relocate exogenous part of PM2.5 & 8.924 & 2.402 & 5.688 & 0.983 & 1.014 & -0.469 \\
\hline Relax hukou & 3.861 & 0.000 & 3.861 & 1.933 & 0.000 & 1.933 \\
\hline Relax overall mobility constraints & 10.066 & 0.000 & 10.066 & 5.384 & 0.000 & 5.384 \\
\hline Relocate PM2.5 \& relax hukou & 19.923 & 4.493 & 12.649 & 2.403 & 1.638 & -0.656 \\
\hline Relocate PM2.5 \& lower mig costs & 27.784 & 4.493 & 19.864 & 6.701 & 1.638 & 3.166 \\
\hline
\end{tabular}

Notes: In this counterfactual exercise we relocate PM2.5 in all cities based on the amount of skill-biased capital in the city (row 1 ). In row 2 , we relocate only the exogenous component of pollution. In addition to such relocations of pollution, we also relax the hukou restriction in the 24 top tier cities by $50 \%$ (row 3 ). In row 4 we relax overall migration costs to the 24 high tier cities by $50 \%$. Rows 3 and 4 keep pollution fixed. Columns 1-3 show the effects on skilled workers, while columns 4-6 show the effects on unskilled workers.

Table 10 shows wage effects for skilled and unskilled workers. Relocating pollution away from cities with more skill-biased capital raises skilled wages, but has little effect on the wage of the unskilled. This is a consequence of the baseline distribution of skill groups across cities that see pollution changes. As skilled workers leave cities where pollution increases, skilled wages rise in those cities and wages of unskilled (complementary) workers fall. As skilled workers relocate to cities with more skill-biased capital, their overall productivity increases, because there is now a better matching of workers to capital. The skilled workers who were already resident in such cities may see a dampening of their wages, but they could also benefit from agglomeration economies. On net, we find that skilled wages rise by $17.7 \%$, and the relocation channel raises skilled wages by $10.5 \%$. The health channel also raises skilled wages, because skilled workers already tended to locate in high skill-biased capital cities which now saw a reduction in pollution. Wages for unskilled workers improve slightly by $1 \%$.

Relaxing hukou restrictions and lower migration costs (rows 3 and 4) raise wages for both the skilled and unskilled, as workers can match better with where their marginal products are higher. That is, workers locate to where there is more capital, and where there are more complementary workers. The combination of lowering migration costs and relocating pollution (row 6) can raise skilled wages by as much as $27.8 \%$ and unskilled wages by $6.7 \%$, almost 
entirely due to changes in internal migration patterns.

Table 11: Welfare Effects of Relocating Pollution Across Cities

\begin{tabular}{lccc}
\hline \hline & Skilled Welfare & Unskilled Welfare & Average Welfare \\
\cline { 2 - 4 } Relocate steady state PM2.5 & 29.660 & 2.258 & 4.628 \\
Relocate exogenous part of PM2.5 & 13.122 & 1.326 & 2.306 \\
Relax hukou & 9.895 & 0.935 & 1.710 \\
Relax overall mobility constraints & 17.458 & 10.051 & 10.692 \\
Relocate PM2.5 \& relax hukou & 42.911 & 1.502 & 5.085 \\
Relocate PM2.5 \& lower migration costs & 55.354 & 13.289 & 16.928 \\
\hline
\end{tabular}

Notes: In this counterfactual exercise we relocate PM2.5 in all cities based on the amount of skill-biased capital in the city (row 1). In row 2, we relocate only the exogenous component of pollution. In addition to such relocations of pollution, we also relax the hukou restriction in the 24 top tier cities by $50 \%$ (row 3 ). In row 4 we relax overall migration costs to the 24 high tier cities by $50 \%$. Rows 3 and 4 keep pollution fixed. Rows 5 and 6 relocate pollution while relaxing migration costs.

However, wage effects do not capture the entirety of the welfare consequences, as pollution and migration costs also directly determine welfare. This is particularly important to acknowledge, as relocating pollution to less productive areas may be undesirable from an environmental justice point of view, if it makes unskilled workers in poor cities worse off.

Table 11 examines changes to welfare by skill group. Relocating pollution away from cities with skill-biased capital raises the welfare of skilled workers by $29.7 \%$, as it raises their wages, but also lowers their experience of pollution since most skilled workers are already located in such cities. Unskilled workers, however, see more modest improvements in their overall welfare. Welfare in the country improves by $4.6 \%$.

Lowering migration costs (row 4), on the other hand, raises the welfare of both skilled and unskilled workers, by $17.5 \%$ and $10.1 \%$ respectively. The combination of relocating pollution and lowering migration costs improves welfare in the country by a substantial $16.9 \%$. The overall changes in welfare are not simply the sum of the two counterfactuals conducted separately, highlighting the interplay between migration restrictions and pollution exposure. For instance, relaxing migration restrictions directly improves welfare by lowering mobility costs and allowing access to better wages; but when combined with lower pollution, the individuals who immigrate also happen to benefit from better air quality.

The numbers in Table 11 make clear that while the policies we study (relocating pollution away from the most productive places and relaxing hukou) are sensible on efficiency grounds, they raise welfare by primarily benefiting rich, skilled workers. Poor, unskilled workers are also better off, but their gains are only substantial when we reduce overall mobility costs.

Once again, in Appendix Table E2, we re-examine the overall changes to GDP from our most basic formulation of the model, without externalities. That is, without housing, agglomeration, or pollution responses to changing populations. The results are qualitatively similar to Table 9, with some improvements to GDP being slightly larger in magnitude. 


\subsection{How Much of the Cross-city Wage Gap is Due to Pollution?}

Figure 10: Explaining the Wage Gap with Worker Relocation

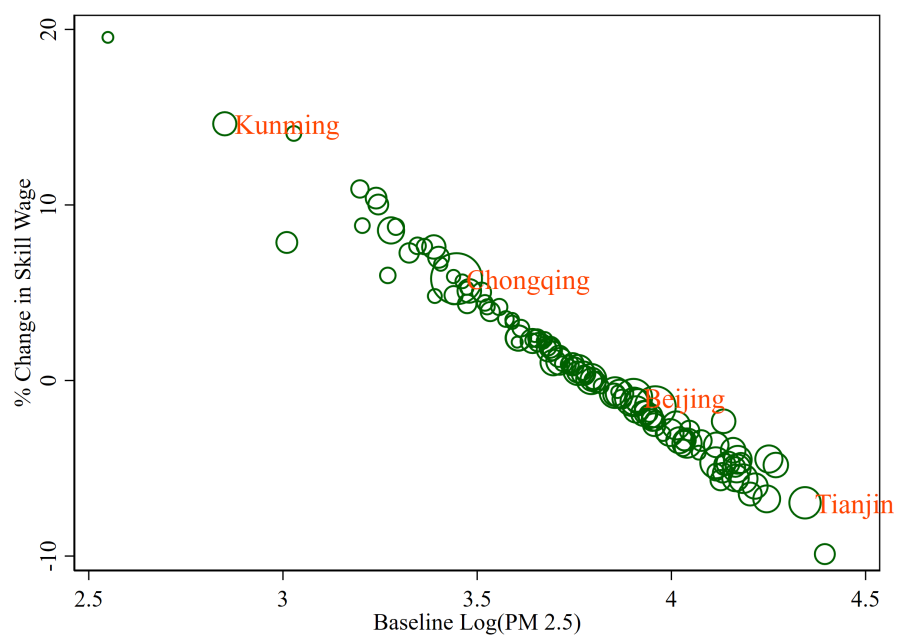

Notes: We plot the change in the skilled wage, solely due to changes in worker location (the relocation channel only), when the amount of pollution in the city is changed to be equal to the pollution in the median city. The horizontal axis plots the baseline amount of pollution in a city. The vertical axis plots the change in the skilled wage as this baseline pollution is equalized across cities. The size of the bubbles represent the baseline population in 2000 .

A persistent puzzle animating a large literature in development and macroeconomics is that despite existent productivity gaps across regions within countries, worker mobility does not equalize wages. We now use our estimated model to explore: how much of the cross-city wage gaps is explained by poor air quality?

We conduct an exercise where we change the amount of pollution in all cities to be that of the median city in the country, while still keeping the total country-level of pollution the same as before. This means raising pollution levels in cities with low pollution and low skill-biasedcapital, and lowering them in polluted, productive cities. In Figure 10 we show how wages would change with this reallocation of pollution, as a way to quantify how much of the wage gap across cities is due to existing patterns of pollution. We use the numbers for Tianjin and Chongqing two comparable representative provincial-level cities - to illustrate. As pollution is lowered in Tianjin, there is an inflow of skilled workers that lowers the skilled wage. The change in wage is the same as the (endogenously determined) compensating differential. Conversely, skilled wages rise in Chongqing as workers emigrate out. On net, the skilled wage gap between Tianjin and Chongqing is bridged by $18 \%$, due only to the pollution-induced reallocation channel, ignoring agglomeration or health effects. Once we incorporate the health and agglomeration benefits of reducing pollution, the Tianjin wage does not fall by as much, while the newly imported pollution into Chongqing mitigates the rise in wages there. So a smaller, $14.4 \%$ of the gap gets bridged under the new equitable configuration of pollution across Chinese cities, once we incorporate the full range of effects of pollution on people's productivity. Only adding health benefits to the resorting effects (ignoring agglomeration) explains $12.5 \%$ of the gap. 


\subsection{Consequences of the 2013 City-level Pollution Caps}

Finally, we quantify the productivity implications of an actual pollution control policy recently implemented by the Chinese government. On Sep 10, 2013, the State Council of China issued an Air Pollution Prevention and Control Plan, which states, "by 2017, annual PM2.5 concentration in China's three major economic circles: Beijing-Tianjin-Hebei, Yangtze River Delta and Pearl River Delta region shall fall by around 25\%, 20\% and 15\% respectively. PM2.5 concentration in Beijing shall be controlled below $60 \mu \mathrm{g} / \mathrm{m}^{3}$." As the logic of our paper would recommend, this plan sensibly targeted China's three most productive areas. This should induce skilled workers to re-sort into those areas, and raise aggregate productivity.

Table 12: The Productivity Effect of Pollution Regulation

\begin{tabular}{lcccc}
\hline \hline & \multicolumn{4}{c}{ Change in GDP per Worker (\%) } \\
& Overall changes & Health & Relocation & Relocate+Agglom \\
\cline { 2 - 5 } Control PM2.5 & 3.570 & 1.519 & 1.702 & 1.937 \\
Control PM2.5 \& relax hukou & 6.300 & 1.519 & 4.064 & 4.570 \\
Control PM2.5 \& lower migration costs & 10.773 & 1.519 & 8.157 & 8.974 \\
\hline
\end{tabular}

Notes: In this counterfactual we reduce pollution according to the targets set by the 2013 Air Pollution Prevention and Control Plan (row 1). In addition to pollution regulations, we also relax the hukou restriction in higher tier cities (row 2), and overall migration costs (row 3 ) by 50\%. Column 1 shows the gain to country GDP. Column 2 shows the gain to GDP from the health-productivity channel. Column 3 shows the GDP change from the relocation channel, and Column 4 also accounts for the agglomeration of skilled workers.

As shown in Table 12, we predict this policy - targeted at only a subset of cities - to increase country-level GDP per worker in China by 3.6\%, mostly driven by workers relocating to more productive cities. While this is already impressive, our model further suggests that if China were to lower migration costs to allow its citizens to take full advantage of the new pollution controls in productive cities, GDP per worker would rise even more, by as much as $10.8 \%$.

Our analysis thus suggests that while pollution control is important, ignoring the spatial re-sorting effects of pollution control leaves some very large bills on the sidewalk. Given how sensitive (skilled) Chinese citizens are to pollution, and how responsive they are through their migration choices (as documented in our empirical section), our model clarifies that pairing

Table 13: Welfare Effects of Pollution Regulation

\begin{tabular}{lccc}
\hline \hline & Skilled Welfare & Unskilled Welfare & Average Welfare \\
\cline { 2 - 4 } Control PM2.5 & 7.150 & 1.087 & 1.611 \\
Control PM2.5 \& relax hukou & 18.425 & 1.978 & 3.401 \\
Control PM2.5 \& lower migration costs & 26.668 & 11.224 & 12.560 \\
\hline
\end{tabular}

Notes: In this counterfactual exercise we reduce pollution according to the targets set by the 2013 Air Pollution Prevention and Control Plan (row 1). In addition to pollution regulations, we also relax the hukou restriction in higher tier cities (row 2), and migration costs (row 3) by 50\%. To capture the distributional implications, we examine how this policy affects wages for different types of workers in Table E3. 
pollution control efforts with easing hukou restrictions or reducing migration costs could produce much larger benefits to society. Table 13 shows that a combined policy of both pollution control and easing mobility would also make the welfare gains more equitable. The 2013 policy of pollution caps raise the welfare of the skilled by $7.2 \%$, but have little effect on the unskilled, who are less sensitive to pollution. However, lowering migration costs as a complementary policy tool would improve welfare for both skilled and unskilled workers.

\section{Conclusion}

Our analysis highlights the aggregate macroeconomic consequences of an important new pattern of mobility. As economies grow and industrial activity pollutes the environment, workers - especially those who are more educated and skilled - emigrate in search of better air quality. Not only is this costly for the polluted cities that skilled workers leave, this process lowers productivity and aggregate economic growth by creating a spatial mismatch between skilled and unskilled workers, and by inducing skilled workers to move out of areas where they would contribute more to the economy. A large literature had already documented that pollution lowers productivity by making workers unhealthy (Adhvaryu et al., 2016; Kahn and Li, 2019; Zivin and Neidell, 2012), and our contribution is to quantify the productivity losses stemming from differential mobility of skilled workers in response to pollution, which we find to be just as important as the pollution-health link. We further document that mobility costs (both physical, and imposed by hukou policy) exacerbate these economic losses, and that migration and pollution control policies are interlinked. This evidence directly speaks to the tensions between environmental regulation and urbanization in the developing world (Glaeser, 2014b).

Finally, our analysis sheds light on an important puzzle in the development and macroeconomics literature: Why are there large productivity gaps across regions within countries (Bryan and Morten, 2019; Gollin et al., 2014), and why don't workers move to arbitrage those gaps (Bryan et al., 2014)? Understanding factors that prevent a more efficient allocation of inputs is consequential for our understanding of aggregate productivity and growth (Hsieh and Klenow, 2009). We find that skilled workers' distaste for air pollution can account for $14 \%$ of the wage difference across a representative pair of Chinese cities. Pollution control coupled with policies easing mobility has the potential to bring about large productivity gains in China. 


\section{References}

Adao, R., M. Kolesar, and E. Morales (2019). Shift-Share Designs: Theory and Inference. The Quarterly Journal of Economics 134(4), 1949-2010.

Adhvaryu, A., N. Kala, and A. Nyshadham (2016). Management and shocks to worker productivity. International Growth Center (IGC). Working Paper.

AFP News (2019, March). Asia's Pollution Exodus: Firms Struggle to Woo Top Talent. AgenceFrance Press News Agency. https://news.yahoo.com/asias-pollution-exodus-firms-strugglewoo-top-talent-035837924.html.

Ahlfeldt, G., S. Redding, D. Sturm, and N. Wolf (2015). The Economics of Density: Evidence from the Berlin Wall. Econometrica 83(6), 2127-2189.

Allen, T., C. Arkolakis, and Y. Takahashi (2020). Universal Gravity. Journal of Political Economy 128(2), 393-433.

Amiti, M. and C. Freund (2010, March). The Anatomy of China's Export Growth, pp. 35-56. University of Chicago Press.

Andreoni, J. and A. Levinson (2001). The Simple Analytics of the Environmental Kuznetz Curve. Journal of Public Economics 80(2), 269-286.

Arceo, E., R. Hanna, and P. Oliva (2016). Does the Effect of Pollution on Infant Mortality Differ between Developing and Developed Countries? Evidence from Mexico City. The Economic Journal 126(591), 257-280.

Arrow, K. J. (1962). Economic Welfare and the Allocation of Resources for Innovation. NBER working paper c2144.

$\mathrm{Au}, \mathrm{C}$. and V. Henderson (2006). How Migration Restrictions Limit Agglomeration and Productivity in China. Journal of Development Economics 80(2), 350-388.

Autor, D., D. Dorn, and G. H. Hanson (2013). The China Syndrome: Local Labor Market Effects of Import Competition in the United States. American Economic Review 103(6), 2121-68.

Bayer, P., N. Keohane, and C. Timmins (2009). Migration and Hedonic Value: The Case of Air Quality. Journal of Environmental Resources and Management 58(1), 1-14.

Bazzi, S. (2017). Wealth Heterogeneity and the Income Elasticity of Migration. American Economic Journal: Applied Economics 9(2), 219-55.

Borusyak, K., P. Hull, and X. Jaravel (2018). Quasi-experimental Shift-share Research Designs. Technical report, National Bureau of Economic Research.

Brandt, L., C.-T. Hsieh, and X. Zhu (2008). Growth and Structural Transformation in China. China's Great Economic Transformation, 683-728.

Bryan, G., S. Chowdhury, and A. M. Mobarak (2014). Underinvestment in a Profitable Technology: The Case of Seasonal Migration in Bangladesh. Econometrica 82(5), 1671-1748.

Bryan, G. and M. Morten (2019). The Aggregate Productivity Eeffects of Internal Migration: Evidence from Indonesia. Journal of Political Economy 127(5), 2229-2268.

Card, D. (2001). Immigrant Inflows, Native Outflows, and the Local Labor Market Impacts of Higher Immigration. Journal of Labor Economics 19(1), 22-64.

Card, D. and T. Lemieux (2001, May). Can Falling Supply Explain the Rising Return to College for Younger Men? A Cohort-Based Analysis. The Quarterly Journal of Economics 116(2), 705-746. 
Chang, T., J. G. Zivin, T. Gross, and M. Neidell (2019). The Effect of Pollution on Worker Productivity: Evidence from Call Center Workers in China. American Economic Journal: Applied Economics 11(1), 151-172.

Che, Y. and L. Zhang (2018). Human Capital, Technology Adoption and Firm Performance: Impacts of China's Higher Education Expansion in the Late 1990s. Economic Journal 128(614), 2282-2320.

Chen, S., P. Oliva, and P. Zhang (2017). The Effect of Air Pollution on Migration: Evidence from China. NBER Working Papers.

Chen, Y., A. Ebenstein, M. Greenstone, and H. Li (2013). Evidence on the Impact of Sustained Exposure to Air Pollution on Life Expectancy from China's Huai River Policy. Proceedings of the National Academy of Sciences of the United States of America 110(32), 12936-12941.

Chen, Y., G. Z. Jin, N. Kumar, and G. Shi (2012). Gaming in Air Pollution Data? Lessons from China. The BE Journal of Economic Analysis 83 Policy 12(3), 1-43.

Clemens, M. A., C. E. Montenegro, and L. Pritchett (2019). The Place Premium: Bounding the Price Equivalent of Migration Barriers. Review of Economics and Statistics 101 (2), 201-213.

Combes, P.-P., S. Demurger, S. Li, and J. Wang (2019). Unequal Migration and Urbanisation Gains in China. Journal of Development Economics 142(1), 102328.

Eaton, J. and S. Kortum (2002). Technology, Geography and Trade. Econometrica 70(5), 1741-1779.

Ebenstein, A., M. Fan, M. Greenstone, G. He, P. Yin, and M. Zhou (2015). Growth, Pollution, and Life Expectancy: China from 1991-2012. American Economic Review 105(5), 226-31.

Ebenstein, A., M. Fan, M. Greenstone, G. He, and M. Zhou (2017). New Evidence on the Impact of Sustained Exposure to Air Pollution on Life Expectancy from China's Huai River Policy. Proceedings of the National Academy of Sciences 114(39), 10384-10389.

Freeman, R., W. Liang, R. Song, and C. Timmins (2019). Willingness to Pay for Clean Air in China. Journal of Environmental Economics and Management, 188-216.

Gaubert, C. (2018). Firm Sorting and Agglomeration. American Economic Review 108(11), $3117-53$.

Ghanem, D. and J. Zhang (2014). Effortless Perfection: Do Chinese Cities Manipulate Air Pollution Data? Journal of Environmental Economics and Management 68(2), 203-225.

Giles, J., A. Park, and M. Wang (2019, October). The Great Proletarian Cultural Revolution, Disruptions to Education, and the Returns to Schooling in Urban China. Economic Development and Cultural Change 68(1), 131-164.

Glaeser, E. (2014a). A World of Cities: The Causes and Consequences of Urbanization in Poorer Countries. Journal of the European Economic Association 12(5), 1154-1199.

Glaeser, E. (2014b). The Supply of Environmentalism: Psychological Interventions and Economics. Review of Environmental Economics and Policy 8(2), 208-229.

Glaeser, E. and M. E. Kahn (2010). The Greenness of Cities: Carbon Dioxide Emissions and Urban Development. Journal of Urban Economics 67(3), 404-418.

Goldsmith-Pinkham, P., I. Sorkin, and H. Swift (2020). Bartik Instruments: What, When, Why, and How. American Economic Review 110(8), 2586-2624.

Gollin, D., D. Lagakos, and M. Waugh (2014). The Agricultural Productivity Gap. Quarterly Journal of Economics 129(2), 939-993. 
Greenstone, M., G. He, R. Jia, and T. Liu (2020). Can Technology Solve the Principal-Agent Problem? Evidence from China's War on Air Pollution. American Economic Review: Insights. Forthcoming.

He, G., M. Fan, and M. Zhou (2016). The Effect of Air Pollution on Mortality in China: Evidence from the 2008 Beijing Olympic Games. Journal of Environmental Economics and Management 79, 18-39.

He, G., T. Lio, and M. Zhou (2020, June). Straw Burning, PM2.5, and Death: Evidence from China. Journal of Development Economics 145(102468).

He, G., Y. Xie, and B. Zhang (2020, June). Expressways, GDP, and the Environment: The Case of China. Journal of Development Economics 145(102485).

Heblich, S., A. Trew, and Y. Zylberberg (2020). East Side Story: Historic Pollution and Neighborhood Segregation. Journal of Political Economy. Forthcoming.

Hicks, D., P. March, and P. Oliva (2015). Air Pollution and Procyclical Mortality: Causal Evidence from Thermal Inversions. Working Paper.

Hsieh, C. T. and P. Klenow (2009). Misallocation and Manufacturing TFP in China and India. The Quarterly Journal of Economics 124(4), 1403-1448. November.

Hsieh, C. T. and E. Moretti (2018). Housing Constraints and Spatial Misallocation. American Economic Journal: Macroeconomics 11(2), 1-39.

Ito, K. and S. Zhang (2019). Willingness to Pay for Clean Air: Evidence from Air Purifier Markets in China. Journal of Political Economy 128(5), 1627-1672.

Jaeger, D. A., J. Ruist, and J. Stuhler (2018). Shift-share Instruments and the Impact of Immigration. National Bureau of Economic Research, WP 24285.

Jans, J., P. Johansson, and P. Nilsson (2014). Economic Status, Air Quality, and Child Health: Evidence from Inversion Episodes. Working Paper.

Jia, Barwick, P., S. Li, L. Lin, and E. Zou (2019). From Fog to Smog: The Value of Pollution Information. National Bureau of Economic Research, WP 26541.

Kahn, M. E. and P. Li (2019). The Effect of Pollution and Heat on High Skill Public Sector Worker Productivity in China. National Burea of Economic Research, WP 25594.

Kapur, M. (2019, November). Many Delhi Residents Want to Escape the Smog. But Where Can They Go? Quartz India.

Khanna, G., K. Shih, A. Weinberger, M. Xu, and M. Yu (2020). Trade Liberalization and Chinese Students in US Higher Education. Working Paper.

Kinnan, C., S.-Y. Wang, and Y. Wang (2018). Access to Migration for Rural Households. American Economic Journal: Applied Economics 10(4), 79-119.

Kone, Z., M. Liu, A. Mattoo, C. Ozden, and S. Sharma (2018). Internal Borders and Migration in India. Journal of Economic Geography 18(4), 729-759.

Lagakos, D., M. Mobarak, and M. Waugh (2019). The Welfare Effects of Encouraging Ruralurban Migration. Working Paper.

Lewis, W. A. (1954). Economic Development with Unlimited Supplies of Labor. The Manchester School 22(2), 139-191. May.

Lustgarten, A. (2020, September). How Climate Migration Will Reshape America. New York Times.

Moretti, E. (2004). Workers' Education, Spillovers, and Productivity: Evidence from Plantlevel Production Functions. American Economic Review 94(3), 656-690. 
Moretti, E. (2011). Local Labor Markets. Handbook of Labor Economics 4b. Elsevier North Holland, Amsterdam.

Munshi, K. and M. Rosenzweig (2016). Networks and Misallocation: Insurance, Migration, and the Rural-urban Wage Gap. American Economic Review 106(1), 46-98.

New York Times (2015, December). Companies in South China See Opportunity in Beijing's Smog. The New York Times Company. https://www.nytimes.com/2015/12/23/world/asia/beijing-air-pollution-china-smog.html.

Peri, G., K. Shih, and C. Sparber (2015). STEM Workers, H-1B Visas, and Productivity in US Cities. Journal of Labor Economics 33(S1), S225 - S255.

Pierce, J. R. and P. K. Schott (2016). The Surprisingly Swift Decline of U.S. Manufacturing Employment. American Economic Review 106(7), 1632-62.

Restuccia, D. and R. Rogerson (2013). Misallocation and Productivity. Review of Economic Dynamics 16(1), 1-10.

Restuccia, D. and R. Rogerson (2017). The Causes and Costs of Misallocation. Journal of Economic Perspectives 31(3), 151-74.

Tombe, T. and X. Zhu (2019). Trade, Migration, and Productivity: A Quantitative Analysis of China. American Economic Review 109(5), 1843-72.

Van Donkelaar, A., R. Martin, M. Brauer, N. C. Hsu, R. Kahn, R. Levy, A. Lyapustin, A. Sayer, and D. Winker (2016). Global Estimates of Fine Particulate Matter Using a Combined Geophysical-statistical Method with Information from Satellites, Models, and Monitors. Environmental Science \& Technology 50(7), 3762-3772.

Xue, S., B. Zhang, and X. Zhao (2020, September). Brain Drain: The Impact of Air Pollution on Firm Performance. Available on SSRN. https://ssrn.com/abstract=3490344 or http://dx.doi.org/10.2139/ssrn.3490344.

Young, A. (2014). Structural Transformation, the Mismeasurement of Productivity Growth, and the Cost Disease of Services. American Economic Review 104(11), 3635-67.

Zhang, J., R. Wang, and C. Lu (2018). A Quantitative Analysis of Hukou Reform in Chinese Cities: 2000-2016. Growth and Change 50(1), 201-221.

Zheng, S. and M. E. Kahn (2013). Understanding China's Urban Pollution Dynamics. Journal of Economic Literature 51(3), 731-72.

Zivin, J. G. and M. Neidell (2012). The Impact of Pollution on Worker Productivity. American Economic Review 102(7), 3652-73. 


\section{Appendix}

\section{Table of Contents}

A Robustness of Empirical Specifications $\quad$ A2

A.1 The Different Instruments and their Sources of Variation . . . . . . . . . . . . A2

A.2 The Huai River Regression Discontinuity . . . . . . . . . . . . . . . . . A10

A.3 Alternative Model Specifications, Controls and Samples . . . . . . . . . . . A12

B Air Pollution Data Disclosure in China $\quad$ A20

$\begin{array}{lll}\text { C Additional Tables and Figures } & \text { A21 }\end{array}$

D Additional Model Derivations $\quad$ A26

D.1 Deriving Labor Supply and Welfare . . . . . . . . . . . . . . . A26

D.2 Elasticity of Capital, and Modelling Skill-biased Capital . . . . . . . . . . A27

D.3 A Note on Existence and Uniqueness of the Equilibrium . . . . . . . . . . . A28

$\begin{array}{lll}\text { E Additional Counterfactual Results } & \text { A29 }\end{array}$ 


\section{A Robustness of Empirical Specifications}

We conduct a wide-range of meaningful robustness checks to evaluate the concreteness of the empirical relationship between air quality and migration. We explore threats to identification, different instrumental variables, alternative model specifications and data sources.

\section{A.1 The Different Instruments and their Sources of Variation}

First, as we describe in the main text, we explore a few different sources of underlying variation. We employ two different instrumental variables strategies discussed in recent work on China to address the endogeneity of air pollution. Specifically, we study the variation underlying the instrument based on wind direction and distant coal-fired power plants (Freeman, Liang, Song, and Timmins, 2019), and the variation in air quality driven by the number and strength of thermal inversions (Chen, Oliva, and Zhang, 2017).

Then, we explore threats to identification for our two main instruments. We test concerns of the endogenous placements of power plants, whereby policy makers may use the same function - the simultaneous interaction between wind directions, distance to a given city and coal consumption - to determine where to place new plants. We thus exclude any plants built within different distance radii around the city, and find a similar empirical pattern. We may still think that newly built plants are endogenously placed. Yet, our results are robust to relying on old power plants, and to make it even more conservative the cities near the newly built plants are in the 'control' group. Last, we show that the IV is not predicted by baseline city-level characteristics.

Table A1: The First Stage Across Different Instruments

\begin{tabular}{|c|c|c|c|c|c|c|c|c|c|}
\hline Panel A: City-level & & & & Depend & lent variable: & $\log ($ PM2.5) & & & \\
\hline Wind+Coal IV & $\begin{array}{c}0.0240^{* * * *} \\
(0.00211)\end{array}$ & $\begin{array}{c}0.0113^{* * *} \\
(0.00235)\end{array}$ & $\begin{array}{c}0.00956^{* * *} \\
(0.00239)\end{array}$ & & & & & & \\
\hline Number of inversions & & & & $\begin{array}{c}0.00222^{* * *} \\
(0.000350)\end{array}$ & $\begin{array}{c}0.00159^{* * *} \\
(0.000329)\end{array}$ & $\begin{array}{c}0.00201^{* * *} \\
(0.000293)\end{array}$ & & & \\
\hline Strength of inversions & & & & & & & $\begin{array}{c}0.000730^{* * *} \\
(0.000214)\end{array}$ & $\begin{array}{c}0.000448^{* *} \\
(0.000185)\end{array}$ & $\begin{array}{c}0.000725^{* * *} \\
(0.000168)\end{array}$ \\
\hline Observations & 332 & 332 & 332 & 332 & 332 & 332 & 332 & 332 & 332 \\
\hline R-squared & 0.297 & 0.394 & 0.444 & 0.212 & 0.441 & 0.538 & 0.097 & 0.389 & 0.483 \\
\hline City Controls & No & Yes & Yes & No & Yes & Yes & No & Yes & Yes \\
\hline Weather Controls & No & No & Yes & No & No & Yes & No & No & Yes \\
\hline Panel B: Individual-level & & & & Depend & lent variable: & Log (PM2.5) & & & \\
\hline Wind+Coal IV & $\begin{array}{l}0.0200 * * * \\
(3.94 \mathrm{e}-05)\end{array}$ & $\begin{array}{l}0.0136 * * * \\
(3.44 \mathrm{e}-05)\end{array}$ & $\begin{array}{l}0.0130 * * * \\
(3.38 \mathrm{e}-05)\end{array}$ & & & & & & \\
\hline Number of inversions & & & & $\begin{array}{c}0.00212^{* * *} \\
(6.24 \mathrm{e}-06)\end{array}$ & $\begin{array}{c}0.00184^{* * *} \\
(6.08 \mathrm{e}-06)\end{array}$ & $\begin{array}{c}0.00227^{* * *} \\
(5.30 \mathrm{e}-06)\end{array}$ & & & \\
\hline Strength of inversions & & & & & & & $\begin{array}{c}0.000822^{* * *} \\
(3.85 \mathrm{e}-06)\end{array}$ & $\begin{array}{c}0.000670 * * * \\
(3.77 \mathrm{e}-06)\end{array}$ & $\begin{array}{c}0.000944^{* * *} \\
(3.29 \mathrm{e}-06)\end{array}$ \\
\hline Observations & 761,548 & 761,548 & 761,548 & 761,548 & 761,548 & 761,548 & 761,548 & 761,548 & 761,548 \\
\hline R-squared & 0.284 & 0.403 & 0.447 & 0.248 & 0.441 & 0.551 & 0.160 & 0.379 & 0.491 \\
\hline City Controls & No & Yes & Yes & No & Yes & Yes & No & Yes & Yes \\
\hline Demographics & No & Yes & Yes & No & Yes & Yes & No & Yes & Yes \\
\hline Weather Controls & No & No & Yes & No & No & Yes & No & No & Yes \\
\hline
\end{tabular}

Notes: City-level regressions of 332 cities in panel A and individual-level regressions across 332 cities in Panel B. Standard errors clustered at the hukou city level are reported in parentheses. City controls include distance to Shanghai, Tianjin and Shenzhen seaports. Weather controls include temperature, wind speed, sunshine duration and humidity. 
We also explore the variation underlying the thermal inversions IV. We fail to find meaningful predictors of future inversions, and as such conclude that such events are random.

Finally, we explore the variation generated by China's Huai river heating policy (Chen et al., 2013). Even though we fail to find substantial effects on out-migration rates, they do help predict differential in-migration by skill.

\section{A.1.1 Instruments Variable Estimates}

In our main text, we use our first instrument based on wind direction and distant coal-fired plants to deal with the endogeneity of local air pollution. Then we isolate exogenous fluctuations in air pollution by leveraging the variation in thermal inversions that trap pollutants. In Table A1 we show the strength of the first stage relationships between our different instruments and our independent variable of interest. In our main Table 1 there is a strong relationship between poor air quality and the out-migration of high-skilled workers.

Table A2: Pollution and Out-migration

\begin{tabular}{|c|c|c|c|c|c|c|c|c|c|}
\hline \multirow[t]{3}{*}{ Panel A: No weather } & \multicolumn{9}{|c|}{ Dependent variable: Leave hukou city indicator } \\
\hline & \multicolumn{3}{|c|}{ Wind+Coal IV } & \multicolumn{3}{|c|}{ Number of inversions } & \multicolumn{3}{|c|}{ Strength of inversions } \\
\hline & Full sample & Low edu & High edu & Full sample & Low edu & High edu & Full sample & Low edu & High edu \\
\hline $\log ($ PM2.5) & $\begin{array}{c}0.0772^{* *} \\
(0.0389)\end{array}$ & $\begin{array}{c}0.0609 \\
(0.0423)\end{array}$ & $\begin{array}{c}0.140^{* * *} \\
(0.0382)\end{array}$ & $\begin{array}{c}0.113^{* * *} \\
(0.0274)\end{array}$ & $\begin{array}{c}0.108^{* * *} \\
(0.0291)\end{array}$ & $\begin{array}{c}0.154^{* * *} \\
(0.0358)\end{array}$ & $\begin{array}{c}0.0970^{* * *} \\
(0.0341)\end{array}$ & $\begin{array}{c}0.0920 * * \\
(0.0358)\end{array}$ & $\begin{array}{c}0.168^{* * *} \\
(0.0553)\end{array}$ \\
\hline Observations & 761,548 & 643,124 & 118,424 & 761,548 & 643,124 & 118,424 & 761,548 & 643,124 & 118,424 \\
\hline R-squared & 0.027 & 0.029 & 0.036 & 0.022 & 0.023 & 0.033 & 0.024 & 0.026 & 0.030 \\
\hline City Controls & Yes & Yes & Yes & Yes & Yes & Yes & Yes & Yes & Yes \\
\hline Demographics & Yes & Yes & Yes & Yes & Yes & Yes & Yes & Yes & Yes \\
\hline Weather Controls & No & No & No & No & No & No & No & No & No \\
\hline F-test of IVs & 52.53 & 46.52 & 41.54 & 52.33 & 50.27 & 39.10 & 19.82 & 20.24 & 11.58 \\
\hline \multirow[t]{3}{*}{ Panel B: Weather controls } & \multicolumn{9}{|c|}{ Dependent variable: Leave hukou city indicator } \\
\hline & \multicolumn{3}{|c|}{ Wind + Coal IV } & \multicolumn{3}{|c|}{ Number of inversions } & \multicolumn{3}{|c|}{ Strength of inversions } \\
\hline & Full sample & Low edu & High edu & Full sample & Low edu & High edu & Full sample & Low edu & High edu \\
\hline $\log (\mathrm{PM} 2.5)$ & $\begin{array}{c}0.0890^{* * *} \\
(0.0343)\end{array}$ & $\begin{array}{c}0.0763^{* *} \\
(0.0368)\end{array}$ & $\begin{array}{c}0.155^{* * *} \\
(0.0359)\end{array}$ & $\begin{array}{c}0.0906^{* * *} \\
(0.0202)\end{array}$ & $\begin{array}{c}0.0871^{* * *} \\
(0.0211)\end{array}$ & $\begin{array}{c}0.112^{\text {*** }} \\
(0.0233)\end{array}$ & $\begin{array}{c}0.0779^{* * *} \\
(0.0228)\end{array}$ & $\begin{array}{c}0.0740^{* * *} \\
(0.0238)\end{array}$ & $\begin{array}{c}0.107^{* * *} \\
(0.0279)\end{array}$ \\
\hline Observations & 761,548 & 643,124 & 118,424 & 761,548 & 643,124 & 118,424 & 761,548 & 643,124 & 118,424 \\
\hline R-squared & 0.036 & 0.039 & 0.039 & 0.035 & 0.037 & 0.047 & 0.037 & 0.039 & 0.047 \\
\hline City Controls & Yes & Yes & Yes & Yes & Yes & Yes & Yes & Yes & Yes \\
\hline Demographics & Yes & Yes & Yes & Yes & Yes & Yes & Yes & Yes & Yes \\
\hline Weather Controls & Yes & Yes & Yes & Yes & Yes & Yes & Yes & Yes & Yes \\
\hline F-test of IVs & 47.20 & 41.91 & 38.24 & 102.5 & 97.33 & 84.83 & 51.09 & 49.60 & 40.54 \\
\hline
\end{tabular}

Notes: Individual level regressions across 332 cities. Standard errors clustered at the hukou city level are reported in parentheses. Instrumental variables specification using the interaction between wind direction, distance to coal plant, and coal consumption at power plant, and using the number of thermal inversions and the strength of thermal inversions. City controls include distance to Shanghai, Tianjin and Shenzhen seaports. Demographics include age, age-squared, gender, marital status, and an urban hukou indicator. In Panel B, weather controls include temperature, wind speed, sunshine duration and humidity.

In Table A2, we study how variation in PM2.5 from our various instruments affects migration. Panel A shows the results without weather controls. This replicates the results in the main text for the coal-fired plants IV in the first three columns. We include distances to three large seaports to account for the spatial distribution of economic development in China. In the next three columns, we employ the annual occurrence of thermal inversions as the instrumental 
Table A3: Combined Instruments

\begin{tabular}{|c|c|c|c|c|c|c|}
\hline & \multicolumn{6}{|c|}{ Dependent variable: Leave hukou city indicator } \\
\hline & \multicolumn{3}{|c|}{ Wind and Coal + Number of inversions } & \multicolumn{3}{|c|}{ Wind and Coal + Strength of inversions } \\
\hline & Full sample & Low edu & High edu & Full sample & Low edu & High edu \\
\hline Log (PM2.5) & $\begin{array}{c}0.0892^{* * *} \\
(0.0189)\end{array}$ & $\begin{array}{c}0.0836^{* * *} \\
(0.0197)\end{array}$ & $\begin{array}{c}0.124^{* * *} \\
(0.0228)\end{array}$ & $\begin{array}{c}0.0795^{* * *} \\
(0.0206)\end{array}$ & $\begin{array}{c}0.0722^{* * *} \\
(0.0213)\end{array}$ & $\begin{array}{c}0.129^{* * *} \\
(0.0263)\end{array}$ \\
\hline Observations & 761,548 & 643,124 & 118,424 & 761,548 & 643,124 & 118,424 \\
\hline R-squared & 0.036 & 0.038 & 0.045 & 0.037 & 0.039 & 0.044 \\
\hline Hansen J statistic & 0.063 & 0.407 & 2.162 & 0.03 & 0.041 & 2.194 \\
\hline Hansen $\mathrm{P}$ value & 0.802 & 0.523 & 0.142 & 0.862 & 0.839 & 0.139 \\
\hline City Controls & Yes & Yes & Yes & Yes & Yes & Yes \\
\hline Demographics & Yes & Yes & Yes & Yes & Yes & Yes \\
\hline Weather Controls & Yes & Yes & Yes & Yes & Yes & Yes \\
\hline F-test of IVs & 68.36 & 65.18 & 54.29 & 45.91 & 43.23 & 36.66 \\
\hline
\end{tabular}

Notes: Individual level regressions across 332 cities. Standard errors clustered at the hukou city level are reported in parentheses. City controls include the log distance to Shanghai seaport, to Tianjin seaport, and to Shenzhen seaport. Demographics include age, age-squared, gender, marital status, and an urban hukou indicator. Weather controls include temperature, wind speed, sunshine duration and humidity.

variable. The results show that the implications of air pollution on emigration are more pronounced for high-skilled workers in comparison with those with lower skills. In the last three columns, we leverage the variation coming from the annual strength of thermal inversions. The results remain similar. Since thermal inversions may be affected by local weather conditions, we further control for a set of weather characteristics. Panel B of Table A2 shows these patterns with weather controls. We find a similar empirical pattern: high-skilled workers are more likely to escape from polluted cites to avoid the adverse effects of pollution, compared to their lower educated counterparts.

Finally, Table A3 shows combinations of the Wind IV and thermal inversions instruments, and the corresponding over-identification tests. Across specifications, we find similar results.

While our earlier results examine the out-migration decision of individuals, we further examine the association between air pollution and destination choices. We regress city-level in-migration rate on local air pollution concentration. The results are in Table A4. We use our instruments to deal with the endogeneity of air quality in destination cities. We find that even for in-migration decisions, the response of high-skilled workers is greater than that of low-skilled workers. In other words, high-skilled workers are more likely to move to cities with clean air when they make location choices. Severe air pollution can not only result in the outflow of high-skilled workers but also reduce their inflow.

\section{A.1.2 Endogeneity Concerns over Instrumental Strategies}

In this section we test the identification assumptions underlying our main instruments. Our first instrument is the interaction between the three components: wind direction, distance and coal consumption. We may expect that policy makers take these components into account when placing large coal-fired plants near certain type of cities. For example, those plants may be systematically built near poorer, less influential cities. Thus, there is a concern that the instrument may be correlated with unobservable characteristics of nearby cities. In Table A5, we exclude any plants built within $200 \mathrm{~km}$ of a given city (first two columns), and then within $400 \mathrm{~km}$ of the city (last two columns). We still restrict the radius to be of $400 \mathrm{~km}$ widths. Our 
Table A4: Pollution and In-migration

\begin{tabular}{|c|c|c|c|c|c|c|c|c|c|}
\hline \multirow{3}{*}{$\begin{array}{l}\text { Panel A } \\
\text { No weather }\end{array}$} & \multicolumn{9}{|c|}{ Dependent variable: Share of In-migrants } \\
\hline & \multicolumn{3}{|c|}{ Wind + Coal IV } & \multicolumn{3}{|c|}{ Number of inversions } & \multicolumn{3}{|c|}{ Strength of inversions } \\
\hline & Full sample & Low edu & High edu & Full sample & Low edu & High edu & Full sample & Low edu & High edu \\
\hline Log (PM2.5) & $\begin{array}{c}-1.856^{* * * *} \\
(0.529)\end{array}$ & $\begin{array}{c}-1.853^{* * *} \\
(0.520)\end{array}$ & $\begin{array}{c}-2.259^{* * *} \\
(0.716)\end{array}$ & $\begin{array}{c}-1.204^{* *} \\
(0.500)\end{array}$ & $\begin{array}{c}-1.137^{* *} \\
(0.475)\end{array}$ & $\begin{array}{c}-1.645^{* *} \\
(0.677)\end{array}$ & $\begin{array}{c}-1.404^{* *} \\
(0.643)\end{array}$ & $\begin{array}{c}-1.275^{* *} \\
(0.606)\end{array}$ & $\begin{array}{c}-2.152^{* *} \\
(0.903)\end{array}$ \\
\hline Observations & 329 & 329 & 329 & 329 & 329 & 329 & 329 & 329 & 329 \\
\hline R-squared & 0.072 & 0.109 & -0.162 & 0.202 & 0.235 & 0.002 & 0.171 & 0.219 & -0.129 \\
\hline City Controls & Yes & Yes & Yes & Yes & Yes & Yes & Yes & Yes & Yes \\
\hline Weather Controls & No & No & No & No & No & No & No & No & No \\
\hline F-test of IVs & 41.91 & 41.91 & 41.91 & 39.56 & 39.56 & 39.56 & 16.36 & 16.36 & 16.36 \\
\hline \multirow{3}{*}{$\begin{array}{l}\text { Panel B } \\
\text { Weather controls }\end{array}$} & \multicolumn{9}{|c|}{ Dependent variable: Share of In-migrants } \\
\hline & \multicolumn{3}{|c|}{ Wind + Coal IV } & \multicolumn{3}{|c|}{ Number of inversions } & \multicolumn{3}{|c|}{ Strength of inversions } \\
\hline & Full sample & Low edu & High edu & Full sample & Low edu & High edu & Full sample & Low edu & High edu \\
\hline $\log (\mathrm{PM} 2.5)$ & $\begin{array}{c}-1.833^{* * *} \\
(0.529)\end{array}$ & $\begin{array}{c}-1.825^{* * *} \\
(0.513)\end{array}$ & $\begin{array}{c}-2.266^{* * *} \\
(0.728)\end{array}$ & $\begin{array}{c}-1.204^{* * *} \\
(0.373)\end{array}$ & $\begin{array}{c}-1.181^{* * *} \\
(0.357)\end{array}$ & $\begin{array}{c}-1.451^{* * *} \\
(0.503)\end{array}$ & $\begin{array}{c}-1.359^{* * *} \\
(0.421)\end{array}$ & $\begin{array}{c}-1.301 * * * \\
(0.401)\end{array}$ & $\begin{array}{c}-1.794^{* * *} \\
(0.583)\end{array}$ \\
\hline Observations & 329 & 329 & 329 & 329 & 329 & 329 & 329 & 329 & 329 \\
\hline R-squared & 0.088 & 0.126 & -0.144 & 0.209 & 0.239 & 0.056 & 0.187 & 0.224 & -0.015 \\
\hline City Controls & Yes & Yes & Yes & Yes & Yes & Yes & Yes & Yes & Yes \\
\hline Weather Controls & Yes & Yes & Yes & Yes & Yes & Yes & Yes & Yes & Yes \\
\hline F-test of IVs & 33.81 & 33.81 & 33.81 & 91.64 & 91.64 & 91.64 & 47.63 & 47.63 & 47.63 \\
\hline
\end{tabular}

Notes: City level regressions of 329 cities. We drop cities with missing in-migration rates. Dependent variable is the log share of in-migrants in city population. Independent variable is destination city PM2.5. Robust standard errors are reported in parentheses. Instrumental variables specification using the interaction between wind direction, distance to coal plant, and coal consumption at power plant, and using the number of thermal inversions and the strength of thermal inversions. City controls include distance to Shanghai, Tianjin and Shenzhen seaports. Demographics include age, age-squared, gender, marital status, and an urban hukou indicator. In Panel B, weather controls include temperature, wind speed, sunshine duration and humidity.

results are similar to before, with a slight increase in precision.

Even though policy makers may not have modeled the polluting potential of plants built in the past in the manner that we do, we may expect that newly built plants are subject to more scrutiny as the conversation about air quality in China has recently escalated. In Table A6 we exclude newly built plants in the construction of IV, and instead include cities with newly built ones in the 'control' group. Although this empirical strategy is more conservative, we find similar patterns and magnitudes.

We may also expect that coal-fired plants plants are more likely to be located in coal producing areas. In as far as coal producing areas may also influence the underlying industrial structure, this may raise concerns about other unobservable associations with migration rates. Shanxi is the largest coal producing province in China, we thus exclude Shanxi in our estimation. As reported in in Table A7, the results are slightly more precisely estimated.

Our wind-direction and coal-plants IV is constructed using the interaction between wind direction, distance to coal plants and the capacity of plants. It is natural to ask which of the three components drives our results. In Table A8 we try different versions of the instrument in which we exclude each of the three components, respectively. Our results hardly change when we exclude distance to coal plant and coal consumption at power plant. In contrast, the coefficient estimates of air pollution become meaningfully smaller when we exclude the component of wind direction, indicating that our main IV results are primarily driven by the 
Table A5: Different Distance Bins for Selection of Plants

\begin{tabular}{lcccccc}
\hline \hline \multicolumn{7}{c}{ Dependent variable: Leave hukou city indicator } \\
& \multicolumn{7}{c}{ Distance 200-600km } & \multicolumn{3}{c}{ Distance 400-800km } \\
& Full sample & Low edu & High edu & Full sample & Low edu & High edu \\
\hline \multirow{2}{*}{ Log (PM2.5) } & $0.0947^{* * *}$ & $0.0798^{* *}$ & $0.163^{* * *}$ & $0.0973^{* * *}$ & $0.0834^{* * *}$ & $0.168^{* * *}$ \\
& $(0.0365)$ & $(0.0396)$ & $(0.0383)$ & $(0.0304)$ & $(0.0319)$ & $(0.0385)$ \\
& & & & & & \\
Observations & 761,548 & 643,124 & 118,424 & 761,548 & 643,124 & 118,424 \\
R-squared & 0.025 & 0.027 & 0.031 & 0.024 & 0.027 & 0.030 \\
City Controls & Yes & Yes & Yes & Yes & Yes & Yes \\
Demographics & Yes & Yes & Yes & Yes & Yes & Yes \\
F-test of IVs & 56.73 & 50.95 & 43.11 & 59.73 & 53.08 & 58.44 \\
\hline \hline
\end{tabular}

Notes: Individual level regressions across 332 cities. Standard errors clustered at the hukou city level are reported in parentheses. Instrumental variables specification based on the interaction between wind direction, distance to coal plant, and coal consumption of power plant. City controls include distance to Shanghai, Tianjin and Shenzhen seaports. Demographics include age, age-squared, gender, marital status, and an urban hukou indicator.

Table A6: Excluding Newly Built Power Plants

\begin{tabular}{|c|c|c|c|c|c|c|}
\hline & \multicolumn{6}{|c|}{ Dependent variable: Leave hukou city indicator } \\
\hline & \multicolumn{3}{|c|}{ Plants $>5$ yrs ago } & \multicolumn{3}{|c|}{ Plants $>10$ yrs ago } \\
\hline & Full sample & Low edu & High edu & Full sample & Low edu & High edu \\
\hline $\log ($ PM2.5) & $\begin{array}{c}0.0775^{* *} \\
(0.0387)\end{array}$ & $\begin{array}{c}0.0611 \\
(0.0421)\end{array}$ & $\begin{array}{c}0.138^{* * *} * \\
(0.0379)\end{array}$ & $\begin{array}{c}0.0916^{* *} \\
(0.0415)\end{array}$ & $\begin{array}{c}0.0761^{*} \\
(0.0451)\end{array}$ & $\begin{array}{c}0.146^{* * *} \\
(0.0412)\end{array}$ \\
\hline Observations & 761,548 & 643,124 & 118,424 & 761,548 & 643,124 & 118,424 \\
\hline R-squared & 0.027 & 0.029 & 0.036 & 0.025 & 0.028 & 0.035 \\
\hline City Controls & Yes & Yes & Yes & Yes & Yes & Yes \\
\hline Demographics & Yes & Yes & Yes & Yes & Yes & Yes \\
\hline \multirow[t]{4}{*}{ F-test of IVs } & 50.37 & 44.39 & 40.57 & 38.94 & 33.08 & 34.42 \\
\hline & \multicolumn{6}{|c|}{ Dependent variable: Leave hukou city indicator } \\
\hline & \multicolumn{3}{|c|}{ Plants $>15$ yrs ago } & \multicolumn{3}{|c|}{ Plants $>20$ yrs ago } \\
\hline & Full sample & Low edu & High edu & Full sample & Low edu & High edu \\
\hline $\log (\mathrm{PM} 2.5)$ & $\begin{array}{c}0.0920^{* *} \\
(0.0397)\end{array}$ & $\begin{array}{c}0.0762^{*} \\
(0.0432)\end{array}$ & $\begin{array}{c}0.150^{* * * *} \\
(0.0401)\end{array}$ & $\begin{array}{c}0.111^{* * * *} \\
(0.0428)\end{array}$ & $\begin{array}{c}0.0992^{* *} \\
(0.0469)\end{array}$ & $\begin{array}{c}0.156^{* * *} \\
(0.0398)\end{array}$ \\
\hline Observations & 761,548 & 643,124 & 118,424 & 761,548 & 643,124 & 118,424 \\
\hline R-squared & 0.025 & 0.028 & 0.034 & 0.022 & 0.024 & 0.033 \\
\hline City Controls & Yes & Yes & Yes & Yes & Yes & Yes \\
\hline Demographics & Yes & Yes & Yes & Yes & Yes & Yes \\
\hline F-test of IVs & 42.63 & 35.28 & 42.99 & 37.18 & 30.87 & 38.36 \\
\hline
\end{tabular}

Notes: Individual level regressions across 332 cities. Cities affected by new plants included in sample (i.e. in the 'control' regions) so as to generate conservative estimates. Standard errors clustered at the hukou city level are reported in parentheses. Instrumental variables specification using the interaction between wind direction, distance to coal plant, and coal consumption at power plant. City controls include the log distance to Shanghai seaport to Tianjin seaport and to Shenzhen seaport. Demographics include age, age-squared, gender, marital status, and an urban hukou indicator. 
Table A7: Without Coal Producing Regions

\begin{tabular}{|c|c|c|c|}
\hline \multicolumn{4}{|c|}{ Dependent variable: Leave hukou city indicator } \\
\hline & Full sample & Low edu & High edu \\
\hline Log (PM2.5) & $\begin{array}{c}0.0921^{* * *} \\
(0.0349)\end{array}$ & $\begin{array}{c}0.0773^{* *} \\
(0.0375)\end{array}$ & $\begin{array}{c}0.148^{* * *} \\
(0.0345)\end{array}$ \\
\hline Observations & 722,306 & 609,605 & 112,701 \\
\hline R-squared & 0.024 & 0.026 & 0.034 \\
\hline City Controls & Yes & Yes & Yes \\
\hline Demographics & Yes & Yes & Yes \\
\hline F-test of IVs & 84.82 & 77.61 & 68.94 \\
\hline
\end{tabular}

Notes: Individual level regressions across 321 cities (we drop coal producing regions, like all cities in Shanxi province). Standard errors clustered at the hukou city level are reported in parentheses. Instrumental variables specification using the interaction between wind direction, distance to coal plant, and coal consumption at power plant. City controls include the log distance to Shanghai seaport, to Tianjin seaport and to Shenzhen seaport and to the nearest big city. Demographics include age, age-squared, gender, marital status, and an urban hukou indicator.

variation in wind direction across locations. Wind direction is determined by nature and is stable over long periods of time, thus it can be considered as exogenous to local economies.

Table A8: Decomposing the Wind Direction IV

\begin{tabular}{|c|c|c|c|c|c|c|c|c|c|}
\hline & \multicolumn{9}{|c|}{ Dependent variable: Leave hukou city indicator } \\
\hline & \multicolumn{3}{|c|}{ IV:Excluding distance } & \multicolumn{3}{|c|}{ IV:Excluding coal consumption } & \multicolumn{3}{|c|}{ IV:Excluding wind direction } \\
\hline & Full sample & Low edu & High edu & Full sample & Low edu & High edu & Full sample & Low edu & High edu \\
\hline $\log (\mathrm{PM} 2.5)$ & $\begin{array}{c}0.0943^{* *} \\
(0.0392)\end{array}$ & $\begin{array}{l}0.0785^{*} \\
(0.0424)\end{array}$ & $\begin{array}{c}0.163^{* * *} \\
(0.0392)\end{array}$ & $\begin{array}{c}0.0905^{* *} \\
(0.0358)\end{array}$ & $\begin{array}{c}0.0765^{* *} \\
(0.0385)\end{array}$ & $\begin{array}{c}0.144^{* * *} \\
(0.0350)\end{array}$ & $\begin{array}{c}0.0360 \\
(0.0343)\end{array}$ & $\begin{array}{c}0.0199 \\
(0.0378)\end{array}$ & $\begin{array}{c}0.0911^{* * * *} \\
(0.0330)\end{array}$ \\
\hline Observations & 761,548 & 643,124 & 118,424 & 761,548 & 643,124 & 118,424 & 761,548 & 643,124 & 118,424 \\
\hline R-squared & 0.025 & 0.027 & 0.031 & 0.025 & 0.028 & 0.035 & 0.029 & 0.029 & 0.043 \\
\hline City Controls & Yes & Yes & Yes & Yes & Yes & Yes & Yes & Yes & Yes \\
\hline Demographics & Yes & Yes & Yes & Yes & Yes & Yes & Yes & Yes & Yes \\
\hline F-test of IVs & 46.07 & 40.52 & 39.33 & 79.24 & 73.06 & 63.70 & 55.14 & 50.21 & 38.13 \\
\hline
\end{tabular}

Notes: Individual level regressions across 332 cities. Standard errors clustered at the hukou city level are reported in parentheses. Instrumental variables specification using the interaction between wind direction and coal consumption at power plant (first two columns), the interaction between wind direction and distance to plant (next two columns), and the interaction between distance to plant and coal consumption (last two columns). City controls include distance to Shanghai, Tianjin and Shenzhen seaports. Demographics include age, age-squared, gender, marital status, and an urban hukou indicator.

One concern with the exogeneity of wind direction is that the Chinese government might select thermal plant locations in a way that pollution did not travel to populated or politically important cities. If that were the case, coal-fired plants are less likely to be located upwind of such cities. In Table A9, we present the number of large-scale thermal plants located up wind of five largest metropolitan areas in 2014 along with their total coal consumption. Beijing and Tianjin are among the most populated and politically important cities in Northern China, but have high levels of pollution. There are 58 large scale coal-fired plants located upwind of Beijing, and 59 large scale thermal power plants located upwind of Tianjin. The total consumption of 
them is as large as 2372 million tons and 2123 million tons respectively. We also calculate the ratio of the upwind large thermal plants to the total number of large thermal plants. As presented in column 2, this ratio is $22.4 \%$ and $50.9 \%$ for Beijing and Tianjin, respectively. The mean of the ratio for all Chinese cities is $37.8 \%$, which is between the values in Beijing and Tianjin. This may suggest that the Chinese government does not necessarily locate the coal-fired plants away from populated or politically important cities.

Table A9: The Coal-fired Plants Located Upwind of Large metropolitans

\begin{tabular}{lcccc}
\hline \hline City & $\begin{array}{c}\text { Number of } \\
\text { Upwind Plants }\end{array}$ & $\begin{array}{c}\text { Ratio of } \\
\text { Upwind Plants }\end{array}$ & $\begin{array}{c}\text { Coal Consumption of } \\
\text { Upwind Plants }\end{array}$ & $\begin{array}{c}\text { Smallest Angle } \\
\text { of Plants }\end{array}$ \\
\hline Beijing & 58 & $22.41 \%$ & 2372 & 25 \\
Tianjin & 59 & $50.85 \%$ & 2123 & 26 \\
Shanghai & 62 & $1.61 \%$ & 2067 & 16 \\
Guangzhou & 30 & $16.67 \%$ & 899 & 22 \\
Shenzhen & 25 & $44.00 \%$ & 785 & 26 \\
National mean & 43.16 & $37.82 \%$ & 511 & 25 \\
\hline \hline
\end{tabular}

Notes: The statistics are calculated using the large-scale thermal power plants located outside a given city and within 500km. Following Freeman, Liang, Song, and Timmins (2019), we define the upwind region as a section of a circular buffer drawn at a distance of $500 \mathrm{~km}$ from a given city, and the angle between the section and the annual dominant wind direction of the city being at least 45 degrees.

To further test whether politicians avoid populated, politically important and rich cities when building new plants in a manner that simultaneously incorporates the interactions between wind direction, distance and coal consumption, we explore whether baseline city features predict newly built plants. In Table A10, we explore whether city-level characteristics in 2004 can predict (a) the ratio of upwind plants built after 2005, and (b) the IV based on plants built after 2005. We find no meaningful associations between these variables and possible predictors of a city's influence, like baseline populations, GDP, total electricity consumption and industrial electricity consumption. In the following section, we also show that our results are robust to excluding big cities and major provincial capitals (Table A17).

In Table A11, we construct placebo instruments, artificially changing the wind direction angle by 90 degrees, and then 180 degrees. The first two columns report the first stage results. As the angle is increased, the falsified instrument is less likely to predict PM2.5 or emigration.

Finally, we turn our attention to the thermal inversions IV, used extensively by researchers in many different contexts (Arceo et al., 2016; Chen et al., 2017; Hicks et al., 2015; Jans et al., 2014), and as such, been scrutinized thoroughly. Nonetheless, we examine whether lagged pollution levels can predict future levels of the strength of thermal inversions in Table A12. We fail to find any such meaningful associations. Furthermore, we also find that lagged inversions do not predict future inversions, suggesting that levels of auto-correlation in inversions are low, and we may consider the data generating process underlying inversions to be close to random. 
Table A10: Baseline Economy and the Wind Direction IV

\begin{tabular}{|c|c|c|c|c|}
\hline Dependent variable: & \multicolumn{2}{|c|}{ The ratio of upwind plants } & \multicolumn{2}{|c|}{ Wind direction and coal plants IV } \\
\hline Baseline Population & $\begin{array}{l}-0.0106 \\
(0.0309)\end{array}$ & $\begin{array}{l}-0.0132 \\
(0.0279)\end{array}$ & $\begin{array}{c}0.412 \\
(0.489)\end{array}$ & $\begin{array}{c}0.226 \\
(0.440)\end{array}$ \\
\hline Baseline GDP per capita & $\begin{array}{l}-0.0151 \\
(0.0302)\end{array}$ & $\begin{array}{l}-0.0231 \\
(0.0289)\end{array}$ & $\begin{array}{l}-0.132 \\
(0.526)\end{array}$ & $\begin{array}{l}-0.414 \\
(0.522)\end{array}$ \\
\hline Industrial Elec cons & $\begin{array}{c}0.0225 \\
(0.0224)\end{array}$ & & $\begin{array}{l}0.210 \\
(0.347)\end{array}$ & \\
\hline Baseline Elec cons & & $\begin{array}{c}0.0255 \\
(0.0178)\end{array}$ & & $\begin{array}{c}0.414 \\
(0.269)\end{array}$ \\
\hline Observations & 281 & 281 & 281 & 281 \\
\hline R-squared & 0.006 & 0.010 & 0.015 & 0.020 \\
\hline City Controls & Yes & Yes & Yes & Yes \\
\hline
\end{tabular}

Notes: City level regressions for 281 cities. We drop cities with missing values in baseline characteristics.

Dependent variables are based on plants built post 2005, independent variables are measured in the year 2004 . Standard errors clustered at the hukou city level are reported in parentheses. City controls include distance to Shanghai, Tianjin and Shenzhen seaports.

Table A11: Placebo Wind Directions

\begin{tabular}{|c|c|c|c|c|c|c|}
\hline & \multirow{3}{*}{\multicolumn{2}{|c|}{$\log (\mathrm{PM} 2.5)$}} & \multicolumn{4}{|c|}{ Leave hukou city indicator } \\
\hline & & & \multicolumn{2}{|c|}{ Coal IV Placebo (+90 degrees) } & \multicolumn{2}{|c|}{ Coal IV Placebo (+180 degrees) } \\
\hline & & & Low edu & High edu & Low edu & High edu \\
\hline $\log (\mathrm{PM} 2.5)$ & & & $\begin{array}{l}-0.0708 \\
(0.0594)\end{array}$ & $\begin{array}{c}0.0235 \\
(0.0518)\end{array}$ & $\begin{array}{l}-0.159 \\
(0.157)\end{array}$ & $\begin{array}{l}-0.0281 \\
(0.0760)\end{array}$ \\
\hline $\begin{array}{l}\text { Coal IV Placebo } \\
\text { (wind direction+90 degrees) }\end{array}$ & $\begin{array}{c}0.00957^{* *} \\
(0.00478)\end{array}$ & & & & & \\
\hline $\begin{array}{l}\text { Coal IV Placebo } \\
\text { (wind direction+180 degrees) }\end{array}$ & & $\begin{array}{c}0.00134 \\
(0.00173)\end{array}$ & & & & \\
\hline Observations & 332 & 332 & 643,124 & 118,424 & 643,124 & 118,424 \\
\hline R-squared & 0.376 & 0.365 & 0.011 & 0.044 & 0.000 & 0.038 \\
\hline City Controls & Yes & Yes & Yes & Yes & Yes & Yes \\
\hline Demographics & $\mathrm{N}$ & $\mathrm{N}$ & Yes & Yes & Yes & Yes \\
\hline F-test of IVs & & & 6.324 & 8.940 & 0.935 & 1.521 \\
\hline
\end{tabular}

Notes: Individual level regressions across 332 cities. Standard errors clustered at the hukou city level are reported in parentheses. Instrumental variables specification using the interaction between wind direction (falsified), distance to coal plant, and coal consumption at power plant. City controls include the log distance to Shanghai seaport, to Tianjin seaport, and to Shenzhen seaport. Demographics include age, age-squared, gender, marital status, and an urban hukou indicator. 
Table A12: Lagged Pollution and Thermal Inversions

\begin{tabular}{lccc}
\hline \hline & \multicolumn{3}{c}{ Dependent variable: Strength of inversions } \\
\cline { 2 - 4 } & & & \\
Lagged Log(PM2.5) & -11.68 & -11.79 & -11.38 \\
& $(12.88)$ & $(12.77)$ & $(12.80)$ \\
Lagged number of inversions & & & 0.241 \\
& & & $(0.181)$ \\
Lagged strength of inversions & & 0.0332 & -0.0373 \\
& & $(0.0330)$ & $(0.0774)$ \\
Observations & & & 3,652 \\
R-squared & 3,652 & 3,652 & 0.961 \\
City fixed effects & 0.961 & 0.961 & Yes \\
Year fixed effects & Yes & Yes & Yes \\
\hline \hline
\end{tabular}

Notes: Standard errors clustered at city level are reported in parentheses. City level regressions for 332 cities over 11 years (2005 to 2015). Specifications include city and year fixed effects.

\section{A.2 The Huai River Regression Discontinuity}

Between 1950-1980 China established coal-based free heating systems to residences and offices north of the Huai River. This policy had long lasting effects, as even today the heating systems are different between the northern and southern parts of the country. The north relies on coal boilers which releases a large amount of pollutants. Chen et al. (2013) examine the effects of this policy on life expectancy using a regression discontinuity design where they compare cities just north of the river to those just south of it.

Here, we leverage the same empirical setup to examine migration decisions. Figure A1 shows the RD graphs where the horizontal axis represents the distance between the city and the Huai river. In our top row we show the discontinuity in PM10 and PM2.5 levels. In the middle row, we look at out-migration decisions, and fail to find any meaningful changes in out-migration rates. In the bottom row, we look at in-migration rates, and find that only for the high-skill workforce, there is less in-migration in cities that have more pollution. This effect is statistically and economically meaningful in our RD regressions. We find no such differential response on in-migration for the low-skilled. 
Figure A1: The Huai River RD
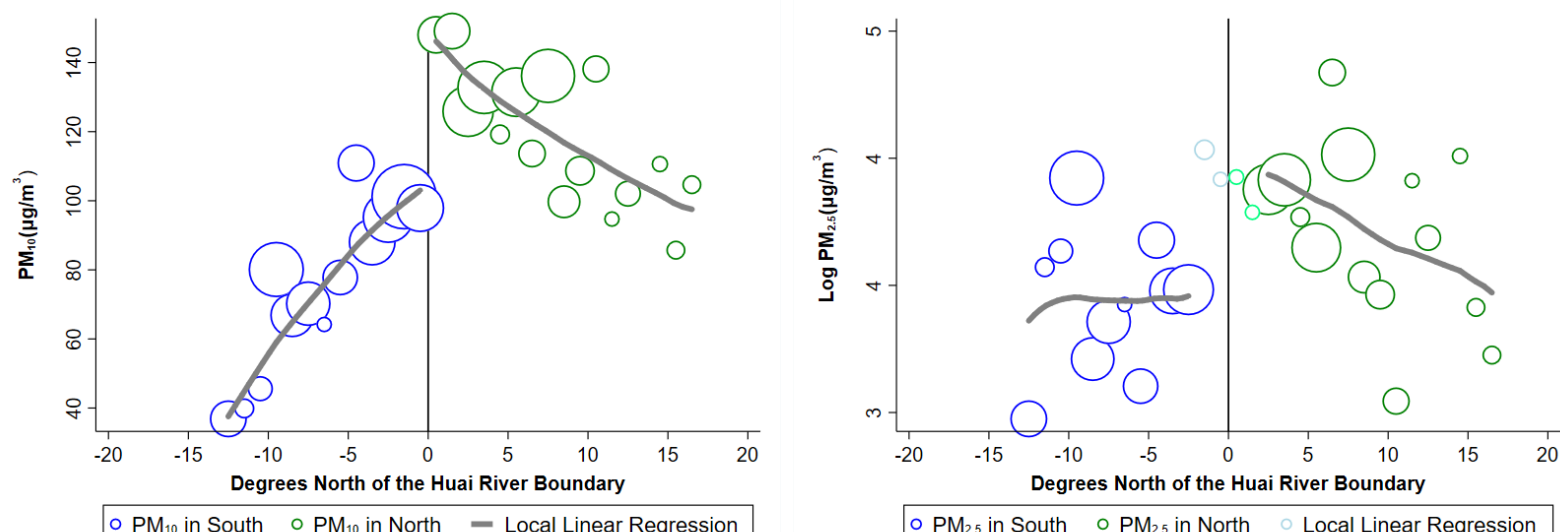

$\circ \mathrm{PM}_{2.5}$ in South $\circ \mathrm{PM}_{2.5}$ in North Local Linear Regression
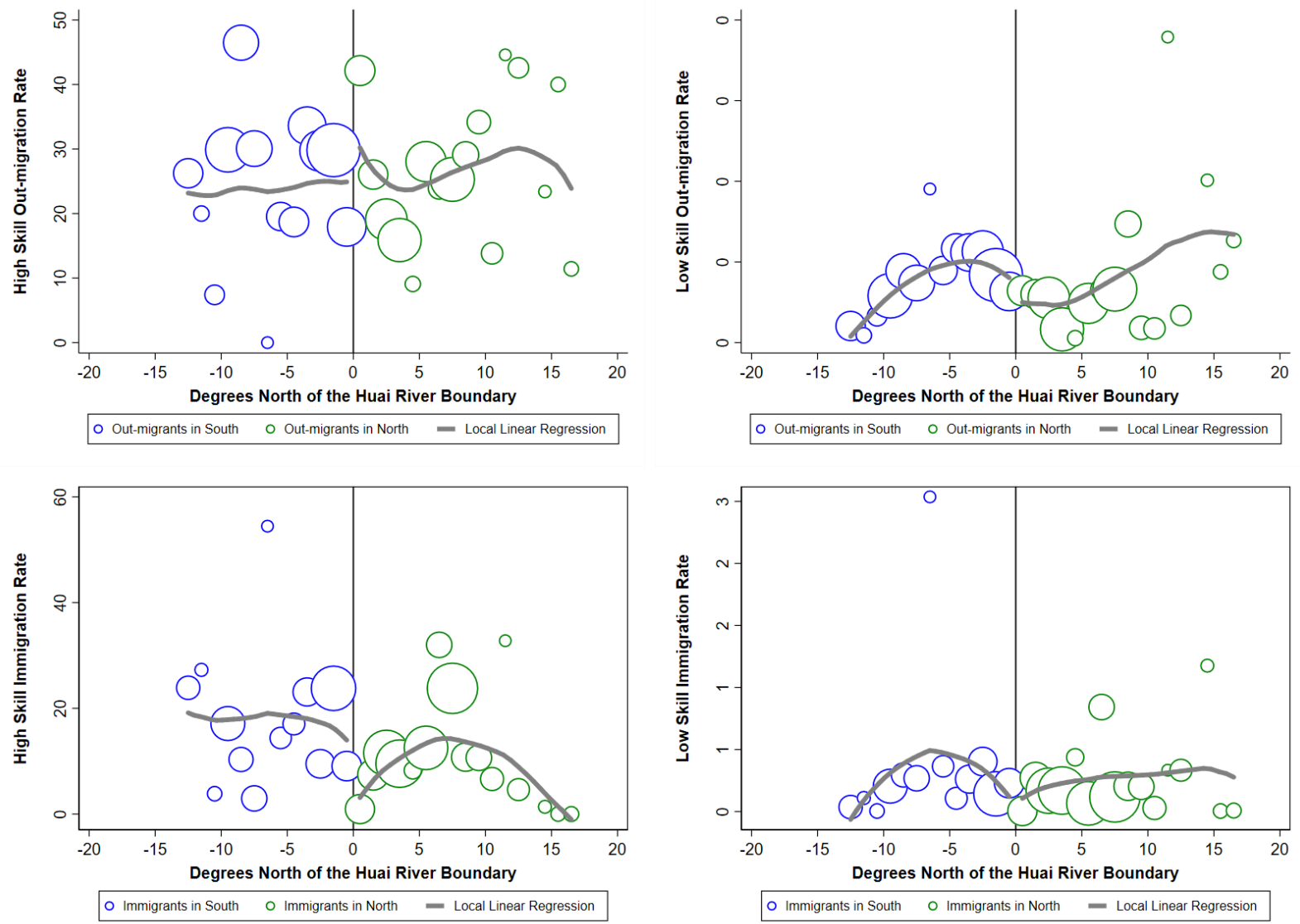

Notes: The top row shows the discontinuity in PM10 and PM2.5 at the Huai River. Second row shows the out-migration by skill level. Bottom row shows the in-migration rate by skill-level. Bubble sizes are baseline city populations. 


\section{A.3 Alternative Model Specifications, Controls and Samples}

In this section we examine different model specifications, sample restrictions and control variables. Once again, our aim is to test the robustness of our estimates to various empirical concerns.

First, we employ an individual-level longitudinal panel data to estimate the association between air quality and workers' spatial sorting. The longitudinal data allow us to track individuals over time and control for individual-level unobservables. Importantly, we use an alternative definition for migration status regardless of hukou location, and show results similar to before.

Then, we turn to the implications of cumulative pollution. We find that workers are more sensitive to cumulative pollution when they make location choices, compared to short-term pollution. Once again, the impacts of cumulative pollution are more pronounced for highskilled workers than their low-skilled counterparts.

In the section that follows thereafter, we use alternative samples to examine the effects of pollution on migration decisions. Using different samples does little to affect our empirical pattern. Our results are also robust to employing an alternative measure of local air quality.

Finally, we add a wide range of covariates that may confound the relationship between air quality and internal migration. Incorporating additional controls hardly change our results.

\section{A.3.1 Individual Longitudinal Panel and Alternative Definition of Migration}

We employ an individual-level longitudinal panel and a different definition of migration status to explore the spatial sorting of Chinese workers. We use an alternative data source, the China Labor-force Dynamic Survey (CLDS), which is a national social survey targeted at labor force dynamics in China. CLDS 2016 asks a retrospective history of locations for individuals. We use this retrospective location history to create an individual-level longitudinal panel between 2008 and 2016. Here, we define migration to be an indicator for whether or not an individual changed city location between years, regardless of whether they change their hukou location or not. The strengths of the individual-level panel lie in that it allows us to account for individual-specific unobservables and track those who have moved multiple times and who have moved and returned home. We combine the longitudinal data with annual information on PM2.5 at the city level.

Since data on large-scale coal-fired plants are not available for each year during the sample period, we employ the instrument of the number of thermal inversions to address the endogeneity of air pollution. Table A13 presents the IV estimation of the relationship between air pollution and the out-migration tendency of individuals, controlling for year- and individualfixed effects. Including individual-specific fixed effects allow us to account for individual-level unobservables (such as taste for clean air, individual preferences for a specific city) that may be systematically correlated with migration decisions. The results show that once again, the response of high-skill migration to air pollution is a lot stronger than that of low-skill workers. A $10 \%$ increase in PM2.5 raises out-migration rates by 2.19 percentage points for high-skilled workers.

In our main text, migrants are defined as those who are away from their hukou city. Under this definition, we may miss those who move to a different city and obtain local hukou in the city. Thus, we may understate high-skilled workers' migration response to pollution, as migrants with high education attainment find it easier to obtain local hukou than those without. We include both non-hukou migration (change residential locations without changing hukou locations) and hukou migration (change both residential and hukou location) in this definition of migration status. The effects on high-skill migration shown in Table A13 are larger in magnitude than 
Table A13: Individual Longitudinal Panel with Individual Fixed Effects

\begin{tabular}{|c|c|c|c|c|c|c|c|c|c|}
\hline & \multicolumn{9}{|c|}{ Dependent variable: Leave city location indicator } \\
\hline & Full sample & Low edu & High edu & Full sample & Low edu & High edu & Full sample & Low edu & High edu \\
\hline $\log (\mathrm{PM} 2.5)$ & $\begin{array}{l}0.115^{* *} \\
(0.0558)\end{array}$ & $\begin{array}{c}0.0812 \\
(0.0542)\end{array}$ & $\begin{array}{c}0.219^{* *} \\
(0.100)\end{array}$ & $\begin{array}{l}0.0960^{*} \\
(0.0540)\end{array}$ & $\begin{array}{c}0.0644 \\
(0.0525)\end{array}$ & $\begin{array}{l}0.193^{* *} \\
(0.0964)\end{array}$ & $\begin{array}{c}0.0774 \\
(0.0539)\end{array}$ & $\begin{array}{c}0.0385 \\
(0.0538)\end{array}$ & $\begin{array}{l}0.206^{* *} \\
(0.0972)\end{array}$ \\
\hline Observations & 122,841 & 104,184 & 18,657 & 122,841 & 104,184 & 18,657 & 122,841 & 104,184 & 18,657 \\
\hline Individual FE & Yes & Yes & Yes & Yes & Yes & Yes & Yes & Yes & Yes \\
\hline Year FE & Yes & Yes & Yes & Yes & Yes & Yes & Yes & Yes & Yes \\
\hline Weather Controls & No & No & No & Yes & Yes & Yes & No & No & No \\
\hline Regional trend & No & No & No & No & No & No & Yes & Yes & Yes \\
\hline Demographics & Yes & Yes & Yes & Yes & Yes & Yes & Yes & Yes & Yes \\
\hline F-test of IVs & 51.62 & 43.38 & 55.60 & 53.91 & 43.99 & 59.93 & 50.67 & 42.48 & 56.85 \\
\hline
\end{tabular}

Notes: Individual-level regressions across 277 cities and between 2008 and 2016. The CLDS asks a retrospective history of residential locations, which include 277 cities. Standard errors clustered at the city level are reported in parentheses. Instrumental variables specification using the number of thermal inversions. Demographics include age, age-squared. Weather controls include temperature, wind speed, sunshine duration and humidity. Region trend is a region-specific time trend.

our baseline estimates, perhaps as here we measure both hukou and non-hukou migration.

We control for weather amenities in the next three columns. The coefficient estimates are quantitatively and qualitatively similar. In China, migrant workers are more likely to move from the inland to coastal regions to gain access to better economic opportunities. As a result, the vast majority of migrants are concentrated in large coastal cities. To account for the potential role played by differential migration patterns between coastal and inland China, we further add region-specific trends in the last three columns. Including region-specific do not affect our results meaningfully.

\section{A.3.2 Accumulated Pollution over Time}

As migration decisions are long-lasting, we expect that people are more likely to response to accumulated pollution, compared to contemporaneous pollution shocks. While we measure outmigration in 2015, we wish to understand how migration decisions depend on the cumulative PM2.5 concentration over different time intervals. Since the large-scaled coal-fired power plants are essentially leveraging the cross-sectional nature of the data, we use the occurrence of thermal inversions averaged over different time periods to deal with the endogeneity of cumulative air pollution.

In Table A14, we use specifications where PM2.5 are averaged over 5, 10, 15 and 18 years, respectively, leading up to the migration decision. We find that the longer the time period of PM2.5 exposure, the larger is the response in small increments. As such, pollution exposure in a short time frame have a slightly smaller impact than the same amount of exposure spread out over a longer time period. Once again, we see similar empirical patterns as our baseline estimates. The effects of cumulative pollution on emigration are also more pronounced for skilled workers, relative to their unskilled counterparts.

In Table A15, we further add cumulative weather conditions that may confound the association between the thermal inversions IV and migration decisions. We consistently find stronger effects on out-migration for the higher educated group of workers. 
Table A14: PM2.5 Measured over Different Time Intervals

\begin{tabular}{|c|c|c|c|c|c|c|}
\hline & \multicolumn{6}{|c|}{ Dependent variable: Leave hukou city indicator } \\
\hline & Full sample & Low edu & High edu & Full sample & Low edu & High edu \\
\hline Log (Mean PM2.5: 1998-2015) & $\begin{array}{c}0.138^{* * *} \\
(0.0346)\end{array}$ & $\begin{array}{c}0.132^{* * *} \\
(0.0364)\end{array}$ & $\begin{array}{c}0.202^{* * *} \\
(0.0493)\end{array}$ & & & \\
\hline Log (Mean PM2.5: 2001-2015) & & & & $\begin{array}{c}0.134^{* * *} \\
(0.0334)\end{array}$ & $\begin{array}{c}0.128^{* * *} \\
(0.0352)\end{array}$ & $\begin{array}{c}0.195^{* * *} \\
(0.0473)\end{array}$ \\
\hline Observations & 761,548 & 643,124 & 118,424 & 761,548 & 643,124 & 118,424 \\
\hline R-squared & 0.015 & 0.017 & 0.019 & 0.016 & 0.018 & 0.021 \\
\hline City Controls & Yes & Yes & Yes & Yes & Yes & Yes \\
\hline Demographics & Yes & Yes & Yes & Yes & Yes & Yes \\
\hline \multirow[t]{3}{*}{ F-test of IVs } & 37.87 & 35.91 & 27.09 & 40.25 & 38.20 & 28.65 \\
\hline & \multicolumn{6}{|c|}{ Dependent variable: Leave hukou city indicator } \\
\hline & Full sample & Low edu & High edu & Full sample & Low edu & High edu \\
\hline Log (Mean PM2.5: 2006-2015) & $\begin{array}{c}0.126^{* * *} \\
(0.0310)\end{array}$ & $\begin{array}{c}0.120^{* * *} \\
(0.0326)\end{array}$ & $\begin{array}{c}0.185^{* * *} * \\
(0.0445)\end{array}$ & & & \\
\hline Log (Mean PM2.5: 2011-2015) & & & & $\begin{array}{c}0.117^{* * *} * \\
(0.0290)\end{array}$ & $\begin{array}{c}0.111^{* * *} \\
(0.0307)\end{array}$ & $\begin{array}{c}0.173^{* * *} \\
(0.0415)\end{array}$ \\
\hline Observations & 761,548 & 643,124 & 118,424 & 761,548 & 643,124 & 118,424 \\
\hline R-squared & 0.018 & 0.020 & 0.024 & 0.020 & 0.021 & 0.028 \\
\hline City Controls & Yes & Yes & Yes & Yes & Yes & Yes \\
\hline Demographics & Yes & Yes & Yes & Yes & Yes & Yes \\
\hline F-test of IVs & 41.72 & 39.68 & 30.12 & 42.11 & 40.08 & 31.10 \\
\hline
\end{tabular}

Notes: Individual level regressions across 332 cities. Instrumental variables using the number of thermal inversions averaged over different time intervals. Standard errors clustered at the hukou city level are reported in parentheses. City controls include distance to Shanghai, Tianjin and Shenzhen seaports. Demographics include age, age-squared, gender, marital status, and an urban hukou indicator.

\section{A.3.3 Alternative Samples, Controls and Alternative Measure of Air Quality}

In this section, we use different samples to explore the relationship between pollution and out-migration. We then use an alternative measure of air quality as your main independent variable.

First, we look at different ways to reformulate the estimation sample. In Table A16, instead of splitting up the sample into low and high skilled, we split it up into three categories: high school or below, those with some college education, and those with college or above education. A steep education gradient is apparent, where the elasticity of migration with respect to PM2.5 is higher for higher levels of education.

We next examine whether big cities, high polluting cities, or major province capitals are driving our results. We do this by excluding such cities one at a time in Table A17. This may help allay concerns about the influence of major cities or province capitals in pollution policy, placement of plants, or being outliers in terms of pollutants and/or skilled jobs.

We further conduct heterogeneity analysis. In Table A18, we split up the sample into two age groups. We see that the implications of pollution on emigration are stronger for younger workers. There are two reasons for the differential migration pattern by age. First, young people may have lower mobility costs than their older counterparts. Second, they may have better knowledge about the adverse effects of air pollution.

In Table A19 we split up the sample by rural and urban origin locations. We find that the elasticity for high-skill out-migration is larger in rural areas than it is in urban areas. 
Table A15: PM2.5 Measured over Different Time Intervals: Controlling for Weather Conditions

\begin{tabular}{|c|c|c|c|c|c|c|}
\hline & \multicolumn{6}{|c|}{ Dependent variable: Leave hukou city indicator } \\
\hline & Full sample & Low edu & High edu & Full sample & Low edu & High edu \\
\hline Log (Mean PM2.5: 1998-2015) & $\begin{array}{c}0.113^{* * *} \\
(0.0236)\end{array}$ & $\begin{array}{c}0.104^{* * *} \\
(0.0235)\end{array}$ & $\begin{array}{c}0.173 * * * \\
(0.0394)\end{array}$ & & & \\
\hline Log (Mean PM2.5: 2001-2015) & & & & $\begin{array}{c}0.107^{* * *} \\
(0.0230)\end{array}$ & $\begin{array}{c}0.0979 * * * \\
(0.0231)\end{array}$ & $\begin{array}{c}0.168^{* * *} \\
(0.0387)\end{array}$ \\
\hline Observations & 761,548 & 643,124 & 118,424 & 761,548 & 643,124 & 118,424 \\
\hline R-squared & 0.032 & 0.036 & 0.029 & 0.032 & 0.036 & 0.031 \\
\hline City Controls & Yes & Yes & Yes & Yes & Yes & Yes \\
\hline Demographics & Yes & Yes & Yes & Yes & Yes & Yes \\
\hline \multirow[t]{3}{*}{ F-test of IVs } & 65.36 & 63.86 & 44.57 & 68.08 & 66.49 & 45.59 \\
\hline & \multicolumn{6}{|c|}{ Dependent variable: Leave hukou city indicator } \\
\hline & Full sample & Low edu & High edu & Full sample & Low edu & High edu \\
\hline Log (Mean PM2.5: 2006-2015) & $\begin{array}{c}0.122^{* * *} \\
(0.0264)\end{array}$ & $\begin{array}{c}0.114^{* * *} \\
(0.0273)\end{array}$ & $\begin{array}{c}0.167^{* * *} \\
(0.0359)\end{array}$ & & & \\
\hline Log (Mean PM2.5: 2011-2015) & & & & $\begin{array}{c}0.0913^{* * *} \\
(0.0220)\end{array}$ & $\begin{array}{c}0.0850 * * * \\
(0.0231)\end{array}$ & $\begin{array}{c}0.129 * * * \\
(0.0297)\end{array}$ \\
\hline Observations & 761,548 & 643,124 & 118,424 & 761,548 & 643,124 & 118,424 \\
\hline R-squared & 0.023 & 0.026 & 0.031 & 0.033 & 0.035 & 0.043 \\
\hline City Controls & Yes & Yes & Yes & Yes & Yes & Yes \\
\hline Demographics & Yes & Yes & Yes & Yes & Yes & Yes \\
\hline F-test of IVs & 80.66 & 78.19 & 57.01 & 91.53 & 87.48 & 71.38 \\
\hline
\end{tabular}

Notes: Individual level regressions across 332 cities. Instrumental variables using the number of thermal inversions averaged over different time intervals. Standard errors clustered at the hukou city level are reported in parentheses. City controls include distance to Shanghai, Tianjin and Shenzhen seaports. Demographics include age, age-squared, gender, marital status, and an urban hukou indicator. Weather controls include temprature, humidity, sunshine duration and wind speed averaged over different time intervals.

Finally, we turn our attention to an alternative measure of local air quality. As sources of pollution affect not just PM2.5 but also other pollutants, we may be picking up the combined impact of many pollutants. Recall that Air Quality Index (AQI) is an overall indicator for air pollution concentration calculated using multiple atmospheric pollutants including SO2, NO2, PM10, PM2.5, O3 and CO. Furthermore, the AQI is officially reported and widely disseminated, and certain individuals may be more likely to respond to it. As shown in Table A20, our empirical pattern are robust to using the AQI as our independent variable of interest.

\section{A.3.4 Additional Controls}

In this section, we include various sets of controls that may confound the association between local air pollution and migration decisions. In the first few columns of Table A21 Panel A, we account for other determinants of the demand for skilled work at baseline. We do this to check whether the potential for skilled work just so happens to be in places that are correlated with skill-specific migration. We find our estimates display similar patterns as before if we add controls for the teacher-student ratio, the number of hospitals and doctors per capita in 2000.

In the next three columns of Table A21 Panel A, we include controls for local economic production in 2000. Our economic controls include baseline measures of GDP per capita, as well as the ratio of product values of services and manufacturing as proxies for the industrial structure. Our results are not meaningfully affected by these controls. 
Table A16: Disaggregated Education Levels

\begin{tabular}{lccc}
\hline \hline & \multicolumn{2}{c}{ Dependent variable: Leave hukou city indicator } \\
& High school or below & Some college & College or above \\
\hline Log (PM2.5) & 0.0609 & $0.116^{* * *}$ & $0.176^{* * *}$ \\
& $(0.0423)$ & $(0.0401)$ & $(0.0409)$ \\
Observations & 643,124 & 64,598 & 53,826 \\
R-squared & 0.029 & 0.041 & 0.031 \\
City Controls & Yes & Yes & Yes \\
Demographics & Yes & Yes & Yes \\
F-test of IVs & 46.52 & 44.18 & 34.59 \\
\hline \hline
\end{tabular}

Notes: Individual level regressions across 332 cities. Standard errors clustered at the individual level are reported in parentheses. Instrumental variables specification using the interaction between wind direction, distance to coal plant, and coal consumption at power plant. City controls include distance to Shanghai, Tianjin and Shenzhen seaports. Demographics include age, age-squared, gender, marital status, and an urban hukou indicator.

Table A17: Without Big Cities, High Polluters and Major Province Capitals

\begin{tabular}{|c|c|c|c|c|c|c|c|c|c|}
\hline & \multicolumn{3}{|c|}{ Exclude Beijing } & \multicolumn{3}{|c|}{ Exclude Tianjin } & \multicolumn{3}{|c|}{ Exclude Shijiazhuang } \\
\hline & Full sample & Low edu & High edu & Full sample & Low edu & High edu & Full sample & Low edu & High edu \\
\hline $\log (\mathrm{PM} 2.5)$ & $\begin{array}{l}0.0761^{*} \\
(0.0389)\end{array}$ & $\begin{array}{c}0.0609 \\
(0.0424)\end{array}$ & $\begin{array}{c}0.132^{* * *} \\
(0.0369)\end{array}$ & $\begin{array}{l}0.142^{* *} \\
(0.0556)\end{array}$ & $\begin{array}{l}0.129 * * \\
(0.0619)\end{array}$ & $\begin{array}{c}0.180^{* * *} \\
(0.0487)\end{array}$ & $\begin{array}{c}0.0783^{* *} \\
(0.0393)\end{array}$ & $\begin{array}{c}0.0623 \\
(0.0426)\end{array}$ & $\begin{array}{c}0.140^{* * *} \\
(0.0390)\end{array}$ \\
\hline Observations & 752,993 & 638,529 & 114,464 & 745,903 & 632,324 & 113,579 & 758,412 & 640,631 & 117,781 \\
\hline R-squared & 0.027 & 0.029 & 0.038 & 0.017 & 0.021 & 0.026 & 0.027 & 0.029 & 0.036 \\
\hline City Controls & Yes & Yes & Yes & Yes & Yes & Yes & Yes & Yes & Yes \\
\hline Demographics & Yes & Yes & Yes & Yes & Yes & Yes & Yes & Yes & Yes \\
\hline \multirow[t]{3}{*}{ F-test of IVs } & 52.58 & 46.35 & 42.31 & 31.46 & 27.67 & 29.28 & 51.78 & 45.94 & 40.28 \\
\hline & \multicolumn{3}{|c|}{ Exclude Shenyang } & \multicolumn{3}{|c|}{ Exclude Zhengzhou } & \multicolumn{3}{|c|}{ Exclude Wuhan } \\
\hline & Full sample & Low edu & High edu & Full sample & Low edu & High edu & Full sample & Low edu & High edu \\
\hline Log (PM2.5) & $\begin{array}{c}0.0766^{* *} \\
(0.0387)\end{array}$ & $\begin{array}{c}0.0605 \\
(0.0421)\end{array}$ & $\begin{array}{c}0.138^{* * *} \\
(0.0377)\end{array}$ & $\begin{array}{c}0.0816^{* *} \\
(0.0397)\end{array}$ & $\begin{array}{c}0.0641 \\
(0.0431)\end{array}$ & $\begin{array}{c}0.155^{* * *} \\
(0.0377)\end{array}$ & $\begin{array}{c}0.0775^{* *} \\
(0.0392)\end{array}$ & $\begin{array}{c}0.0612 \\
(0.0425)\end{array}$ & $\begin{array}{c}0.141^{* * *} \\
(0.0390)\end{array}$ \\
\hline Observations & 758,589 & 641,096 & 117,493 & 754,535 & 637,980 & 116,555 & 758,065 & 640,833 & 117,232 \\
\hline R-squared & 0.027 & 0.029 & 0.037 & 0.027 & 0.029 & 0.035 & 0.027 & 0.029 & 0.036 \\
\hline City Controls & Yes & Yes & Yes & Yes & Yes & Yes & Yes & Yes & Yes \\
\hline Demographics & Yes & Yes & Yes & Yes & Yes & Yes & Yes & Yes & Yes \\
\hline F-test of IVs & 53.42 & 47.25 & 42.65 & 51.02 & 45.21 & 40.14 & 52.22 & 46.37 & 40.90 \\
\hline
\end{tabular}

Notes: Individual level regressions across 331 cities (we exclude one big city at a time). Standard errors clustered at the hukou city level are reported in parentheses. Instrumental variables specification using the interaction between wind direction, distance to coal plant, and coal consumption at power plant. City controls include distance to Shanghai, Tianjin and Shenzhen seaports. Demographics include age, age-squared, gender, marital status, and an urban hukou indicator. 
Table A18: By Age Groups

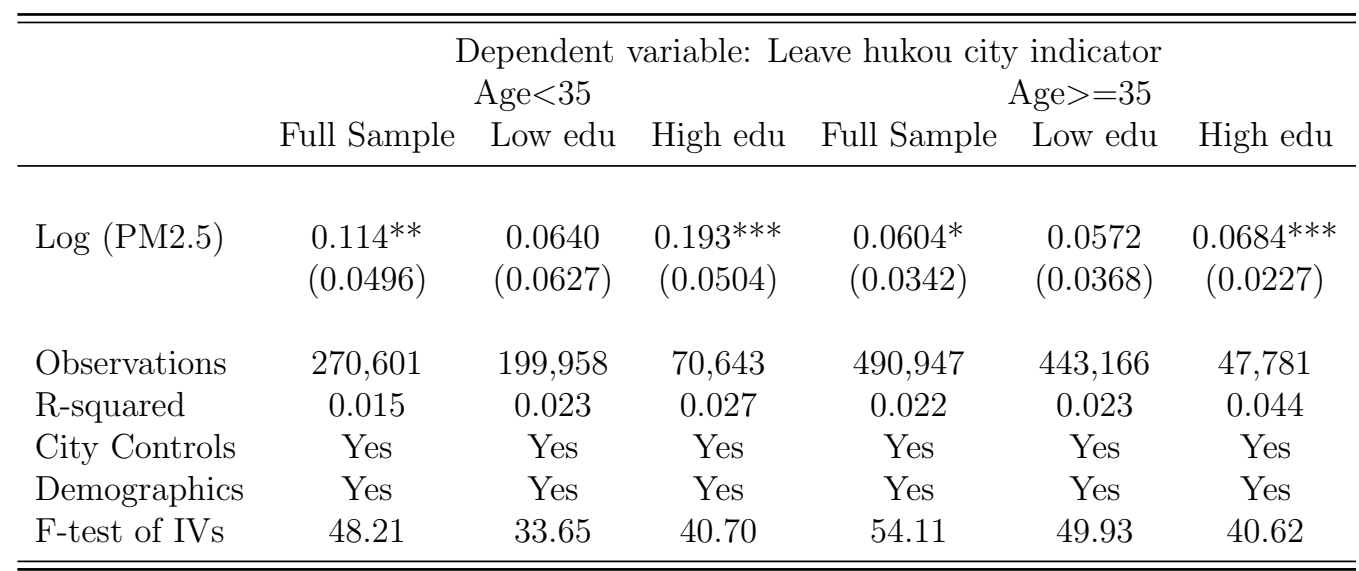

Notes: Individual level regressions across 332 cities. Standard errors clustered at the hukou city level are reported in parentheses. Instrumental variables specification using the interaction between wind direction, distance to coal plant, and coal consumption at power plant. City controls include distance to Shanghai, Tianjin and Shenzhen seaports. Demographics include age, age-squared, gender, marital status, and an urban hukou indicator.

Table A19: Urban vs Rural Outmigration

\begin{tabular}{lcccccc}
\hline \hline \multicolumn{7}{c}{ Dependent variable: Leave hukou city indicator } \\
& \multicolumn{7}{c}{ Rural hukou } \\
& Full sample & Low edu & High edu & Full sample & Low edu & High edu \\
\hline Log (PM2.5) & $0.0589^{* *}$ & 0.0386 & $0.110^{* * *}$ & $0.106^{*}$ & 0.0899 & $0.342^{* * *}$ \\
& $(0.0283)$ & $(0.0299)$ & $(0.0313)$ & $(0.0641)$ & $(0.0647)$ & $(0.0932)$ \\
& & & & & & \\
Observations & 401,351 & 302,344 & 99,007 & 360,197 & 340,780 & 19,417 \\
R-squared & 0.020 & 0.025 & 0.012 & 0.030 & 0.030 & 0.027 \\
City Controls & Yes & Yes & Yes & Yes & Yes & Yes \\
Demographics & Yes & Yes & Yes & Yes & Yes & Yes \\
F-test of IVs & 58.20 & 58.24 & 38.10 & 30.70 & 28.98 & 35.71 \\
\hline \hline
\end{tabular}

Notes: Individual level regressions across 332 cities. Standard errors clustered at the hukou city level are reported in parentheses. Instrumental variables specification using the interaction between wind direction, distance to coal plant, and coal consumption at power plant. City controls include distance to Shanghai, Tianjin and Shenzhen seaports. Demographics include age, age-squared, gender, marital status, and an urban hukou indicator. 
Table A20: Air Quality Index

\begin{tabular}{lccc}
\hline \hline \multicolumn{4}{c}{ Dependent variable: Leave hukou city indicator } \\
& Full sample & Low edu & High edu \\
\hline \multirow{4}{*}{ Log (AQI) } & 0.0795 & 0.0581 & $0.176^{* *}$ \\
& $(0.0659)$ & $(0.0682)$ & $(0.0736)$ \\
& & & \\
Observations & 708,482 & 595,958 & 112,524 \\
R-squared & 0.025 & 0.027 & 0.035 \\
City Controls & Yes & Yes & Yes \\
Demographics & Yes & Yes & Yes \\
F-test of IVs & 36.16 & 34.99 & 29.59 \\
\hline \hline
\end{tabular}

Notes: Individual level regressions across 238 cities that report AQI in 2014. Independent variable is Log (Annual mean Air Quality Index). Standard errors clustered at the hukou city level are reported in parentheses. Instrumental variables specification using the interaction between wind direction, distance to coal plant, and coal consumption at power plant. City controls include the log distance to Shanghai seaport, to Tianjin seaport, and to Shenzhen seaport. Demographics include age, age-squared, gender, marital status, and an urban hukou indicator.

Fine particle concentration tends to be correlated with local industrial pollutant emissions. To account for the potential role played local industrial emissions, we add industrial SO2 emission, waste water emission and dust emission as covariates in last three columns of Table A21 Panel A. The inclusion of these industrial emissions does little to affect the impacts of PM2.5 concentration.

In the first three columns of Panel B, we start with all three sets of controls that we have in Panel A entered simultaneously. After which, we address the concern that power plants may be built near cities that require more electricity. Even though those plants supply electricity to vast areas of China including many remote provinces (Freeman, Liang, Song, and Timmins, 2019), we examine this concern by controlling for city-level electricity consumption. We include total (industrial, commercial and residential) electricity consumption in the next three columns of Table A21 Panel B, and add industrial electricity consumption in the last three columns. Accounting for city-level electricity consumption barely changes our empirical patterns. 
Table A21: Additional Control Variables

\begin{tabular}{|c|c|c|c|c|c|c|c|c|c|}
\hline \multirow{3}{*}{$\begin{array}{l}\text { Panel A } \\
\text { Additional Controls: }\end{array}$} & \multicolumn{9}{|c|}{ Dependent variable: Leave hukou city indicator } \\
\hline & \multicolumn{3}{|c|}{ Baseline skill controls } & \multicolumn{3}{|c|}{ Baseline economy controls } & \multicolumn{3}{|c|}{ Industrial emmisions controls } \\
\hline & Full Sample & Low edu & High edu & Full Sample & Low edu & High edu & Full Sample & Low edu & High edu \\
\hline Log (PM2.5) & $\begin{array}{c}0.0712 \\
(0.0433)\end{array}$ & $\begin{array}{c}0.0592 \\
(0.0466)\end{array}$ & $\begin{array}{c}0.124^{* * *} \\
(0.0427)\end{array}$ & $\begin{array}{c}0.0403 \\
(0.0422)\end{array}$ & $\begin{array}{c}0.0251 \\
(0.0454)\end{array}$ & $\begin{array}{c}0.0984^{* *} \\
(0.0444)\end{array}$ & $\begin{array}{c}0.0539 \\
(0.0435)\end{array}$ & $\begin{array}{c}0.0396 \\
(0.0470)\end{array}$ & $\begin{array}{c}0.119^{* * *} \\
(0.0373)\end{array}$ \\
\hline Observations & 674,032 & 565,239 & 108,793 & 674,032 & 565,239 & 108,793 & 674,032 & 565,239 & 108,793 \\
\hline R-squared & 0.036 & 0.037 & 0.048 & 0.038 & 0.038 & 0.053 & 0.033 & 0.033 & 0.051 \\
\hline City Controls & Yes & Yes & Yes & Yes & Yes & Yes & Yes & Yes & Yes \\
\hline Demographics & Yes & Yes & Yes & Yes & Yes & Yes & Yes & Yes & Yes \\
\hline F-test of IVs & 55.68 & 53.73 & 33.41 & 51.43 & 48.91 & 33.90 & 60.76 & 59.45 & 36.89 \\
\hline Panel B & \multicolumn{9}{|c|}{ Dependent variable: Leave hukou city indicator } \\
\hline Additional Controls: & \multicolumn{6}{|c|}{ All 3 sets + Total elec cons } & \multicolumn{3}{|c|}{ All $3+$ Industry elec cons } \\
\hline & Full Sample & Low edu & High edu & Full Sample & Low edu & High edu & Full Sample & Low edu & High edu \\
\hline $\log ($ PM2.5) & $\begin{array}{c}0.0756^{* *} \\
(0.0343)\end{array}$ & $\begin{array}{l}0.0677^{*} \\
(0.0362)\end{array}$ & $\begin{array}{c}0.109^{* * *} \\
(0.0335)\end{array}$ & $\begin{array}{l}0.0653^{*} \\
(0.0369)\end{array}$ & $\begin{array}{c}0.0587 \\
(0.0393)\end{array}$ & $\begin{array}{c}0.0959^{* * *} \\
(0.0346)\end{array}$ & $\begin{array}{l}0.0643^{*} \\
(0.0358)\end{array}$ & $\begin{array}{c}0.0574 \\
(0.0380)\end{array}$ & $\begin{array}{c}0.0972^{* * *} \\
(0.0338)\end{array}$ \\
\hline Observations & 674,032 & 565,239 & 108,793 & 650,828 & 544,681 & 106,147 & 650,828 & 544,681 & 106,147 \\
\hline R-squared & 0.047 & 0.050 & 0.060 & 0.049 & 0.051 & 0.063 & 0.049 & 0.052 & 0.063 \\
\hline City Controls & Yes & Yes & Yes & Yes & Yes & Yes & Yes & Yes & Yes \\
\hline Demographics & Yes & Yes & Yes & Yes & Yes & Yes & Yes & Yes & Yes \\
\hline F-test of IVs & 58.67 & 58.10 & 34.15 & 53.59 & 52.68 & 31.95 & 54.78 & 54.32 & 31.76 \\
\hline
\end{tabular}

Notes: Individual level regressions across 261 cities in Panel A, and columns 1-3 of Panel B (cities for which we have measures of the controls). Individual-level regressions across the 253 cities for which we have electricity consumption data and the full set of city controls, in columns 4-9 of Panel B. Standard errors clustered at the hukou city level are reported in parentheses. Instrumental variables specification using the interaction between wind direction, distance to coal plant, and coal consumption at power plant. Baseline skill controls include teacher student ratio, log hospitals per capita and log doctors per capita in 2000. Baseline economy controls include log GDP per capita and industrial structure (the product value at service sector / manufacture sector). Industrial emissions controls include log industrial SO2 emission, log industrial waste water emission and log industrial dust emission. City controls include distance to Shanghai, Tianjin and Shenzhen seaports. Demographics include age, age-squared, gender, marital status, and an urban hukou indicator. Total electricity consumption includes industrial, residential and commercial consumption. 


\section{B Air Pollution Data Disclosure in China}

Despite hazardous levels of pollution, Chinese citizens used to have limited or no access to information about local air quality. Since 2000, the Chinese government released air pollution data in two waves: First, in 2000, the government started publishing air quality data, including an Air Pollution Index (API) and PM10, but only for 42 cities. Although fine particles (i.e. PM2.5) are more hazardous than larger particles (i.e. PM10) with respect to mortality, cardiovascular and respiratory endpoints, PM2.5 was not included in the API. The number of cities in which API and PM10 were available increased to 120 in 2012.

Figure B1: The Number of Air Purifier Sales from 2006 to 2014

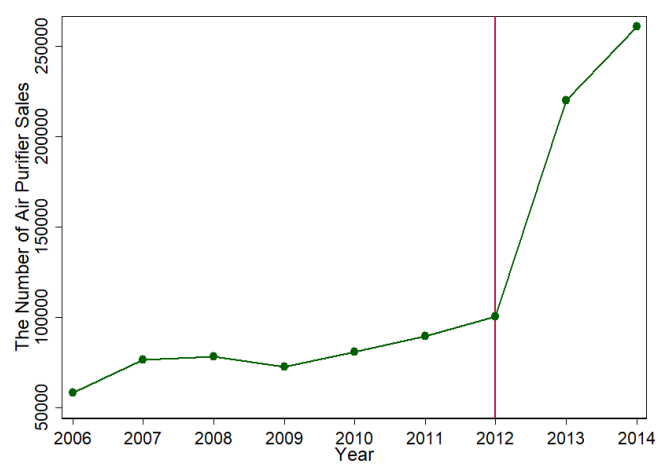

Notes: Air purifier sales transaction data collected by a marketing firm in China from January 2006 through December 2014 for 85 major Chinese cities.

Second, in response to public demand for the publication of PM2.5 data, the Chinese government started to disclose real time PM2.5 data in most Chinese cities from 2012. Information on real time PM2.5 was made available in all Chinese cities by January 1, 2015.

Table B1: PM2.5 Data Disclosure and Outmigration

\begin{tabular}{|c|c|c|c|c|c|c|}
\hline \multirow[t]{2}{*}{ Dependent variable: } & \multicolumn{6}{|c|}{ Leave city location indicator } \\
\hline & Full sample & Low edu & High edu & Full sample & Low edu & High edu \\
\hline $\log (\mathrm{PM} 2.5)_{o t} \times$ Data disclosed indicator ${ }_{o t}$ & $\begin{array}{c}0.000902 \\
(0.00147)\end{array}$ & $\begin{array}{r}-0.000585 \\
(0.00139)\end{array}$ & $\begin{array}{c}0.0106^{* *} \\
(0.00495)\end{array}$ & $\begin{array}{c}0.000997 \\
(0.00143)\end{array}$ & $\begin{array}{r}-0.000482 \\
(0.00130)\end{array}$ & $\begin{array}{c}0.0105^{* *} \\
(0.00488)\end{array}$ \\
\hline Observations & 122,841 & 104,184 & 18,657 & 122,841 & 104,184 & 18,657 \\
\hline Individual FE & Yes & Yes & Yes & Yes & Yes & Yes \\
\hline Year FE & Yes & Yes & Yes & Yes & Yes & Yes \\
\hline Demographics & Yes & Yes & Yes & Yes & Yes & Yes \\
\hline Regional trend & No & No & No & Yes & Yes & Yes \\
\hline
\end{tabular}

Notes: Individual-level regressions across 277 cities. The CLDS lists the history of residential locations, which include 277 cities. Standard errors clustered at the city level. Demographics include age, age-squared. We control for the log of PM2.5 and an indicator for PM2.5 data disclosure. Data disclosure indicator=1 if PM2.5 data was officially made available in a given city-year, $=0$ otherwise.

The disclosure of pollution information had an important effect on household avoidance behavior. Figure B1 shows how the sales of indoor air filtration increased sharply in response to the PM2.5 data disclosure in 2012. Table B1 shows that PM2.5 data disclosure had significant impacts on the out-migration of the high-skilled. 


\section{Additional Tables and Figures}

Table C1: Summary Statistics

\begin{tabular}{llcc}
\hline \hline \multicolumn{1}{c}{ Variable name } & \multicolumn{1}{c}{ Description } & Mean & Std. dev \\
\hline \multirow{2}{*}{$\begin{array}{llc}\text { Out migration } \\
\text { Female }\end{array}$} & $\begin{array}{l}\text { Indicator=1 if the person left his/her hukou } \\
\text { city for more than } 6 \text { month, }=0 \text { otherwise }\end{array}$ & 0.10 & 0.30 \\
Age & Indicator=1 if the person is female & 0.50 & 0.50 \\
Urban hukou & Indicator =1 if the person holds & 39.87 & 10.99 \\
& urban hukou, =0 otherwise & 0.53 & 0.50 \\
Married & Indicator =1 if the person is married & & \\
High-skill & Indicator=1 if the highest degree is & 0.82 & 0.39 \\
& some college or above, =0 otherwise & 0.16 & 0.36 \\
\hline $\begin{array}{l}\text { Pollution Levels } \\
\text { GDP per capita }\end{array}$ & Annual PM2.5 concentration & 38.95 & 16.67 \\
Distance to Tianjin seaport & & 81002.09 & 61579.87 \\
Distance to Shanghai seaport & & 1223.47 & 677.02 \\
Distance to Shenzhen seaport & & 1289.79 & 758.51 \\
Temperature & & 1470.92 & 835.869 \\
Wind speed & Annual mean temperature & 141.79 & 54.60 \\
Huminity & Annual mean wind speed & 45.47 & 336.07 \\
Sunshine duration & Annual mean huminity & 66.98 & 11.91 \\
\hline \hline
\end{tabular}

Note: Table shows summary statistics for most outcomes, control variables, and determinants of the different samples. In most regressions we control for distance to the three largest seaports: Tianjin seaport, Shanghai seaport, and Shenzhen seaport. These seaports are located at the three major economic circles of China: Beijing-Tianjin-Hebei Metropolitan Region, The Yangtze River Delta, the Pearl River Delta.

Table C2: Examples of the Points-based Hukou Policy Across Chinese Cities

\begin{tabular}{|c|c|c|c|c|}
\hline City & Beijing & Shanghai & Guangzhou & Shenzhen \\
\hline Total hukou points needed & Varies & 72 & 60 & 100 \\
\hline Education & $\begin{array}{l}\text { Doctoral degree: } 37 \text { points } \\
\text { Master degree: } 26 \text { points } \\
\text { Bachelor degree: } 15 \text { points } \\
\text { Some college: } 10.5 \text { points }\end{array}$ & $\begin{array}{l}\text { Doctoral degree: } 27 \text { points } \\
\text { Master degrees: } 24 \text { points } \\
\text { Bachelor degree: } 21 \text { points }\end{array}$ & $\begin{array}{l}\text { Above college: } 60 \text { points } \\
\text { Some college: } 40 \text { points } \\
\text { High school: } 40 \text { points }\end{array}$ & $\begin{array}{l}\text { Doctoral degree: } 100 \text { points } \\
\text { Master degrees: } 90 \text { points } \\
\text { Bachelor degree: } 80 \text { points } \\
\text { College: } 60 \text { points }\end{array}$ \\
\hline Skills & & $\begin{array}{l}\text { College English Test 6-8: } 8 \text { points } \\
\text { College English Test 4: } 7 \text { points }\end{array}$ & $\begin{array}{l}\text { Junior workers: } 10 \text { points } \\
\text { Middle-level workers: } 30 \text { points } \\
\text { High-level workers: } 50 \text { points }\end{array}$ & $\begin{array}{l}\text { Junior workers: } 20 \text { points } \\
\text { Middle-level workers: } 40 \text { points } \\
\text { High-level workers: } 70 \text { points } \\
\text { Senior technical worker: } 100 \text { points } \\
\text { Junior professional: } 70 \text { points } \\
\text { Middle professional: } 90 \text { points } \\
\text { Senior professional: } 100 \text { points }\end{array}$ \\
\hline
\end{tabular}

Note: Table shows a few examples of hukou requirements for city workers. Authors' calculations using the official government websites of the Beijing, Shanghai, Guangzhou and Shenzen. 'Total hukou points needed' show the number of points required to obtain local hukou, whereas the lower rows show how different qualifications add to the individual's points. 
Table C3: Preferences for Environmental Issues by Education Levels

\begin{tabular}{lc}
\hline \hline Dependent Variable: The Environmental issue in China is Terrible \\
\hline High school & $0.133^{* * *}$ \\
& $(0.0122)$ \\
& $0.176^{* * *}$ \\
Some college or above & $(0.0145)$ \\
& 0.002 \\
p-values & -3.17 \\
t-values & 0.549 \\
The average value for below high school & $\mathrm{Y}$ \\
Demographics & $\mathrm{Y}$ \\
City FE & 24538 \\
$\mathrm{~N}$ & 0.115 \\
adj. R2 & \\
\hline \hline
\end{tabular}

Note: Individual level regressions from 113 cities. Demographic controls include age, age-squared, gender, marital status and an indicator for urban hukou. The data source is the China Household Panel Survey 2016 (CFPS). In the CFPS 2016, there is a survey question: In your opinion, how terrible the environment issue is in China. ( $0=$ totally not terrible; $2, \cdots, 10=$ very terrible). Based on this question, we define environmental attitude dummy: $\mathrm{D}=1$, if the answer is $6-10 ;=0$, if the answer is $0-5$. P-value: the $\mathrm{p}$-values of test of Some college or above $=$ High school; $t$-value: $t$-values of test of Some college or above $=$ High school. Standard errors clustered at the city level are reported in parentheses. $* p<0.10, * * p<0.05, * * * p<0.01$

Table C4: Concerns and Actions Taken on Environmental Issues

\begin{tabular}{lccc}
\hline \hline & \multicolumn{2}{c}{ Panel A: Concerns on Environmental Issues } \\
& $\begin{array}{c}\text { Discuss environmental } \\
\text { issues }\end{array}$ & $\begin{array}{c}\text { Donation for environment } \\
\text { protection }\end{array}$ & $\begin{array}{c}\text { Concern over } \\
\text { environmental issue }\end{array}$ \\
\hline High school & $0.134^{* * *}$ & $0.0585^{* * *}$ & $0.120^{* * *}$ \\
& $(0.0171)$ & $(0.0115)$ & $(0.0154)$ \\
Some college or above & $0.231^{* * *}$ & $0.151^{* * *}$ & $0.174^{* * *}$ \\
& $(0.0188)$ & $(0.0153)$ & $(0.0189)$ \\
\hline P-value & 0.000 & 0.000 & 0.001 \\
t-value & -6.01 & -5.71 & -3.56 \\
Baseline average & 0.392 & 0.106 & 0.402 \\
City FE & $\mathrm{Y}$ & $\mathrm{Y}$ & $\mathrm{Y}$ \\
Demographics & $\mathrm{Y}$ & $\mathrm{Y}$ & $\mathrm{Y}$ \\
$\mathrm{N}$ & 11147 & 11147 & 0.192 \\
adj. R2 & 0.190 & 0.171 & \\
\hline
\end{tabular}

\begin{tabular}{lccc} 
& $\begin{array}{c}\text { Panel B: Actions Taken on Environmental Issues } \\
\text { Appeal on } \\
\text { Environmental issue }\end{array}$ & $\begin{array}{c}\text { Government environmental } \\
\text { activity }\end{array}$ & $\begin{array}{c}\text { Non-government } \\
\text { environmental activity }\end{array}$ \\
\hline High school & $0.0255^{* * *}$ & $0.119^{* * *}$ & $0.0690^{* * *}$ \\
Some college or above & $(0.00845)$ & $(0.0140)$ & $(0.0118)$ \\
& $0.0574^{* * *}$ & $0.246^{* * *}$ & $0.156^{* * *}$ \\
& $(0.0120)$ & $(0.0169)$ & $(0.0144)$ \\
\hline P-value & 0.010 & 0.000 & 0.000 \\
t-value & -2.62 & -8.21 & -6.31 \\
Baseline average & 0.0597 & 0.135 & 0.100 \\
City FE & $\mathrm{Y}$ & $\mathrm{Y}$ & $\mathrm{Y}$ \\
Demographics & $\mathrm{Y}$ & $\mathrm{Y}$ & $\mathrm{Y}$ \\
$\mathrm{N}$ & 11147 & 11147 & 11147 \\
adj. R2 & 0.176 & 0.186 & 0.194 \\
\hline \hline
\end{tabular}

Note: Individual level regressions from 127 cities. Demographic controls include age, age-squared, gender, marital status and an indicator for urban hukou. The data source is the Chinese General Social Survey (CGSS). In the CGSS, there is a survey question: whether you participate in the following activity. $1=$ never, $2=$ occasionally; $3=$ often. We define an indicator: $\mathrm{D}=1$ if the answer $=2,3 ; \mathrm{D}=0$ if the answer $=1$. P-value: the p-values of test of Some college or above $=$ High school; t-value: $t$-values of test of Some college or above $=$ High school. Standard errors clustered at the city level are reported in parentheses. $* p<0.10, * * p<0.05, * * * p<0.01$ 
Table C5: First-stage Relationships for Additional Model-based Parameter Estimation

\begin{tabular}{|c|c|c|c|c|}
\hline Panel A: For Labor Supply & \multicolumn{2}{|c|}{ Log (Unskilled Real Wage) } & \multicolumn{2}{|c|}{ Log (Skilled Real Wage) } \\
\hline NTR IV & $\begin{array}{l}0.161^{* * *} \\
(0.0161)\end{array}$ & $\begin{array}{l}0.162^{* * *} \\
(0.0153)\end{array}$ & & \\
\hline WID IV & & & $\begin{array}{c}0.00222^{* * *} \\
(0.000123)\end{array}$ & $\begin{array}{r}0.00387^{* * *} \\
(0.000111)\end{array}$ \\
\hline $\begin{array}{l}\text { Pollution IV } \\
\text { Observations } \\
\text { R-squared }\end{array}$ & $\begin{array}{c}\text { No. of Inversions } \\
13,570 \\
0.132\end{array}$ & $\begin{array}{c}\text { Strength of Inversions } \\
13,570 \\
0.132\end{array}$ & $\begin{array}{c}\text { No. of Inversions } \\
13,570 \\
0.136\end{array}$ & $\begin{array}{c}\text { Strength of Inversions } \\
13,570 \\
0.153\end{array}$ \\
\hline Panel B: & \multicolumn{2}{|c|}{$\begin{array}{c}\text { For Agglomeration } \\
\text { Log (Number of Skilled Workers) }\end{array}$} & \multicolumn{2}{|c|}{ For House Prices \& Pollution } \\
\hline$\Delta$ College graduates $_{2001-5}$ & $\begin{array}{c}0.400^{* * *} \\
(0.0386)\end{array}$ & $\begin{array}{c}0.395^{* * *} \\
(0.0390)\end{array}$ & & \\
\hline $\begin{array}{l}\Delta \text { College graduates }_{2001-5} / \text { Baseline } L_{u, 2001} \\
\text { Predicted migration flow }\end{array}$ & & & $\begin{array}{c}0.835^{* * *} \\
(0.130) \\
0.00158 \\
(0.00148)\end{array}$ & $\begin{array}{c}0.127 \\
(0.0915) \\
0.00425^{* * *} \\
(0.00102)\end{array}$ \\
\hline $\begin{array}{l}\text { Pollution IV } \\
\text { Observations } \\
\text { R-squared }\end{array}$ & $\begin{array}{c}\text { No. of Inversions } \\
121 \\
0.672\end{array}$ & $\begin{array}{c}\text { Strength of Inversions } \\
121 \\
0.665\end{array}$ & $\begin{array}{c}121 \\
0.573\end{array}$ & $\begin{array}{c}121 \\
0.546\end{array}$ \\
\hline
\end{tabular}

Notes: We control for number of inversions in Column 1 and 3, and strength of inversions in Column 2 and 4. All regressions weighted by the population in 2000. Panel A: We control for hukou index, the interaction of hukou index to migration status indicator, the inverse hyperbolic sine of distance from origin to destination cities. We also control for temperature, humidity, sunshine duration, and wind speed. Standard errors clustered at the city level are reported in parentheses. Panel B: We control for distance to seaport, region fixed effects, city area and weather amenities (temperature, humidity, sunshine duration and wind speed). Robust standard errors are reported in parentheses 
Figure C1: Event Study of the Number of College Students by Baseline Propensity to Expand

(a) College Students in City

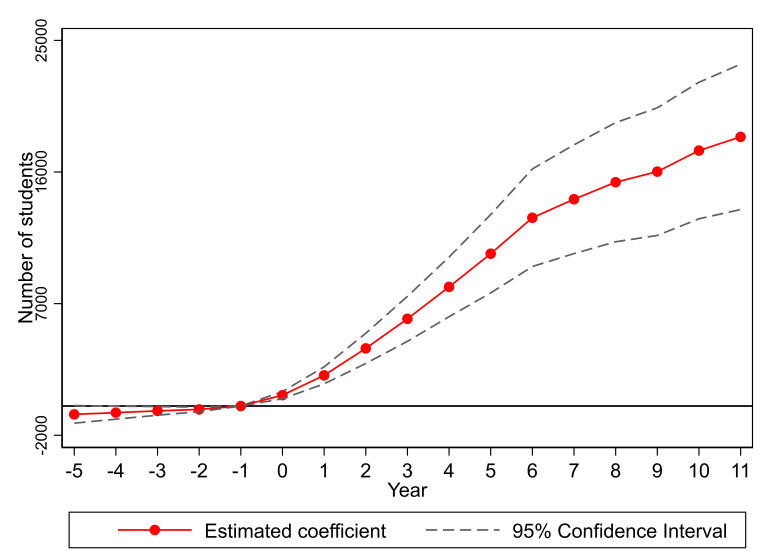

(b) University Professors in City

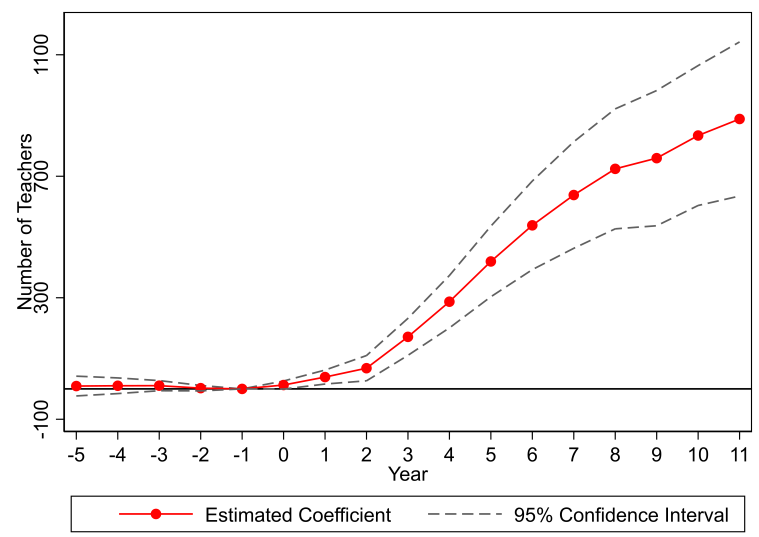

Notes: We test for pre-trends and dynamics of the college expansion policy in an event study framework. City-by-year level regressions from 1994 to 2010. Outcome is number of new college students, relative to one year preceding the expansion (1998). In Figure C1a, we run the regression: Students $_{d t}=\beta_{0}+\sum_{t=1994}^{2010} \beta_{t}\left(1_{t-1998} \times\right.$ Treat $\left._{d, 1990}\right)+\gamma_{t}+\delta_{c}+\epsilon_{d t}$. In Figure C1b the dependent variable is the number of professors in the city. We plot $\beta_{t}$. Treat Tr,1990 $_{\text {is }}$ ise number of university students in 1990. Horizontal axis is normalized to the year preceding the expansion (1998).

Figure C2: Distribution of $\theta_{h d}$ across cities, from Equation 18

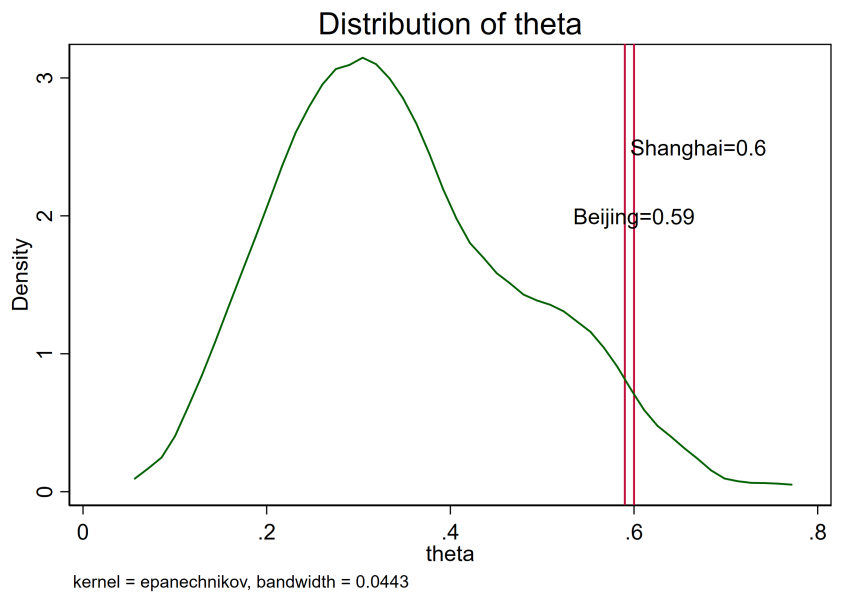

Graph describes the distribution of $\theta_{h d}$ across cities. Equation 18 describes how we estimate $\theta_{h d}$. 
Figure C3: Model Fit and Validation in 2015
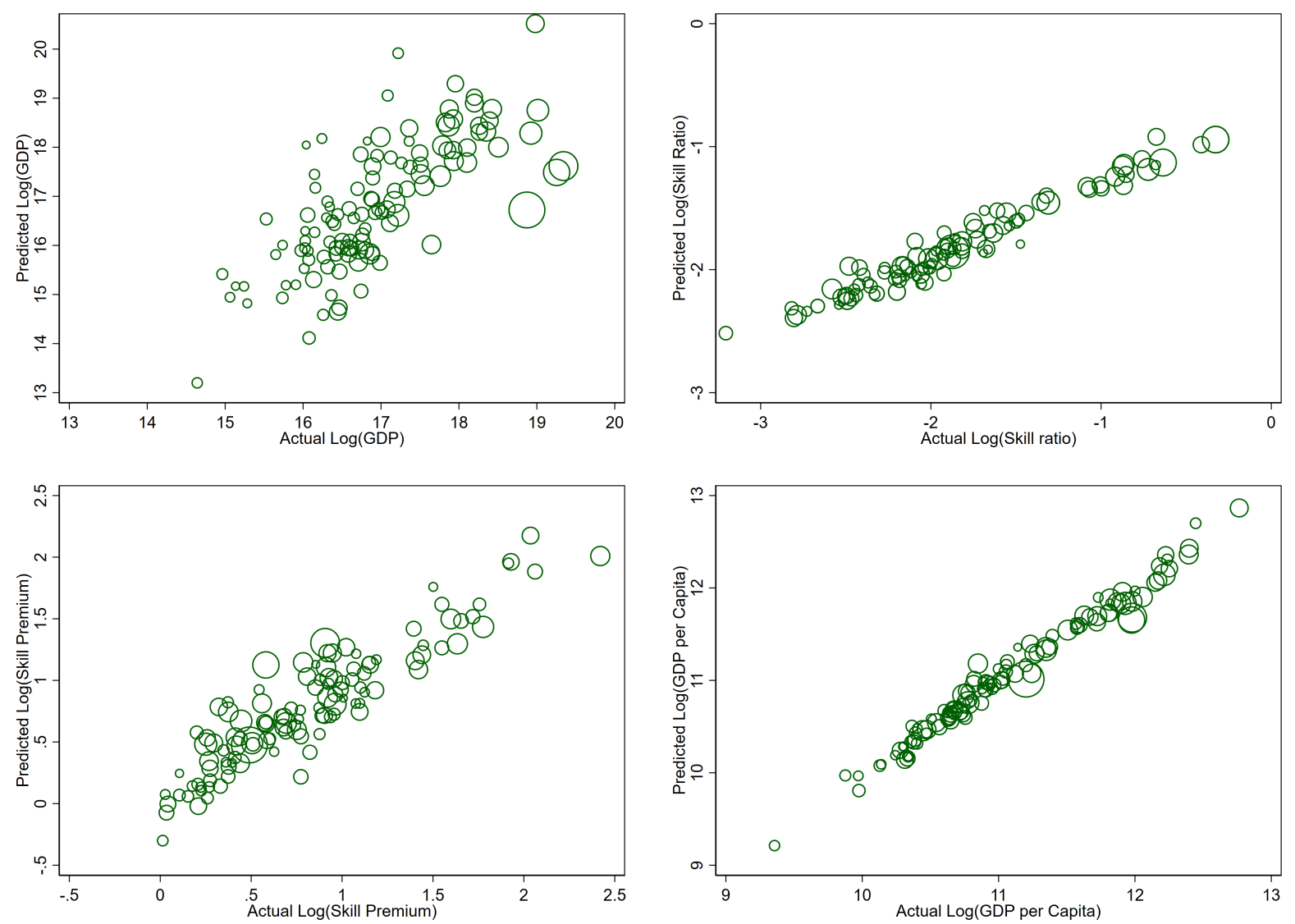

Notes: We plot the actual and predicted relationship between our main variables, where the predictions are based on model-estimated parameters. Bubbles are weighted by populations in the year 2000 . 


\section{Additional Model Derivations}

\section{D.1 Deriving Labor Supply and Welfare}

In this appendix we derive the labor supply curve from the worker utility function.

$$
V_{j s o d}=\epsilon_{j s d} w_{s d} Z_{d}^{-\gamma_{s}} h p_{d}^{-\nu_{s}} a_{d} \exp ^{-M_{s o d}}
$$

Workers will pick the destination with the highest value of $V_{j s o d}=\widetilde{w_{\text {sod }}} \epsilon_{j s d}$, where we define $\widetilde{w_{s o d}} \equiv w_{s d} Z_{d}^{-\gamma_{s}} h p_{d}^{-\nu_{s}} a_{d} e x p^{-M_{s o d}}$ to be a composite of wages, costs and amenities. The probability that someone from origin $o$ picks destination 1 is given by:

$$
\begin{aligned}
\pi_{s o 1} & =\operatorname{Pr}\left[\widetilde{w_{s o 1}} \epsilon_{s 1}>\widetilde{w_{s o d^{\prime}}} \epsilon_{s d^{\prime}}\right] \quad \forall d^{\prime} \neq 1 \\
& =\operatorname{Pr}\left[\epsilon_{s d^{\prime}}<\frac{\widetilde{w_{s 1}} \epsilon_{s 1}}{\widetilde{w_{s o d^{\prime}}}}\right] \quad \forall d^{\prime} \neq 1 \\
& =\int \frac{d F}{d \epsilon_{s 1}}\left(\epsilon_{s 1}, \omega_{s o 1} \epsilon_{s 1}, \ldots \ldots, \omega_{s o D} \epsilon_{s D}\right) d \epsilon_{s 1}
\end{aligned}
$$

where we define $\omega_{\text {sod }} \equiv \frac{\widetilde{w_{s p}}}{\widetilde{w_{s o d^{\prime}}}}$. We assume that the preferences are distributed with the following Frechet distribution:

$$
F\left(\epsilon_{s 1}, \ldots ., \epsilon_{s D}\right)=\exp \left\{-\left[\sum_{d=1}^{D} \epsilon_{s d}^{-\eta_{s}}\right]\right\}
$$

So the derivative of the CDF is given by:

$$
\frac{d F}{d \epsilon_{s 1}}=\eta_{s} \epsilon_{s 1}^{-\eta_{s}-1} \exp \left\{-\left[\sum_{d=1}^{D} \epsilon_{s d}^{-\eta_{s}}\right]\right\}
$$

This derivative evaluated at $\left(\epsilon_{s 1}, \omega_{s o 1} \epsilon_{s 1}, \ldots \ldots, \omega_{s o D} \epsilon_{s D}\right)$, allows us to determine the probability of choosing destination 1 , given by $\pi_{1 o s}$ :

$$
\begin{aligned}
\pi_{s o 1} & =\int \eta_{s} \epsilon_{s 1}^{-\eta_{s}-1} \exp \left\{-\left[\sum_{d=1}^{D}\left(\omega_{s o d} \epsilon_{s d}\right)^{-\eta_{s}}\right]\right\} d \epsilon_{s 1} \\
& =\frac{1}{\sum_{d=1}^{D} \omega_{\text {sod }}^{-\eta_{s}}} \int\left(\sum_{d=1}^{D} \omega_{s o d}^{-\eta_{s}}\right) \epsilon_{s 1}^{-\eta_{s}-1} \exp \left\{-\left[\epsilon_{s 1}^{-\eta_{s}-1}\left(\sum_{d=1}^{D} \omega_{s o d}^{-\eta_{s}}\right)\right]\right\} d \epsilon_{s 1} \\
& =\frac{1}{\sum_{d=1}^{D} \omega_{\text {sod }}^{-\eta_{s}}} \int d F(\epsilon) \\
& =\frac{1}{\sum_{d=1}^{D} \omega_{\text {sod }}^{-\eta_{s}}} \cdot 1=\frac{\left(\widetilde{w_{s o 1}}\right)^{\eta_{s}}}{\sum_{d=1}^{D}\left(\widetilde{w_{\text {sod }}}\right)^{\eta_{s}}}
\end{aligned}
$$

The third line comes from the properties of the Frechet distribution, where we know that the term in the integral of the second line is simply the PDF with a shape parameter $\eta$, and a scale parameter $\sum_{d=1}^{D} \omega_{s o d}^{-\eta_{s}}$. Expanding on the definitions for $\widetilde{w_{s o d}}$, and scaling up the probability by the size of the skilled workforce $P_{o s}$ by origin, we derive labor supply by skill and destination:

$$
\pi_{\text {sod }}=\frac{\left[w_{s d} Z_{d}^{-\gamma_{s}} h p_{d}^{-\nu_{s}} a_{s d} \exp ^{-M_{s o d}}\right]^{\eta_{s}}}{\sum_{d^{\prime}}\left(w_{s d^{\prime}} Z_{d^{\prime}}^{-\gamma_{s}} h p_{d^{\prime}}^{-\nu_{s}} a_{s d^{\prime}} \exp ^{\left.-M_{s o d^{\prime}}\right)^{\eta_{s}}}\right.} \text { and } L_{s d}=\sum_{o} P_{o s} \pi_{s o d}
$$


The Frechet assumptions also allow us to measure aggregate welfare. Using equation 7 , we can integrate over the the location preference $\epsilon_{j s d}$, conditional on choosing a destination.

$$
\begin{aligned}
E\left[V_{j s o d} \mid d\right] & =\left(\widetilde{w_{s o d}}\right) E\left[\epsilon_{j s d} \mid d\right] \\
& =\left(\widetilde{w_{s o d}}\right) \pi_{s o d}^{-\frac{1}{\eta_{s}}} \Gamma\left(1-\frac{1}{\eta_{s}}\right) \\
& =\left(\sum_{d^{\prime}}\left(w_{s d^{\prime}} Z_{d^{\prime}}^{-\gamma_{s}} h p_{d^{\prime}}^{-\nu_{s}} a_{s d^{\prime}} \exp ^{-M_{s o d^{\prime}}}\right)^{\eta_{s}}\right)^{\frac{1}{\eta_{s}}} \Gamma\left(1-\frac{1}{\eta_{s}}\right),
\end{aligned}
$$

where $\Gamma$ is the gamma function, and is constant across cities.

Average city utility may depend on hukou costs. For instance, if a high-amenity city has a very restrictive hukou policy it may have a high average utility as those who originate from this city already have access to the amenities without paying hukou costs. We define average utility for those from city $o$ to be:

$$
\overline{V_{s o}} \equiv\left(\sum_{d^{\prime}}\left(w_{s d^{\prime}} Z_{d^{\prime}}^{-\gamma_{s}} h p_{d^{\prime}}^{-\nu_{s}} a_{s d^{\prime}} \exp ^{-M_{s o d^{\prime}}}\right)^{\eta_{s}}\right)^{\frac{1}{\eta_{s}}}
$$

The equation shows that the average utility depends on the average option value migrating to any other city, and the 'utility' earned there. This average is scaled by the Frechet shape parameter $\eta_{s}$ as it captures the dispersion in tastes across locations. The utility of those in city $o$ is a decreasing function of migration costs to all other cities, as the option value of moving to those cities fall. We can therefore, rewrite the average utility as a function of hukou restrictions, and the labor supply as a function of utility in the manner described in the text, by using the above set of equations:

$$
\log \pi_{\text {sod }}=-\eta_{s} \log \overline{V_{s o}}+\eta_{s}\left(\log w_{s d}-\nu_{s} \log h p_{d}\right)+\eta_{s} \log a_{s d}-\eta_{s} \gamma_{s} \log Z_{d}-\eta_{s} M_{\text {sod }}
$$

\section{D.2 Elasticity of Capital, and Modelling Skill-biased Capital}

So far the model assumes that capital is perfectly supplied at the rate $R^{*}$. If however, capital was fixed at a value $\bar{K}_{d}$ in a city, it would not change the skill-premia. The average earnings for a worker with skill $s$ in district $d$ would be:

$$
\begin{aligned}
\log w_{s d}=\log \left(\frac{\partial Y_{d}}{\partial \ell_{s d}}\right) & =\log \theta_{s d}+\log \varrho+\left[1-\left(1-\frac{1}{\sigma_{E}}\right)\left(\frac{1}{\varrho}\right)\right] \log Y_{d} \\
& +\left(1-\frac{1}{\sigma_{E}}\right)\left(\frac{1}{\varrho}\right)\left(\log A_{d}+(1-\varrho) \log \bar{K}_{d}\right)-\frac{1}{\sigma_{E}} \log L_{s d}
\end{aligned}
$$

Here the modified term $\left(\frac{1}{\varrho}\right)\left(\log A_{d}+(1-\varrho) \log \bar{K}_{d}\right)$ is common across skill levels, and not affect skill premia. It varies across cities, just as TFP in the main model. We can similarly (re)define a modified TFP term that includes the immobile capital.

We can explicitly model skill biased capital as affecting the productivity parameter $\theta_{s d}$. Below, we explicitly model skill biased capital to show how flexible forms of introducing it do not influence the estimation. In the following set up, the noticeable changes are where equation 3 has been modified into equation A.10, which includes an elasticity of substitution between 
labor $\ell_{s d}$ and skill biased capital $k_{s d}$ represented by $\sigma_{s}$ :

$$
\begin{gathered}
Y_{d}=A_{d} L_{d}^{\varrho} K_{d}^{(1-\varrho)} \\
L_{d}=\left(\sum_{s} \theta_{s d} L_{s d}^{\frac{\sigma_{E}-1}{\sigma_{E}}}\right)^{\frac{\sigma_{E}}{\sigma_{E}-1}} \\
L_{s d}=\left(\Lambda_{s} k_{s d}^{\frac{\sigma_{s}-1}{\sigma_{s}}}+\left(1-\Lambda_{s}\right) \ell_{s d}^{\frac{\sigma_{s}-1}{\sigma_{s}}}\right)^{\frac{\sigma_{s}}{\sigma_{s}-1}}
\end{gathered}
$$

where $\ell_{s d}$ is the supply of workers of skill $s$, and $L_{s d}$ is now a labor aggregate over workers and capital. Given this new set up, earnings can be represented by equation A.11, instead of equation 4 :

$\log w_{s d}=\log \left(\frac{\partial Y_{d}}{\partial \ell_{s d}}\right)=\frac{1}{\varrho} \log A_{d}+\log \widetilde{\varrho}+\log \theta_{s d}\left(1-\Lambda_{s}\right)+\frac{1}{\sigma_{E}} \log L_{d}+\left(\frac{1}{\sigma_{s}}-\frac{1}{\sigma_{E}}\right) \log L_{s d}-\frac{1}{\sigma_{s}} \log \ell_{s d}$,

\section{D.3 A Note on Existence and Uniqueness of the Equilibrium}

In Section 6, we present the model and equilibrium. Here we describe the determinants behind the existence and uniqueness of the equilibrium that we define in Section 6.3.

When bilateral migration costs are present we make a few other standard assumptions that help meet sufficient conditions for the existence of a spatial equilibrium (Allen et al., 2020): $M_{\text {sod }}$ are finite, the graph of the matrix of costs is strongly connected, and they are quasisymmetric. The connectivity assumption simply implies that there is a sequential path of finite bilateral migration costs that can link any two cities $o$ and $d$. The quasi-symmetry assumption, which is not entirely necessary for existence (but does aid the solution), simply says that one portion of the costs is symmetric. That is, $M_{s o d}=M_{s o} M_{s d} \widetilde{M_{s o d}}$, and $\widetilde{M_{s o d}}=\widetilde{M_{s d o}}$. So in moving from Shanghai to Beijing, there may be a component of the cost that is Beijing specific (say, related to Beijing hukou policy), a component related to leaving Shanghai (say, its large airport), and a component that is Beijing-Shanghai specific (say, the distance between the two, or number of train connections). This last bilateral component is assumed to be symmetric for ease of proving the existence of an equilibrium.

Additionally, our model contains congestion forces (such as pollution and house prices) and agglomeration (effects on TFP). The existence of multiple equilibria often depends on the relative strength of agglomeration and congestion forces (Allen et al., 2020). An equilibrium is unique if congestion forces are at least as large as the agglomeration forces. That is, the parameters $\psi_{1}, \psi_{2}, \psi_{3}$ and $\psi_{4}$ that determine congestion are meaningful in magnitude, relative to $\phi_{1}$ and $\phi_{2}$ that drive agglomeration. More skilled workers raise TFP (via $\phi_{2}$ ), yet may lead to more congestion, via higher house prices (via $\psi_{3}$ and $\psi_{4}$ ) and more pollution (via $\psi_{1}$ and $\psi_{2}$ ), which in turn may lower TFP (via $\phi_{1}$ ). Given the meaningful congestion forces we may expect a unique equilibrium.

When solving for equilibrium, our model converges to the same unique equilibrium across different starting values. This does not necessarily imply the equilibrium is globally unique. Yet, like other work (Ahlfeldt et al., 2015) we envision that if there were to be multiple equilibria for a different set of parameter values, we would select the counterfactual equilibrium closest to the observed real-world outcome. 


\section{E Additional Counterfactual Results}

Table E1: The Productivity Effect of Reducing Pollution in Beijing (no externalities)

\begin{tabular}{lccc}
\hline \hline & \multicolumn{3}{c}{ Change in GDP per Worker (\%) } \\
& Overal effects & Health & Relocation \\
\cline { 2 - 4 } Reduce steady state PM2.5 & 10.364 & 5.819 & 4.295 \\
Relax skilled hukou & 4.931 & 0.000 & 4.931 \\
Relax unskilled hukou & -4.654 & 0.000 & -4.654 \\
Reduce PM2.5 \& relax skilled hukou & 15.116 & 5.819 & 8.785 \\
Reduce PM2.5 \& relax unskilled hukou & 5.707 & 5.819 & -0.106 \\
\hline
\end{tabular}

Notes: In this counterfactual exercise we reduce the steady state amount of pollution in Beijing by $50 \%$ (row 1). Next, we relax the hukou restrictions by skill level (rows 2 and 3 ) by $50 \%$. Finally (rows 4 and 5 ) we lower the hukou regulation by $50 \%$ while reducing steady state pollution. Column 1 shows the gain to overall GDP per worker. Column 2 shows the component purely explained by the health-productivity channel. Column 3 through the pure relocation channel.

Table E2: The Productivity Effect of Relocating Pollution (no externalities)

\begin{tabular}{lccc}
\hline \hline & & Change in GDP per Worker (\%) \\
& Overall changes & Relocation \\
\cline { 2 - 4 } Relocate steady state PM2.5 & 7.559 & 2.893 & 3.097 \\
Relax hukou & 2.318 & 0.000 & 2.318 \\
Relax overall mobility constraints & 6.319 & 0.000 & 6.319 \\
Relocate PM2.5 \& relax hukou & 9.845 & 2.893 & 5.216 \\
Relocate PM2.5 \& lower migration costs & 14.143 & 2.893 & 9.105 \\
\hline
\end{tabular}

Notes: In this counterfactual exercise we relocate PM2.5 in all cities based on the amount of skill-biased capital in the city (row 1 ). In row 2 , we relocate only the exogenous component of pollution. In addition to such relocations of pollution, we also relax the hukou restriction in the 24 top tier cities by $50 \%$ (row 2). In row 3 we relax overall migration costs to the 24 high tier cities by $50 \%$. Column 1 shows the overall gain to GDP. Column 2 shows the increase in GDP as a consequence of the health effects only. Column 3 shows the gain due to the re-allocation of labor channel only.

Table E3: Distributional Effects of Pollution Regulation

\begin{tabular}{lcccccc}
\hline \hline & \multicolumn{3}{c}{ Skilled Wage } & \multicolumn{3}{c}{ Unskilled Wage } \\
& Overall & Health & Relocate+Agglom & Overall & Health & Relocate+Agglom \\
\cline { 2 - 7 } Control PM2.5 & 3.504 & 1.485 & 1.896 & 3.603 & 1.536 & 1.958 \\
Control PM2.5 \& relax hukou & 7.583 & 1.485 & 5.840 & 5.645 & 1.536 & 3.921 \\
Control PM2.5 \& lower mig costs & 13.964 & 1.485 & 12.115 & 9.142 & 1.536 & 7.368 \\
\hline
\end{tabular}

Notes: In this counterfactual exercise we reduce pollution according to the targets set by the 2013 Air Pollution Prevention and Control Plan (row 1). In addition to pollution regulations, we also relax the hukou restriction in higher tier cities (row 2), and migration costs (row 3 ) by $50 \%$. Columns 1-3 show effects on skilled wages. Columns 4-6 on unskilled wages. 